\title{
ELETROQUÍMICA DO CITOCROMO C EM FILME NANOESTRUTURADO "DENDRÍMERO-Pt" ATIVADO
}

Tese apresentada ao Instituto de Química de São Carlos, da Universidade de São Paulo, como parte dos requisitos para a obtenção do título de Doutor em Química.

Área de concentração: Química Analítica e Inorgânica.

Orientador: Prof. Dr. Sergio Antonio Spinola Machado

\section{Exemplar revisado}

O exemplar original encontra-se em acervo reservado na Biblioteca do IQSC-USP

São Carlos 
Dedico aos meus Pais, Maria e José,

Que não mediram esforços para que eu pudesse chegar até aqui...

Ao meu querido Márcio, namorado, amigo, companheiro de todas as horas. 


\section{AGRADEÇO}

A Deus, pela oportunidade da vida, por mais uma etapa vencida.

Aos meus Pais, pelo amor, apoio incondicional e por estarem sempre comigo.

Ao Márcio, pelo amor, carinho, por sempre estar comigo, e por entender minha ausência, quando eu não podia estar com ele.

Ao meu irmão Carlos, à Vívian e sua família, pelo carinho e pelos momentos de descontração e alegria.

Aos meus cunhados Mário e Vânia, pelo carinho e por sempre torcerem por mim.

Ao meu orientador, prof. Dr. Sergio Antonio Spinola Machado, por todos esses anos de convivência, pela orientação, apoio, exemplos e oportunidade de crescimento.

Ao prof. Dr. Valtencir Zucolotto, pelo apoio no início deste trabalho e pela valiosa idéia inicial.

Ao prof. Dr. Frank Nelson Crespilho, pelas dicas, opiniões, discussões e revisão, contribuição essencial no desenvolvimento e fechamento deste trabalho.

Ao doutorando Roberto Alves de Sousa Luz, do grupo de Bioeletroquímica e Interfaces, pelas orientações e ajuda indispensáveis com os cálculos das constantes pelo método de Laviron. Ao Marcelo Calegaro e ao João Tiengo, pelo profissionalismo, amizade, ajuda e palavras de apoio e incentivo em tantos momentos.

Às minhas amigas Ana Luiza, minha companheirona, Andressa Galli, Eliana Valle, Franciéli Oliveira, Milena Teixeira, Juliana Cancino e Raquel Amaral, longe ou perto, vocês caminham sempre comigo.

Aos queridos Willyam Roger e Juliana Steter, pela alegria e por tantos momentos de muito bate-papo e descontração.

Aos amigos e colegas que são e que já foram do GMEME: Diego Golinelli, Érica Kataoka, Fernanda Scavassa, Fernando Cincotto, Jaqueline Ruiz, Naiza, Paulo Leão, Paulo Raymundo, Pollyana, Sara, Thiago Canevari, Tiaguinho, Tony, Vanessa, Andréa Malagutti, Maria Inês Marinho, Inês Tomita e Alexandra Manzoli. 
Ao Dyovani Coelho e à Lívia Flório, por toda a atenção, ajuda, conversas, questionamentos e muitos momentos de alegria, sem os quais essa etapa teria sido infinitamente mais difícil.

Vocês contribuíram e muito.

Aos queridos Silmary Bertolani e Fábio Martins, se essa etapa foi de crescimento e aperfeiçoamento, vocês fizeram parte disso. Obrigada pelo profissionalismo e pelo carinho sempre dispensados.

A todos os funcionários do IQSC que contribuíram de forma direta ou indireta para o desenvolvimento deste trabalho.

À CAPES pela bolsa de estudos concedida.

MUITO OBRIGADA! 
Com um amigo ao lado, nenhum caminho é longo demais... 


\section{RESUMO}

Esta tese aborda a utilização de um filme fino nanoestruturado de dendrímero-Pt, eletroquimicamente ativado, no estudo da eletroquímica do citocromo C. O objetivo do estudo de proteínas redox em eletrodos é elucidar os mecanismos de transferência de elétrons das proteínas que estão envolvidas em processos redox biológicos, como a fotossíntese e a cadeia respiratória, e a exploração de enzimas redox para o desenvolvimento de biossensores eletroquímicos, células de biocombustíveis e aplicações em nanotecnologia. Antecedendo o processo de imobilização de biomoléculas, é preciso desenvolver eletrodos que facilitem transferências eletrônicas e não interfiram nas propriedades biológicas das biomoléculas a serem imobilizadas. Esta meta tem guiado pesquisadores na busca de um sistema ideal. Nesta busca, sistemas baseados em eletrodos modificados com materiais nanoestruturados (MNEs) têm sido aplicados. Nesta tese, para a obtenção dos eletrodos modificados com o hibrido dendrímero-Pt, primeiramente, foram sintetizadas as nanopartículas de $\mathrm{Pt}$ (NPsPt) encapsuladas no dendrímero poli(amidoamina) (PAMAM) pela redução química dos íons Pt encapsulados nas cavidades do PAMAM. A reação de complexação foi acompanhada por espectroscopia de absorção na região do UV-Vis (UV-Vis) e o encapsulamento foi investigado por espectroscopia de infravermelho com transformada de Fourier. As NPsPt encapsuladas em PAMAM (PAMAM-Pt) foram caracterizadas por microscopia eletrônica de transmissão. O híbrido PAMAM-Pt foi utilizado na obtenção de filmes automontados layerby-layer sobre substrato de ITO. O tempo que o eletrodo deve ficar imerso na suspensão de PAMAM-Pt para que se forme uma camada e o número de camadas de PAMAM-Pt, intercaladas com camadas do poliânion poli(ácidovinilsulfônico), imobilizadas sobre o eletrodo de ITO, foram monitorados e determinados por voltametria cíclica (CV) e UV-Vis. Pela observação dos dados experimentais obtidos durante o processo de determinação do tempo de imersão e número de camadas, e levando-se em conta a importancia da obtenção de NPsPt com sítios eletrocatalíticos disponíveis para estudos e aplicações eletroquímicas, foi realizado um estudo sobre a ativação do eletrodo ITO/PAMAM-Pt por tratamento eletroquímico. A influencia deste tratamento na resposta eletroquímica dos eletrodos ITO/(PAMAM-Pt) $)_{\mathrm{n}}$, para a reação de oxidação do hidrogênio adsorvido, foi investigada por $\mathrm{CV}$ e espectroscopia de impedância eletroquímica. O eletrodo ITO/PAMAM-Pt ativado eletroquimicamente foi utilizado nos estudos da eletroquímica do citocromo $\mathrm{C}$ (CytC) e o valor da constante de transferência de carga $\left(k_{s}\right)$ obtida pelo método de Laviron, foi $5,7 \mathrm{~s}^{-1}$, indicando que este eletrodo atua como um excelente dispositivo para a imobilização do CytC com excelente transferência de elétrons. A principal contribuição desta tese foi mostrar que, mediante tratamento eletroquímico, pode-se ativar e melhorar o desempenho de eletrodos modificados com membranas eletroativas de NPsPt encapsuladas em PAMAM. Também é possível obter eletrodos modificados com um filme nanoestruturado de PAMAM-Pt eletroquimicamente ativado, com excelente desempenho, economia de materiais, sem a necessidade de se produzir membranas com várias camadas e sem o uso de polieletrólitos que possam aumentar a resistência à transferência de elétrons e diminuir a eficiência do eletrodo. 


\begin{abstract}
This thesis discusses the use of a nanostructured thin film of dendrimer-Pt electrochemically activated, in the electrochemical study of cytochrome $\mathrm{C}$. The objective of studying redox proteins at electrodes is to elucidate the mechanisms of electron transfer from the proteins that are involved in biological redox processes, such as photosynthesis and the respiratory chain, and the use of redox enzymes for the development of electrochemical biosensors, biofuel cells and applications in nanotechnology. Preceding the process of immobilization of biomolecules, it is necessary to develop electrodes that facilitate electronic transfers and which do not interfere with the biological properties of biomolecules to be immobilized. This goal has guided researchers in the search for an ideal system. In this quest, systems based on modified electrodes with nanostructured materials (MNEs) have been applied. In this thesis, platinum nanoparticles (NPsPt) encapsulated in the dendrimer poly(amidoamine) (PAMAM) by chemical reduction of ions Pt encapsulated in the cavities of PAMAM were synthesized to obtain the electrodes modified with hybrid dendrimer-Pt. The complexation reaction was monitored by absorption spectroscopy in the UV visible region (UV-Vis) and the encapsulation was investigated by Fourier transform infrared spectroscopy. The NPsPt encapsulated in PAMAM (PAMAM-Pt) were characterized by transmission electron microscopy. The hybrid PAMAM-Pt was used to obtain self-assembled films by layer-bylayer on ITO substrate. The time that the electrode must be immersed in the suspension of PAMAM-Pt for a layer to be formed, and the number of layers of PAMAM-Pt interspersed with layers of polyanion poly(vinylsulfoniacid) immobilized on the ITO electrode were monitored and determined by cyclic voltammetry (CV) and UV-Vis. By observing the experimental data obtained during the process of determining the immersion time and number of layers, and taking into account the importance of obtaining NPsPt with electrocatalytic sites available for studies and electrochemical applications, a study was conducted on the activation of the electrode ITO/PAMAM-Pt by electrochemical treatment. The influence of this treatment on the electrochemical response of electrodes ITO/(Pt-PAMAM)n, for the oxidation of adsorbed hydrogen, was investigated by $\mathrm{CV}$ and electrochemical impedance spectroscopy. The electrode ITO/PAMAM-Pt electrochemically activated was used in the electrochemical studies of cytochrome $\mathrm{C}(\mathrm{CytC})$ and the value of the electron transfer constant (ks), obtained by the method of Laviron, was $5.7 \mathrm{~s}-1$, indicating that this electrode acts as an excellent device for immobilizing the $\mathrm{CytC}$ with excellent electron transfer. The main contribution of this thesis was to show that, upon electrochemical treatment, it is possible to activate and improve the performance of electrodes modified with electroactive membranes of NPsPt encapsulated in PAMAM. It is also possible to obtain modified electrodes with a nanostructured film PAMAM-Pt electrochemically activated with excellent performance, economy of materials, without the need to produce membranes with several layers and without the use of polyelectrolytes that may increase resistance to electron transfer and decrease the efficiency of the electrode.
\end{abstract}


SUMÁRIO

RESUMO vi

ABSTRACT

Erro! Indicador não definido.

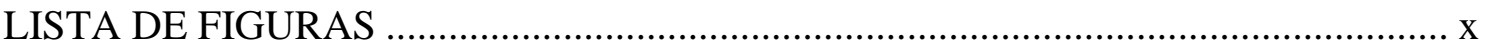

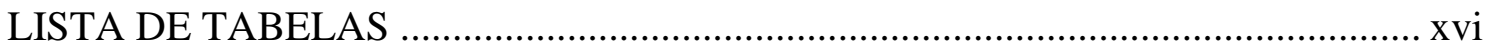

LISTA DE ABREVIATURAS E SIGLAS ......................................................... xvii

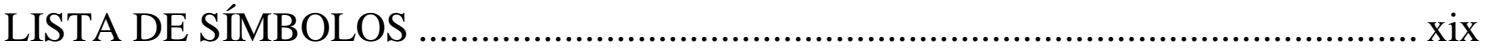

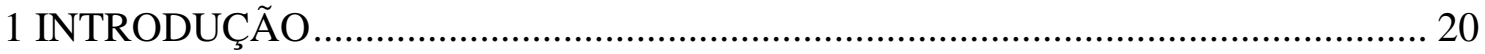

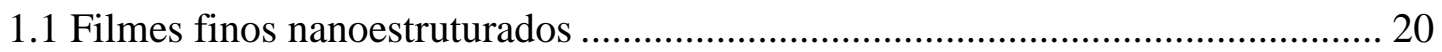

1.2 Preparação de biodispositivos utilizando LBL e nanopartículas de platina ........ 22

1.3 Nanopartículas encapsuladas em dendrímeros ............................................... 25

1.4 Ativação do eletrodo de ITO modicado com camadas do híbrido PAMAM-Pt alternadas com o poliânion PVS .............................................................................. 29

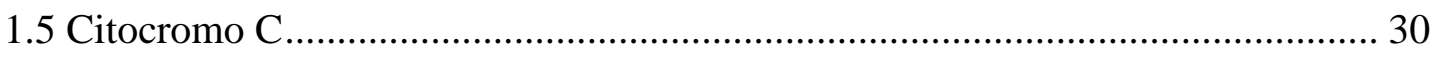

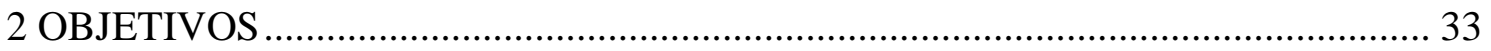

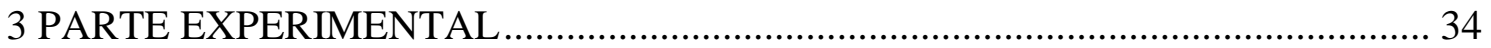

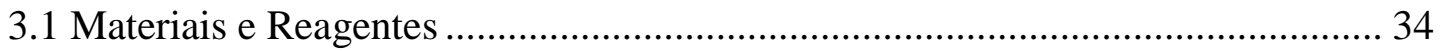

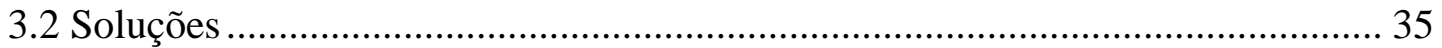

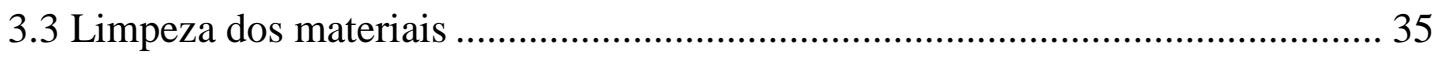

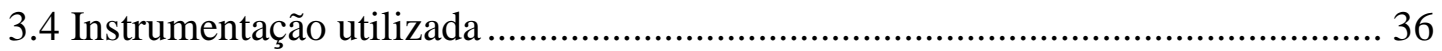

3.5 Construção do eletrodo de referência $\mathrm{Ag} / \mathrm{AgCl}\left(\mathrm{KCl} 3,0 \mathrm{~mol} \mathrm{~L}^{-1}\right)$..................... 37

3.6 Síntese das nanopartículas de platina encapsuladas em PAMAM G4.0- $\mathrm{NH}_{2}$ reduzidas com solução aquosa de $\mathrm{NaBH}_{4} 0,5 \mathrm{~mol} \mathrm{~L}^{-1}$........................................................... 37

3.7 Caracterização eletroquímica dos eletrodos ITO e ITO/PAMAM ....................... 38

3.7.1 Construção do eletrodo ITO/PAMAM-Pt.................................................... 39

3.7.1.1 Tempo de adsorção do híbrido PAMAM-Pt sobre o eletrodo de ITO........... 39

3.7.1.2 Tempo de adsorção do poliânion PVS sobre o eletrodo ITO/PAMAM-Pt ... 40 
3.7.1.3 Número de camadas do híbrido PAMAM-Pt sobre o eletrodo de ITO 40

3.8 Influência do tratamento eletroquímico na resposta eletroquímica dos eletrodos

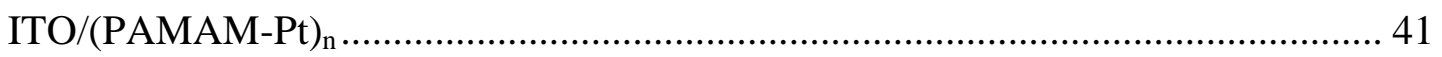

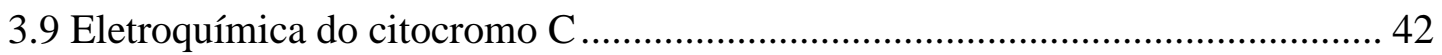

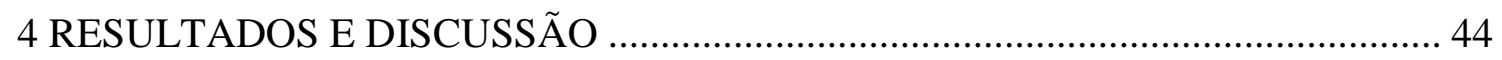

4.1 Síntese e caracterização das NPsPt encapsuladas em PAMAM reduzidas com $\mathrm{NaBH}_{4}$ $0,5 \mathrm{~mol} \mathrm{~L}^{-1}$ 45

4.2 Caracterização eletroquímica dos eletrodos ITO e ITO/PAMAM ....................... 51

4.2.1 Construção do eletrodo ITO/PAMAM-Pt..................................................... 55

4.2.1.1 Tempo de adsorção do híbrido PAMAM-Pt sobre o eletrodo de ITO............ 56

4.2.1.2 Tempo de adsorção do poliânion PVS sobre o eletrodo ITO/PAMAM-Pt ... 57

4.2.1.3 Número de camadas do híbrido PAMAM-Pt sobre o eletrodo de ITO .......... 58

4.3 Influência do tratamento eletroquímico na resposta eletroquímica dos eletrodos

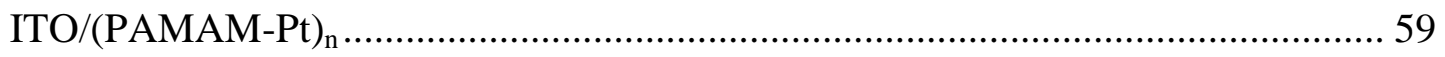

4.3.1 Transferência de carga no eletrodo ITO/PAMAM-Pt ................................... 73

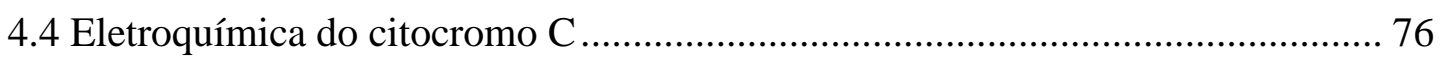

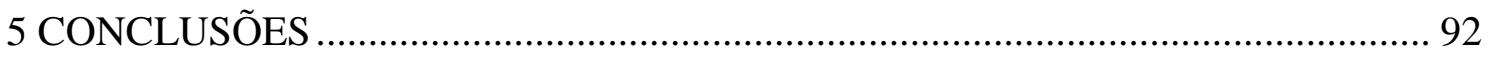

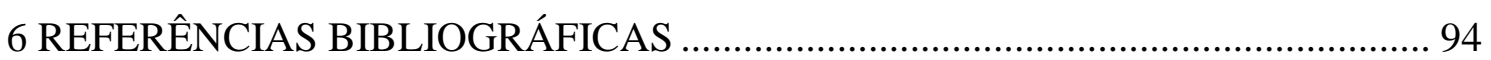




\section{LISTA DE FIGURAS}

Figura 1 - Esquema do processo de deposição de filmes pela técnica LBL.

Figura 2 - Estrutura do PAMAM G4.0. $\mathrm{Z}=\mathrm{NH}_{2}$ (64 unidades) para o PAMAM G4.0- $\mathrm{NH}_{2}$ e $\mathrm{Z}=\mathrm{OH}$ (64 unidades) para o PAMAM G4.0-OH.

Figura 3 - Ilustração esquemática do processo de síntese das NPs encapsuladas em dendrímero. Primeiro os íons metálicos são complexados nas cavidades do dendrímero template. Em seguida os íons são reduzidos, resultando em nanopartículas metálicas monodispersas. 26

Figura 4 - Estrutura do citocromo C de coração bovino. 31

Figura 5 - Espectros de UV-Vis da reação de encapsulamento dos íons $\mathrm{PtCl}_{6}{ }^{2-}$ no dendrímero PAMAM. 46

Figura 6 - Fotografia da suspensão PAMAM-Pt.

Figura 7 - Imagens de TEM em (A) campo claro e (B) campo escuro, com escala de $20 \mathrm{~nm}$, (C) EDX e (D) HRTEM, com escala de $5 \mathrm{~nm}$, das NPsPt (PAMAM-Pt) sem purificação...... 48

Figura 8 - (A) Centro da molécula de PAMAM. (B) Ramificações da molécula de PAMAM.

Figura 9 - Espectros de FTIR da solução de PAMAM e da suspensão de PAMAM-Pt. 50

Figura 10 - Voltamogramas cíclicos (10 ciclos) para os eletrodos (A) ITO e (B) ITO-PAMAM em $\mathrm{H}_{2} \mathrm{SO}_{4} 0,1 \mathrm{~mol} \mathrm{~L}^{-1}$, saturado com $\mathrm{N}_{2}$. Velocidade de varredura de $0,1 \mathrm{~V} \mathrm{~s}^{-1}$.

Figura 11 - Voltamogramas cíclicos do eletrodo de ITO nas velocidades de varredura de 10, 25, 50, 75, 100, 150, 200, 250, 300 e $400 \mathrm{mV} \mathrm{s}^{-1}$, em solução de $\mathrm{K}_{4}\left[\mathrm{Fe}(\mathrm{CN})_{6}\right]$ 3,0 mmol L ${ }^{-1}$. Eletrólito $\mathrm{H}_{2} \mathrm{SO}_{4} 0,1 \mathrm{~mol} \mathrm{~L}{ }^{-1}$, saturado com $\mathrm{N}_{2}$. Inserido: correntes de pico anódica e catódica em função da raiz quadrada da velocidade de varredura. 52

Figura 12 - Voltamogramas cíclicos do eletrodo de (-) ITO em $\mathrm{H}_{2} \mathrm{SO}_{4} 0,1$ mol L ${ }^{-1}$, saturado com $\mathrm{N}_{2}$ e (-) ITO em $\mathrm{H}_{2} \mathrm{SO}_{4} 0,1 \mathrm{~mol} \mathrm{~L}^{-1}$, saturado com $\mathrm{N}_{2}$, contendo 3,0 mmol L $\mathrm{me}^{-1}$ de $\mathrm{K}_{4}\left[\mathrm{Fe}(\mathrm{CN})_{6}\right]$. Velocidade de varredura $0,1 \mathrm{~V} \mathrm{~s}^{-1}$. 53 
Figura 13 - Voltamogramas cíclicos dos eletrodos (A) ITO e (B) ITO/PAMAM nas velocidades de varredura de 10, 25, 50, 75, 100, 150, 200, 250, 300, 400, 500, 600,700, 800, 900 e $1000 \mathrm{mV} \mathrm{s}^{-1}$ em solução de $\left[\mathrm{Ru}\left(\mathrm{NH}_{3}\right)_{6}\right]^{2+} /\left[\mathrm{Ru}\left(\mathrm{NH}_{3}\right)_{6}\right]^{3+} 3,0 \mathrm{mmol} \mathrm{L}{ }^{-1}$. Eletrólito $\mathrm{H}_{2} \mathrm{SO}_{4}$ $0,1 \mathrm{~mol} \mathrm{~L}{ }^{-1}$, saturado com $\mathrm{N}_{2}$. Inseridos: correntes de pico anódica e catódica em função da raiz quadrada da velocidade de varredura. 54

Figura 14 - Voltamogramas cíclicos do eletrodo ITO/PAMAM-Pt. Eletrólito $\mathrm{H}_{2} \mathrm{SO}_{4}$ 0,1 mol $\mathrm{L}^{-1}$, saturado com $\mathrm{N}_{2}$. Velocidade de varredura de $0,1 \mathrm{~V} \mathrm{~s}^{-1}$. (-) sem e (-) com tratamento eletroquímico após os 20 minutos de adsorção de PAMAM-Pt. Inserido: Voltamograma cíclico para o eletrodo de platina em $\mathrm{H}_{2} \mathrm{SO}_{4} 0,1 \mathrm{~mol} \mathrm{~L}^{-1}$, saturado com $\mathrm{N}_{2}$. Velocidade de varredura de $0,1 \mathrm{~V} \mathrm{~s}^{-1}$.

Figura 15 - Voltamogramas cíclicos do eletrodo de ITO imerso, por diferentes tempos, na suspensão de PAMAM-Pt. Eletrólito $\mathrm{H}_{2} \mathrm{SO}_{4}$ 0,1 mol L ${ }^{-1}$, saturado com $\mathrm{N}_{2}$. Velocidade de varredura de $0,1 \mathrm{~V} \mathrm{~s}^{-1}$. Inserido: variação da corrente de oxidação do hidrogênio adsorvido para os diferentes tempos de imersão até 40 minutos. 56

Figura 16 - Espectros de UV-Vis do substrato de quartzo imerso, por diferentes tempos, na suspensão de PAMAM-Pt. Inserido: variação da absorbância total, em $450 \mathrm{~nm}$, para os diferentes tempos de imersão, até 40 minutos. .57

Figura 17 - Estrutura do PVS. 57

Figura 18 - Voltamogramas cíclicos do eletrodo de ITO recoberto com diferentes números de camadas do híbrido PAMAM-Pt intercaladas com camadas do poliânion PVS. Eletrólito $\mathrm{H}_{2} \mathrm{SO}_{4} 0,1 \mathrm{~mol} \mathrm{~L}^{-1}$, saturado com $\mathrm{N}_{2}$. Velocidade de varredura de $0,1 \mathrm{~V} \mathrm{~s}^{-1}$. Inserido: variação da corrente de oxidação do hidrogênio adsorvido em função do número de camadas do híbrido PAMAM-Pt para 9 camadas. 58

Figura 19 - Espectros de UV-Vis do substrato de quartzo recoberto com diferentes números de camadas de PAMAM-Pt intercaladas com camadas do poliânion PVS. Inserido: variação da absorbância total, em 450 nm, em função do número de camadas do híbrido PAMAM-Pt para 10 camadas. 59

Figura 20 - Circuito equivalente dos espectros no plano complexo, obtidos na região de adsorção/dessorção de hidrogênio, dos eletrodos ITO/(PAMAM-Pt) $)_{n}$, sem e com tratamento eletroquímico. 
Figura 21 - (A) Voltamogramas cíclicos dos eletrodos ITO/(PAMAM-Pt) $)_{1}$ em $\mathrm{H}_{2} \mathrm{SO}_{4}$ 0,1 mol $\mathrm{L}^{-1}$, saturado com $\mathrm{N}_{2}$. Velocidade de varredura $0,1 \mathrm{~V} \mathrm{~s}^{-1}$. Espectros de impedância no plano complexo, em $\mathrm{H}_{2} \mathrm{SO}_{4}$ 0,1 mol L ${ }^{-1}$, saturado com $\mathrm{N}_{2}$, para os eletrodos ITO/(PAMAM-Pt) (B) sem trat. elet após confecção, (C) com trat. elet. após confecção e (D) com trat. elet. entre imersões. Variação de frequência de $65 \mathrm{kHz}$ a $0,1 \mathrm{~Hz}$.

Figura 22 - Espectros de impedância no plano complexo, em $\mathrm{H}_{2} \mathrm{SO}_{4} 0,1 \mathrm{~mol} \mathrm{~L}^{-1}$, saturado com $\mathrm{N}_{2}$, para o eletrodo ITO/(PAMAM-Pt) ${ }_{1}$ sem tratamento eletroquímico. Variação de frequência de $65 \mathrm{kHz}$ a $0,1 \mathrm{~Hz}$.

Figura 23 - (A) Voltamogramas cíclicos dos eletrodos ITO/(PAMAM-Pt) ${ }_{2}$ em $\mathrm{H}_{2} \mathrm{SO}_{4}$ 0,1 mol $\mathrm{L}^{-1}$, saturado com $\mathrm{N}_{2}$. Velocidade de varredura $0,1 \mathrm{~V} \mathrm{~s}^{-1}$. Espectros de impedância no plano complexo, em $\mathrm{H}_{2} \mathrm{SO}_{4}$ 0,1 mol L ${ }^{-1}$, saturado com $\mathrm{N}_{2}$, para os eletrodos ITO/(PAMAM-Pt) (B) com trat. elet. após confecção e (C) com trat. elet. entre camadas. Variação de frequência de $65 \mathrm{kHz}$ a $0,1 \mathrm{~Hz}$. 64

Figura 24 - (A) Voltamogramas cíclicos dos eletrodos ITO/(PAMAM-Pt) ${ }_{3} \mathrm{em} \mathrm{H}_{2} \mathrm{SO}_{4}$ 0,1 mol $\mathrm{L}^{-1}$, saturado com $\mathrm{N}_{2}$. Velocidade de varredura $0,1 \mathrm{~V} \mathrm{~s}^{-1}$. Espectros de impedância no plano complexo, em $\mathrm{H}_{2} \mathrm{SO}_{4}$ 0,1 mol L ${ }^{-1}$, saturado com $\mathrm{N}_{2}$, para os eletrodos ITO/(PAMAM-Pt) (B) com trat. elet. após confecção e (C) com trat. elet. entre camadas. Variação de frequência de $65 \mathrm{kHz}$ a $0,1 \mathrm{~Hz}$. 65

Figura 25 - (A) Voltamogramas cíclicos dos eletrodos ITO/(PAMAM-Pt) em H$_{2} \mathrm{SO}_{4}$ 0,1 mol $\mathrm{L}^{-1}$, saturado com $\mathrm{N}_{2}$. Velocidade de varredura $0,1 \mathrm{~V} \mathrm{~s}^{-1}$. Espectros de impedância no plano complexo, em $\mathrm{H}_{2} \mathrm{SO}_{4}$ 0,1 mol L ${ }^{-1}$, saturado com $\mathrm{N}_{2}$, para os eletrodos ITO/(PAMAM-Pt) (B) com trat. elet. após confecção e (C) com trat. elet. entre camadas. Variação de frequência de $65 \mathrm{kHz}$ a $0,1 \mathrm{~Hz}$. 66

Figura 26 - (A) Voltamogramas cíclicos dos eletrodos ITO/(PAMAM-Pt), com tratamento eletroquímico após confecção, em $\mathrm{H}_{2} \mathrm{SO}_{4} 0,1 \mathrm{~mol} \mathrm{~L} \mathrm{~L}^{-1}$, saturado com $\mathrm{N}_{2}$. Velocidade de varredura $0,1 \mathrm{~V} \mathrm{~s}^{-1}$. (B) Variação das correntes de pico, para a reação de oxidação do hidrogênio adsorvido, em função do número de camadas 67 
Figura 27 - (A) Voltamogramas cíclicos dos eletrodos ITO/(PAMAM-Pt)n, com tratamento eletroquímico entre as camadas, em $\mathrm{H}_{2} \mathrm{SO}_{4} 0,1 \mathrm{~mol} \mathrm{~L}^{-1}$, saturado com $\mathrm{N}_{2}$. Velocidade de varredura $0,1 \mathrm{~V} \mathrm{~s}^{-1}$. (B) Variação das correntes de pico, para a reação de oxidação do hidrogênio adsorvido, em função do número de camadas 68

Figura 28 - Área eletroativa dos eletrodos ITO/(PAMAM-Pt $)_{\mathrm{n}}$ em função do tratamento eletroquímico.

Figura 29 - Resistência à transferência de carga, nos eletrodos ITO/(PAMAM-Pt) $)_{\mathrm{n}}$, para a reação de oxidação do hidrogenio adsorvido em função do tratamento eletroquímico. 71

Figura 30 - Correntes de pico, dos eletrodos ITO/(PAMAM-Pt) , para a reação de oxidação do hidrogenio adsorvido em função do tratamento eletroquímico. 72

Figura 31 - Voltamogramas cíclicos (10 ciclos) para o eletrodo ITO/PAMAM-Pt em $\mathrm{H}_{2} \mathrm{SO}_{4}$ $0,1 \mathrm{~mol} \mathrm{~L}^{-1}$, saturado com $\mathrm{N}_{2}$. Velocidade de varredura de $0,1 \mathrm{~V} \mathrm{~s}^{-1}$. .74

Figura 32 - (A) e (C) Voltamogramas cíclicos do eletrodo ITO/PAMAM-Pt nas velocidades de varredura de $10,25,50,75,100,150,200,250,300,400,500,600,700,800,900$ e 1000 $\mathrm{mV} \mathrm{s}^{-1}$. Eletrólito $\mathrm{H}_{2} \mathrm{SO}_{4} 0,1 \mathrm{~mol} \mathrm{~L}^{-1}$, saturado com $\mathrm{N}_{2}$. (B) Variação das correntes de pico anódica e catódica, dos voltamogramas da Figura A, em função da velocidade de varredura. 75

Figura 33 - Voltamogramas cíclicos do eletrodo de ITO-PAMAM-Pt nas velocidades de varredura de 10, 25, 50,75, 100, 150, 200, 250, 300, 400, 500, 600,700, 800, 900 e 1000 $\mathrm{mV} \mathrm{s}^{-1}$ em solução de $\left[\mathrm{Ru}\left(\mathrm{NH}_{3}\right)_{6}\right]^{2+} /\left[\mathrm{Ru}\left(\mathrm{NH}_{3}\right)_{6}\right]^{3+} 3,0 \mathrm{mmol} \mathrm{L}{ }^{-1}$. Eletrólito $\mathrm{H}_{2} \mathrm{SO}_{4} 0,1 \mathrm{~mol} \mathrm{~L}^{-1}$, saturado com $\mathrm{N}_{2}$. Inserido: correntes de pico anódica e catódica em função da raiz quadrada da velocidade de varredura. .76

Figura 34 - Voltamogramas cíclicos (10 ciclos) para os eletrodos (A) ITO, (B) ITO/PAMAM e (C) ITO/PAMAM-Pt em TF 5,0 mmol $\mathrm{L}^{-1}, \mathrm{pH}$ 7,0, saturado com $\mathrm{N}_{2}$. Inserido: Voltamograma do eletrodo de $\mathrm{Pt}$ em TF 5,0 $\mathrm{mmol} \mathrm{L}^{-1}$, pH 7,0, saturado com $\mathrm{N}_{2}$. Velocidade de varredura de $0,1 \mathrm{~V} \mathrm{~s}^{-1}$ 77

Figura 35 - Voltamogramas cíclicos do eletrodo ITO nas velocidades de varredura de 10, 25, $50,75,100,150,200,250$ e $300 \mathrm{mV} \mathrm{s}^{-1}$, em solução de $\mathrm{K}_{4}\left[\mathrm{Fe}(\mathrm{CN})_{6}\right]$ 3,0 $\mathrm{mmol} \mathrm{L}^{-1}$. Eletrólito TF 5,0 mmol L-1, $\mathrm{pH}$ 7,0, saturado com $\mathrm{N}_{2}$. Inserido: correntes de pico anódica e catódica em função da raiz quadrada da velocidade de varredura. 78 
Figura 36 - Voltamogramas cíclicos do eletrodo ITO/PAMAM nas velocidades de varredura de $10,25,50,75,100,150,200,250$ e $300 \mathrm{mV} \mathrm{s}^{-1}$, em solução de $\mathrm{K}_{4}\left[\mathrm{Fe}(\mathrm{CN})_{6}\right]$ 3,0 mmol L ${ }^{-1}$. Eletrólito TF 5,0 mmol L ${ }^{-1}, \mathrm{pH} \mathrm{7,0,} \mathrm{saturado} \mathrm{com} \mathrm{N}_{2}$. Inserido: correntes de pico anódica e catódica em função da raiz quadrada da velocidade de varredura.

Figura 37 - Voltamogramas cíclicos do eletrodo ITO/PAMAM-Pt nas velocidades de varredura de $10,25,50,75,100,150,200,250$ e $300 \mathrm{mV} \mathrm{s}^{-1}$, em solução de $\mathrm{K}_{4}\left[\mathrm{Fe}(\mathrm{CN})_{6}\right]$ 3,0 $\mathrm{mmol} \mathrm{L}^{-1}$. Eletrólito TF 5,0 mmol L ${ }^{-1}$, pH 7,0, saturado com $\mathrm{N}_{2}$. Inserido: correntes de pico anódica e catódica em função da raiz quadrada da velocidade de varredura. .79

Figura 38 - Espectros de impedância no plano complexo obtidos em OCP em solução de $\left[\mathrm{Fe}(\mathrm{CN})_{6}\right]^{3-} /\left[\mathrm{Fe}(\mathrm{CN})_{6}\right]^{4-}$ 3,0 mmol L ${ }^{-1}$ em TF 5,0 mol L-1 $\mathrm{pH}$ 7,0, saturado com $\mathrm{N}_{2}$. Variação de frequência de $100 \mathrm{kHz}$ a 0,1 Hz. Inserido: Circuito de Randles. 80

Figura 39 - Estrutura do aminoácido cisteína e os valores de pka de seus grupos funcionais. 81

Figura 40 - Voltamogramas cíclicos em TF 5,0 mmol L-1, pH 7,0, saturado com $\mathrm{N}_{2}$. Velocidade de varredura $0,1 \mathrm{~V} \mathrm{~s}^{-1}$.

Figura 41 - Voltamogramas cíclicos do eletrodo ITO/PAMAM/Cys/CytC em TF 5,0 mmol L ${ }^{-1}, \mathrm{pH} 7,0$, saturado com $\mathrm{N}_{2}$

Figura 42 - (A) Variação das correntes de pico anódica e catódica, dos voltamogramas cíclicos da Figura 41, em função da velocidade de varredura. (B) Variação dos potenciais de pico anódico e catódico, dos voltamogramas cíclicos da Figura 41, em função da velocidade de varredura. .84

Figura 43 - Relação entre os potenciais de pico e o logaritmo da velocidade de varredura.... 85

Figura 44 - Voltamogramas cíclicos em TF 5,0 mmol L-1, pH 7,0, saturado com $\mathrm{N}_{2}$. Velocidade de varredura $0,1 \mathrm{~V} \mathrm{~s}^{-1}$. 86

Figura 45 - Voltamogramas cíclicos e de varredura linear do eletrodo

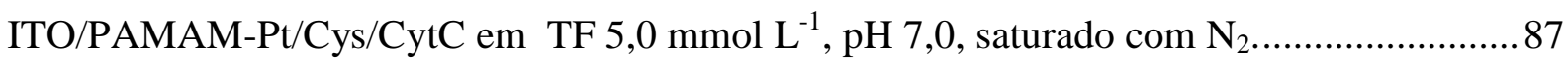

Figura 46 - Voltamogramas de varredura linear do eletrodo ITO/PAMAM-Pt/Cys/CytC em TF 5,0 mmol L ${ }^{-1}, \mathrm{pH} 7,0$, saturado com $\mathrm{N}_{2}$ 88 
Figura 47 - (A) Variação das correntes de pico anódica e catódica, dos voltamogramas cíclicos da Figura 45, em função da velocidade de varredura. (B) Variação dos potenciais de pico anódico e catódico, dos voltamogramas cíclicos da Figura 45, em função da velocidade de varredura. 89

Figura 48 - Relação entre os potenciais de pico e o logaritmo da velocidade de varredura....89

Figura 49 - Voltamogramas cíclicos em TF 5,0 mmol L-1, pH 7,0, saturado com $\mathrm{N}_{2}$. Velocidade de varredura (A) $0,1 \mathrm{~V} \mathrm{~s}^{-1} \mathrm{e}$ (B) $4,0 \mathrm{~V} \mathrm{~s}^{-1}$ 90 


\section{LISTA DE TABELAS}

Tabela 1 - Diferentes funções das NPs em sensores eletroquímicos.

Tabela 2 - Procedência e características dos materiais e reagentes utilizados.

Tabela 3 - Correntes de pico e resistência à transferência de carga para a reação de oxidação do hidrogênio adsorvido nos eletrodos ITO/(PAMAM-Pt) $)_{n}$, e tempo de confecção destes eletrodos.

Tabela 4 - Dispositivos utilizados no estudo da eletroquímica do CytC e/ou como biossensores. 


\section{LISTA DE ABREVIATURAS E SIGLAS}

$\left(\mathrm{IO}_{4}{ }^{-}\right)$- íon periodato

BSA (bovine serum albumin) - albumina de soro bovino

Chi (chitosan) - quitosana

ChOx - (cholesterol oxidase enzyme) - enzima colesterol oxidase

CNTs (carbon nanotubes) - nanotubos de carbono

ConA - concanavalina A

CV (cyclic voltammetry) - voltametria cíclica

Cys - cisteína

CytC - citocromo C

DEN - dendrímero

EDC - 1-etil-3-(3-dimetilaminopropil)carbodiimida

EG - etileno glicol

EDX - espectroscopia de raios X por dispersão em energia

EHR - hydrogen electrode reaction

EIS (electrochemical impedance spectroscopy) - espectroscopia de impedância eletroquímica

FTIR - espectroscopia de infravermelho com transformada de Fourier

GC (glassy carbono) - carbono vítreo

GLDH (glutamate dehydrogenase enzyme) - enzima glutamato dehidrogenase

GOx (glucose oxidase enzyme) - enzima glicose oxidase

Gp - grafeno

HRP - enzima horseradish peroxidase

HRTEM (high resolution transmission electron microscopy) - microscopia eletrônica de transmissão de alta resolução

ITO (indium tin oxide) - vidro recoberto com óxido de estanho e índio

LB - Langmuir-Blodgett

LBL (layer-by-layer) - camada-por-camada

MCH - 6-marcapto-1-hexanol

MNEs - Materiais nanoestruturados

MPS - 3-mercaptopropanosulfonico

MS - sílica mesoporosa

MUA - ácido 11-mercaptoundecanóico

MWCNTs (multi-walled carbon nanotubes) - nanotubos de carbono de paredes múltiplas 
NAD (nicotinamide adenine dinucleotide) - dinucleótido de nicotinamida-adenina

NPs - nanopartículas

NPsAu - nanopartículas de ouro

NPsPt - nanopartículas de platina

NR (neutral red) - corante vermelho neutro

$\mathbf{O C P}$ - potencial de circuito aberto

ORR - reação de redução de $\mathrm{O}_{2}$

PA - poliacrilato

PAMAM - dendrímero poli(amidoamina)

PAMAM G4.0-NH $\mathbf{N H}_{2}$ - dendrímero poli(amidoamina), geração 4.0, com grupos terminais amina

PAMAM G4.0-OH - dendrímero poli(amidoamina), geração 4.0, com grupos terminais hidroxila

PAMAM-Pt - NPsPt encapsuladas em PAMAM

PANS - nanoesferas de polianilina

PDDA - poli(dialildimetilamonio)

Ppy - polipirrol

PSS - poli(4-estirenosulfonato de sódio)

Pt-Chi - NPsPt preparadas em matriz de quitosana

Pt-DENs - NPsPt encapsuladas em dendrímero

PTFE - politetrafluoretileno

PVS - poli(ácidovinilsulfônico)

RCA - RCA Laboratories, Princeton, New Jersey

RTIL - líquidos iônicos à temperatura ambiente

SAM (self-assembled monolayer) - monocamada auto-oganizada

TEM (transmission electron microscopy) - microscopia eletrônica de transmissão

TF - tampão fosfato

TTAB - brometo de tetradeciltrimetilamonio

UPD (underpotential deposition) - deposição em regime de subtensão

UV-Vis - espectroscopia de absorção na região do ultravioleta-visível 


\section{LISTA DE SÍMBOLOS}

$\boldsymbol{\alpha}$ - coeficiente de transferência de carga

$\mathbf{C p}$ - capacitância da dupla camada

$\Delta \mathbf{E p}$ - variação dos potenciais de pico

$\mathbf{E}$ - potencial de eletrodo (V)

F - constante de Faraday

I - corrente elétrica $(\mu \mathrm{A})$

$\mathbf{j}$ - densidade da corrente elétrica $\left(\mathrm{A} \mathrm{cm}^{-2}\right)$

$\boldsymbol{k}_{\boldsymbol{s}}$ - constante de transferência de carga

$\lambda$-comprimento de onda (nm)

$\mathbf{v}$ - velocidade de varredura

$\mathbf{R}$ - constante universal dos gases

$\mathbf{R}_{\boldsymbol{\Omega}}-$ resistência da solução

$\mathbf{R}_{\mathbf{t c}}-$ resistência à transferência de carga

$\mathbf{T}$ - temperatura

Z' - impedância real

-Z" - impedância imaginária

$\mathbf{Z}_{\mathbf{w}}$ - impedância de Warburg 


\section{INTRODUÇÃO}

\subsection{Filmes finos nanoestruturados}

Nanociência e nanotecnologia foram reconhecidas como os mais modernos tópicos de pesquisa nas décadas passadas. E os materiais nanoestruturados (MNEs), definidos como materiais cujos elementos estruturais têm dimensões entre 1 e $100 \mathrm{~nm}^{1}$, são, sem dúvida, o núcleo chave e agem como promotores para o intenso desenvolvimento de novos campos de pesquisa. Atualmente, há um esforço intenso em desenvolver os métodos de produção de novos MNEs com diferentes morfologias e/ou composições, que são de grande importância para alcançar aplicações com alto desempenho. Esta nova área da tecnologia tem estimulado os pesquisadores a se concentrarem principalmente na identificação de novas propriedades e na compreensão das propriedades relacionadas à estrutura, pois o tamanho, forma, arquitetura, composição, engenharia molecular, montagem e microestrutura dos MNEs são os principais parâmetros que revelam suas novas e melhores funções e determinam seus diferentes potenciais de aplicação ${ }^{2}$.

Por apresentarem muitas propriedades particulares, os MNEs têm muitas aplicações difundidas em eletroquímica, eletrocatálise, ótica, eletrônica, dispositivos analíticos e dispositivos de geração de energia ${ }^{3,4}$, sendo utilizados, por exemplo, em drug delivery e catálise enzimática ${ }^{5}$, eletrodos para armazenamento e conversão de energia ${ }^{6}$, nanofotônica e optoeletrônica $^{7}$, biossensores e células de biocombustível $^{8}$, supercapacitores $^{9}$ e catálise heterogênea ${ }^{10}$.

Os MNEs multicompósitos podem combinar várias propriedades desejáveis, como estabilidade, resistência, condutividade e estrutura tridimensional, dependendo de seus componentes e de como estes componentes estão estruturados no material, ou seja, uma maior funcionalidade está diretamente ligada ao controle da orientação molecular e organização ${ }^{11}$. Desta forma, fez-se necessário desenvolver métodos que permitissem o controle da montagem destes MNEs multicompósitos.

Filmes finos de MNEs multicompósitos (com espessura entre 10 e $1000 \AA$ ) são preparados por diversas técnicas, dentre as quais, tem-se Langmuir-Blodgett (LB) e a automontagem de monocamadas (do inglês, self-assembled monolayers - SAMs). Na técnica de LB, monocamadas de materiais, solúveis em solventes orgânicos, são formadas sobre a superfície da água e, em seguida, transferidas para a superfície de um suporte sólido ${ }^{12,13}$. Tal 
técnica requer ambiente e equipamentos especiais e caros, além de possuir limitações quanto ao tamanho e topologia dos substratos utilizados. A técnica $\mathrm{SAM}^{14}$, emprega camadas monomoleculares que exibem uma alta organização, e que são formadas espontaneamente, como consequência da imersão de uma superfície sólida em solução constituída de moléculas anfóteras. Enquanto que, a adsorção é um resultado da afinidade de um grupo funcional do adsorvente, que apresenta certa especificidade para interagir com a superfície do substrato, a força motriz para a organização se origina a partir de interações hidrofóbicas (por exemplo, do tipo Van der Waals) das cadeias longas ligadas ao grupo funcional. Uma variedade de materiais (por exemplo, superfícies de $\mathrm{Pt}, \mathrm{Au}, \mathrm{Ag}, \mathrm{Cu}$ etc.) e de moléculas anfóteras (como derivados alquil, álcoois, aminas, tióis etc.) tem sido empregada na confecção de sistemas organizados. Esta metodologia não permite a preparação de estruturas com multicamadas, e as interações entre as moléculas ocorrem por ligações covalentes ou coordenadas, o que a limita a certas classes de compostos orgânicos.

A automontagem camada por camada (layer-by-layer - LBL), desenvolvida por Decher $^{11,15}$ para polieletrólitos, posteriormente estendida à aplicação de polímeros ${ }^{16}$, consiste na deposição de camadas alternadas de polieletrólitos de cargas opostas adsorvidos (por atrações Coulombicas entre as cargas opostas dos materiais utilizados) a partir de soluções aquosas (Figura 1). Esta técnica surgiu como um meio viável para manipular poliíons em multicamadas de filmes finos, oferecendo alto controle no nível molecular, na espessura e arquitetura das multicamadas. Por LBL, podem se obter filmes nanoestruturados com uma ampla variedade de polímeros eletroativos, nanopartículas (NPs), enzimas, entre outros.

Figura 1 - Esquema do processo de deposição de filmes pela técnica LBL.

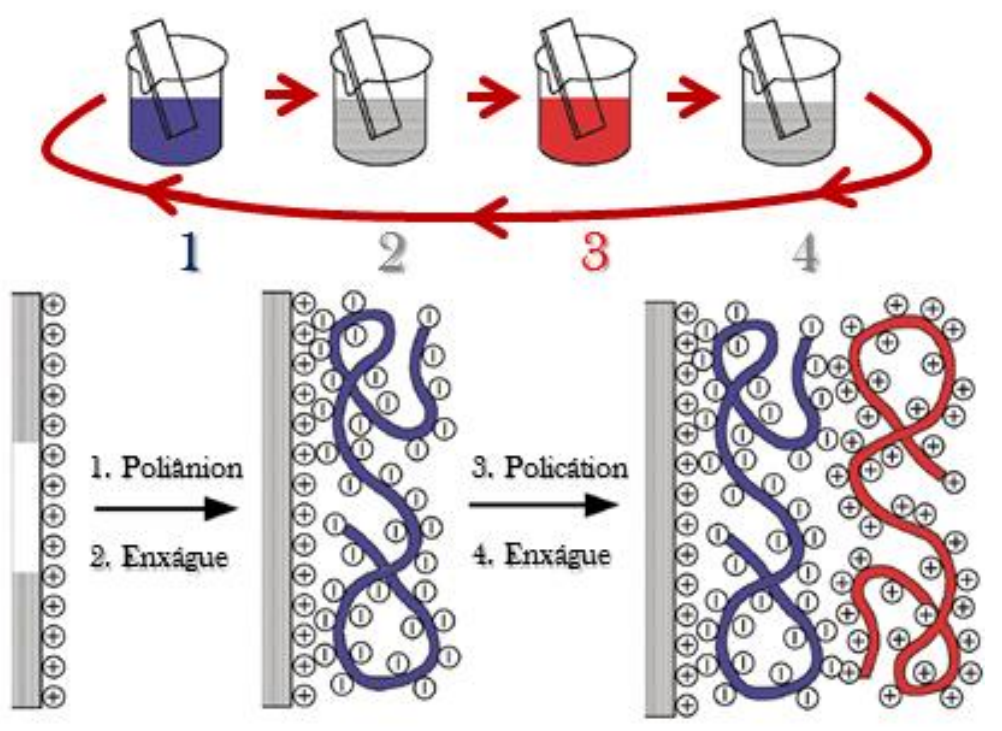

Fonte $^{11}$ : adaptado de Decher, G. Science, v. 277, n. 5330, p. 1232-1237, 1997. 


\subsection{Preparação de biodispositivos utilizando LBL e nanopartículas de platina}

Além da fabricação de novos materiais, a técnica LBL permite investigar, em nível molecular, processos fundamentais como os mecanismos de transferência de carga que envolvem biomoléculas e NPs ${ }^{17-19}$. As propriedades químicas e físicas únicas das NPs as tornam extremamente úteis no desenvolvimento de novos dispositivos de detecção, especialmente sensores eletroquímicos e biossensores. Diferentes tipos de NPs (metálicas, óxidos e semicondutoras) têm sido utilizadas para a construção de sensores eletroquímicos e biossensores, desempenhando funções, como a imobilização de biomoléculas, catálise de reações eletroquímicas e otimização na transferência de elétrons entre eletrodos e proteínas $(\text { Tabela } 1)^{20,21}$.

Tabela 1 - Diferentes funções das NPs em sensores eletroquímicos.

\begin{tabular}{|c|c|c|c|c|}
\hline Funções & Propriedades & Nanopartículas & Vantagens & Exemplo \\
\hline $\begin{array}{l}\text { Imobilização } \\
\text { de } \\
\text { biomoléculas }\end{array}$ & $\begin{array}{c}\text { Biocompatibilidade; } \\
\text { Aumento da área } \\
\text { superficial }\end{array}$ & $\begin{array}{c}\mathrm{Au}, \mathrm{Ag} \\
\mathrm{SiO}_{2}, \mathrm{TiO}_{2} \\
\end{array}$ & $\begin{array}{l}\text { Aumento da } \\
\text { estabilidade }\end{array}$ & $\begin{array}{l}\text { Anticorpo imobilizado em NPsAu } \\
\text { mantem-se estável por } 100 \text { dias }^{22}\end{array}$ \\
\hline Catálise & $\begin{array}{l}\text { Superfície com } \\
\text { energia elevada }\end{array}$ & $\mathrm{Au}, \mathrm{Pt}$ & $\begin{array}{c}\text { Aumento da } \\
\text { sensibilidade } \\
\text { e } \\
\text { seletividade }\end{array}$ & $\begin{array}{c}\text { Sensor de } \mathrm{H}_{2} \mathrm{O}_{2} \text { baseado em NPs e } \\
\text { Azul da Prússia com sensibilidade de } \\
103,5 \mu \mathrm{A} \mathrm{mM}^{-1} \mathrm{~cm}^{-223}\end{array}$ \\
\hline $\begin{array}{l}\text { Aumento na } \\
\text { transferência } \\
\text { de elétrons }\end{array}$ & $\begin{array}{l}\text { Condutividade; } \\
\text { Dimensões } \\
\text { minúsculas } \\
\end{array}$ & $\begin{array}{c}\mathrm{Au}, \mathrm{Ag} \\
\mathrm{TiO}_{2}, \mathrm{ZrO}_{2}\end{array}$ & $\begin{array}{c}\text { Maior } \\
\text { sensibilidade }\end{array}$ & $\begin{array}{c}\text { Velocidade de transferência de } \\
\text { elétrons de } 5000 \mathrm{~s}^{-1} \text { para a glicose } \\
\text { oxidase aumentou devido às NPsAu } \\
\end{array}$ \\
\hline Reagente & Atividade química & $\mathrm{MnO}_{2}$ & $\begin{array}{c}\text { Novos } \\
\text { mecanismos } \\
\text { de resposta }\end{array}$ & $\begin{array}{l}\text { Biossensor para lactato com NPs de } \\
\mathrm{MnO}_{2} \text { mostrou-se } 50 \text { vezes mais } \\
\text { sensível do que sem as } \mathrm{Nps}^{25}\end{array}$ \\
\hline
\end{tabular}

A seguir, destacam-se alguns trabalhos que empregam nanoestruturas baseadas em LBL de nanopartículas de platina (NPsPt) para construção de biodispositivos.

Wang et al. ${ }^{26}$ propuseram uma nanoestrutura para aplicação em biossensores e células de combustível utilizando CNTs de paredes múltiplas (MWCNTs) funcionalizados com poli(dialildimetilamonio) (PDDA) e NPsPt estabilizadas em citrato. A nanoestrutura foi preparada layer-by-layer pela imersão de um eletrodo de ouro modificado com o tiol (3-mercaptopropanosulfonico) (MPS), alternadamente, em solução do PDDA-MWCNTs e em solução das NPsPt. Além do ouro foram utilizados quatzo e ITO (vidro recoberto com óxido de estanho e índio) como substratos. A nanoestrutura apresentou arquitetura 
Au-MPS/(PDDA-MWCNTs/NPsPt) $)_{n}$ com excelente atividade eletrocatalítica para a redução do oxigênio molecular.

$\mathrm{Xu}$ et al. $^{27}$ descreveram um biossensor para glicose preparado com CNTs, PDDA, poli(4-estirenosulfonato de sódio) (PSS), NPsPt encapsuladas em dendrímero (Pt-DENs) e a enzima glicose oxidase (GOx) modificada com o íon periodato $\left(\mathrm{IO}_{4}^{-}\right)$. Os CNTs foram modificados layer-by-layer com PDDA, PSS, Pt-DENs e a GOx. Sobre um eletrodo de Pt molhado com albumina de soro bovino (BSA) foi aplicado por dropping $10 \mu \mathrm{L}$ do compósito (CNT/PDDA/PSS/Pt-DENs/GOx) e glutaraldeído 5\%. O biossensor apresentou arquitetura $\mathrm{Pt} /(\mathrm{CNT} / \mathrm{PDDA} / \mathrm{PSS} / \mathrm{Pt}-\mathrm{DENs} / \mathrm{GOx})$ e foi utilizado para determinação de $\mathrm{H}_{2} \mathrm{O}_{2}$ com limite de detecção de 2,5 $\mu \mathrm{mol} \mathrm{L} \mathrm{L}^{-1}$, intervalo linear de $5 \mu \mathrm{mol} \mathrm{L}^{-1}$ a $0,65 \mathrm{mmol} \mathrm{L}^{-1}$, com tempo de resposta de $5 \mathrm{~s}$, sensibilidade de $30,64 \mu \mathrm{A} \mathrm{mmol}^{-1} \mathrm{~L} \mathrm{~cm}^{-2}$ e mantendo $80 \%$ de resposta após 30 dias.

Tang et al. $^{28}$ estudaram um biossensor para glutamato preparado com NPsPt encapsuladas em dendrímero poli(amidoamina) (PAMAM), CNTs e a enzima glutamato dehidrogenase (GLDH). Os CNTs foram modificados layer-by-layer com Pt-DENs e a enzima GLDH. Sobre um eletrodo de carbono vítreo (GC) foi aplicado por dropping $20 \mu \mathrm{L}$ do nanocompósito Pt-DENs/GLDH. Um filme de polipirrol (Ppy) foi eletrodepositado sobre o eletrodo $\mathrm{GC} /(\mathrm{Pt}-\mathrm{DENs} / \mathrm{GLDH})_{\mathrm{n}}$. O biossensor para glutamato apresentou arquitetura GC/(Pt-DENs/GLDH) $/$ Ppy com sensibilidade de 51,48 $\mu \mathrm{A} \mathrm{mmol}^{-1} \mathrm{~L}$, tempo de resposta de 3 s e limite de detecção de cerca de $10 \mathrm{nmol} \mathrm{L}^{-1}$.

Wang et al. ${ }^{29}$ construíram um biossensor para glicose utilizando NPsPt e CNTs sulfonatados (S-MWCNTs). Sobre um eletrodo GC foram aplicados, por casting, $5 \mu \mathrm{L}$ do compósito Pt/S-MWCNTs disperso em Nafion ${ }^{\circledR}$. Então $5 \mu \mathrm{L}$ de solução de GOx foram também aplicados, por casting. Após várias repetições tem-se o biossensor com arquitetura $\mathrm{GC} /(\mathrm{Pt} / \mathrm{S}-\mathrm{MWCNTs} / \mathrm{GOx})_{\mathrm{n}}$ o qual apresentou sensibilidade de $1,36 \mu \mathrm{A} \mathrm{mmol}^{-1} \mathrm{~L}$, faixa linear de $2,5 \mathrm{mmol} \mathrm{L}^{-1}$ e coeficiente de correlação de 0,972 .

Zhang et al. ${ }^{30}$ descrevem a construção de um biossensor amperométrico para a detecção de $\mathrm{H}_{2} \mathrm{O}_{2}$ utilizando NPsPt, corante vermelho neutro (NR), MWCNTs e a enzima horseradish peroxidase (HRP). Sobre um eletrodo GC modificado com MWCNTs foi eletrodepositado um filme de NPsPt e NR. O eletrodo obtido foi imerso em uma solução da enzima HRP resultando em um biossensor de arquitetura GC/MWCNTs/NPsPt-NR/HRP. O biossensor apresentou atividade eletrocatalítica para $\mathrm{H}_{2} \mathrm{O}_{2}$ com resposta proporcional à 
concentração do analito numa faixa de $3,6 \mu \mathrm{mol} \mathrm{L}{ }^{-1}$ a $4,3 \mathrm{mmol} \mathrm{L}^{-1}$ e limite de detecção de $1,1 \mu \mathrm{mol} \mathrm{L}{ }^{-1}$.

Yang et al. ${ }^{31}$ prepararam um biossensor para determinação de colesterol utilizando NPsPt preparadas em matriz de quitosana (Pt-Chi) e reduzidas com borohidreto de sódio $\left(\mathrm{NaBH}_{4}\right)$. MWCNTs foram dispersos nesta solução de Pt-Chi resultando em uma solução Pt-CNT-Chi. Os filmes self-assembled foram preparados layer-by-layer pela imersão de um eletrodo de ouro modificado com o tiol MPS em solução Pt-CNT-Chi e em PSS alternadamente. A enzima colesterol oxidase (ChOx) foi imobilizada por dropping sobre o sensor Au-MPS/(Pt-CNT-Chi/PSS) n recoberto com solução de glutaraldeído 0,5\% \% O biossensor apresentou arquitetura Au-MPS/(Pt-CNT-Chi/PSS) $/$ /ChOx e foi aplicado na determinação de colesterol com resposta linear de 0,01 a $3,00 \mathrm{mmol} \mathrm{L}^{-1}$ e tempo de resposta de $30 \mathrm{~s}$.

Tang et al. ${ }^{32}$ desenvolveram um biossensor para glutamato baseado em NPsPt encapsuladas em PAMAM, CNTs e a enzima GLDH. As heteroestruturas CNTs/PAMAM-Pt foram estabilizadas por 1-etil-3-(3-dimetilaminopropil)carbodiimida (EDC). GLDH foi imobilizada sobre a heteroestrutura CNTs/PAMAM-Pt por layer-by-layer de GLDH e PAMAM-Pt formando o nanocompósito CNTs/PAMAM-Pt/(GLDG-PAMAM-Pt). Sobre um eletrodo GC foi aplicado, por casting, $20 \mu \mathrm{L}$ do nanocompósito. O biossensor para glutamato, com arquitetura GC/CNTs/PAMAM-Pt/(GLDG-PAMAM-Pt) $)_{n}$ foi avaliado na presença de $\mathrm{NAD}^{+}$a um potencial de $0,2 \mathrm{~V}$ e apresentou um intervalo de determinação de 0,2 a $250 \mu \mathrm{mol} \mathrm{L} \mathrm{L}^{-1}$, tempo de resposta de $3 \mathrm{~s}$, sensibilidade de $433 \mu \mathrm{A} \mathrm{mmol}{ }^{-1} \mathrm{~L} \mathrm{~cm}^{-2}$ e estabilidade, mantendo $85 \%$ da resposta após 4 semanas.

Li et al. ${ }^{33}$ desenvolveram um biossensor para glicose utilizando NPsPt suportadas em CNTs. As NPsPt suportadas em CNTs foram dispersas em solução de quitosana formando NPsPt-CNTs-Chi. Sobre um eletrodo GC foi aplicado, por dropping, $8 \mu \mathrm{L}$ do nanocompósito NPsPt-CNTs-Chi. O eletrodo GC/NPsPt-CNTs-Chi foi imerso em solução de concanavalina A (ConA) e, alternadamente, em solução de GOx, formando o biossensor para glicose com arquitetura GC/NPsPt-CNTs-Chi/(ConA/GOx) . O mesmo foi aplicado na determinação de glicose com resposta linear para o analito numa faixa de $1,2 \mu \mathrm{mol} \mathrm{L}^{-1}$ a $2,0 \mathrm{mmol} \mathrm{L}{ }^{-1}$, com limite de detecção de $0,4 \mu \mathrm{mol} \mathrm{L}{ }^{-1}$.

Zhang et al. $^{34}$ produziram um nanocompósito de NPsPt encapsuladas em PAMAM, CNTs e GOx e estudaram suas propriedades para aplicação como anodo de células de combustível. As heteroestruturas PAMAM-Pt/CNTs foram ligadas covalentemente por EDC. 
A GOx foi imobilizada por layer-by-layer de GOx e PAMAM-Pt resultando na arquitetura CNTs/(PAMAM-Pt/GOx) $)_{n}$. Os resultados mostraram que a o híbrido PAMAM-Pt/CNTs promoveu boa condução dos elétrons e potencial aplicação na construção de novas células de combustível.

De acordo com os trabalhos apresentados, podemos concluir que NPsPt associadas a outros materiais, automontados em diferentes arquiteturas, apresentaram notável desempenho e atividade eletrocatalítica para aplicação em células de combustível, e como plataforma para biossensores, com ótimos limites de detecção, estabilidade e rápido tempo de resposta.

\subsection{Nanopartículas encapsuladas em dendrímeros}

O dendrímero PAMAM vem sendo utilizado há alguns anos para mediar a síntese de NPs de metais de transição ${ }^{35-39}$. Em geral, escolhas adequadas da geração do PAMAM, razão dendrímero-metal, e outras variáveis de síntese levam a suspensões de NPs com distribuição de tamanho reduzida e reprodutível, com tamanho médio controlado ${ }^{40}$. Em 1999, Zhao e Crooks $^{35}$ apresentaram um método, baseado no uso de template, para preparar NPsPt monodispersas para estudos fundamentais e aplicação em eletrocatálise. Esta abordagem emprega o dendrímero PAMAM geração 4 (G4.0) com grupos terminais hidroxila (PAMAM G4.0-OH) como template e estabilizador das NPsPt. O dendrímero PAMAM G4.0 (Figura 2) é um dendrímero Starburst ${ }^{41}$, monodisperso, hiper-ramificado, de forma esférica, altamente funcionalizado, estericamente aglomerado no exterior, com cavidades no interior. As cavidades deste dendrímero permitem que íons de metais de transição se complexem fortemente com seus grupos funcionais, ocupando tais cavidades de maneira monodispersa. A redução química destes íons, complexados pelo dendrímero, permite a obtenção de NPs encapsuladas e monodispersas (Figura 3). O tamanho das NPs formadas depende da geração do dendrímero utilizado como template, da carga do íon metálico e do número de íons complexados por molécula de dendrímero, razão íon/dendrímero. 
Figura 2 - Estrutura do PAMAM G4.0. $\mathrm{Z}=\mathrm{NH}_{2}$ (64 unidades) para o PAMAM G4.0-NH $\mathrm{NH}_{2}$ e $=\mathrm{OH}(64$ unidades) para o PAMAM G4.0-OH.

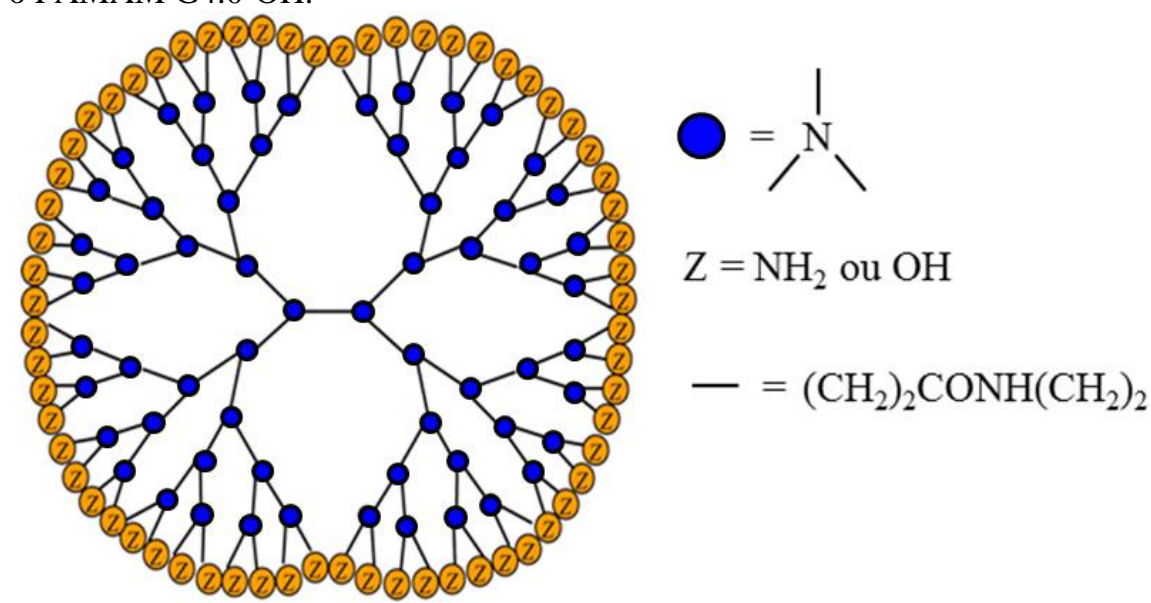

Fonte $^{42}$ : adaptado de CHAUHAN, A.S.; JAIN, N.K.; DIWAN, P.V. Pre-clinical and behavioural toxicity profile of PAMAM dendrimers in mice. Proceedings of the Royal Society A-Mathematical Physical and Engineering Sciences, v. 466, n. 2117, p. 1535-1550, 2010.

Figura 3 - Ilustração esquemática do processo de síntese das NPs encapsuladas em dendrímero. Primeiro os íons metálicos são complexados nas cavidades do dendrímero template. Em seguida os íons são reduzidos, resultando em nanopartículas metálicas monodispersas.

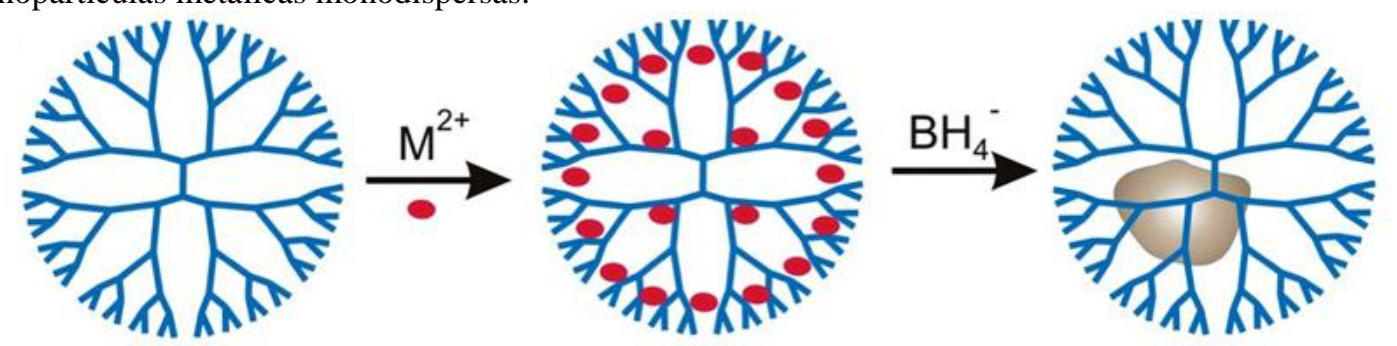

Fonte $^{\mathbf{4 3}}$ : RUTGERS CATALYSIS RESEARCH CENTER. 2011. Disponível em:

$<$ http://catalysis.rutgers.edu/content/synthesis-characterization-and-electrocatalytic-applications-dendrimerencapsulated>. Acesso em: 08 jul. 2013.

Na aplicação de NPs em catálise, dois desafios são importantes: (1) desenvolver métodos para a estabilização de nanopartículas, eliminando a agregação sem bloquear a maioria dos sítios ativos na superfície das nanopartículas ou reduzir a eficiência catalítica (2) controlar o tamanho das nanopartículas, a distribuição de tamanho, e até mesmo a forma da nanopartícula $^{37}$. O dendrímero estabiliza as NPs e impede a aglomeração, no entanto, não passiva a superfície do metal, de forma que o híbrido dendrímero-NPs pode ser utilizado para aplicações catalíticas.

Crooks e colaboradores utilizaram NPs de metais de transição encapsuladas em dendrímero em catálise homogênea em meio aquoso ${ }^{44}$, em meio de solventes orgânicos ${ }^{37,45} \mathrm{e}$ de solventes bifásicos organofluorados ${ }^{46}$. Crespilho et al. ${ }^{47}$ descreveram a fabricação de uma membrana eletroativa nanoestruturada para a redução de $\mathrm{O}_{2}$, baseada em filmes LBL de NPs de ouro encapsuladas em PAMAM G4.0- $\mathrm{NH}_{2}$, alternadas com o poliânion PVS. O eletrodo de 


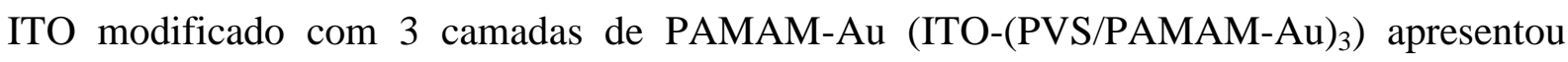
ótimo desemprenho para a redução de $\mathrm{O}_{2}$ quando comparado com o ITO sem modificação, indicando que as NPsAu apresentam atividade catalítica para a redução do $\mathrm{O}_{2}$ promovendo a transferência de carga entre camadas.

A seguir apresentamos a revisão de alguns trabalhos que empregam NPsPt encapsuladas em PAMAM para aplicações eletroquímicas em redução de $\mathrm{O}_{2}$, detecção de dopamina e $\mathrm{H}_{2} \mathrm{O}_{2}$, catodos tolerantes a metanol e determinação de glicose.

Zhao e Crooks $^{35}$ descreveram a síntese das NPsPt encapsuladas em PAMAM G4.0-OH e a aplicação de um eletrodo de Au modificado com PAMAM-Pt na redução de $\mathrm{O}_{2}$. O eletrodo Au/PAMAM-Pt foi comparado com um eletrodo Au/PAMAM e apresentou excelente desempenho, demonstrando que as NPsPt estão acessíveis para participar da reação atuando como eletrocatalisadores para redução de $\mathrm{O}_{2}$ sem necessidade do uso de mediadores.

Siqueira Jr. et al. $^{48}$ descreveram a fabricação de uma membrana eletroativa nanoestruturada bifuncional baseada em um filme LBL de NPsPt encapsuladas em PAMAM G4.0- $\mathrm{NH}_{2}$ e ftalocianina de níquel tetrasulfonada. Com esta membrana é possível estudar a atividade catalítica para dopamina e peróxido de hidrogênio em um único dispositivo.

Crespilho et al. ${ }^{49}$ relataram a fabricação de um catodo tolerante a metanol baseado em um eletrodo de ITO modificado com um filme LBL de NPsPt encapsuladas em PAMAM G4.0- $\mathrm{NH}_{2}$, alternadas com o poliânion PVS. As NPsPt no eletrodo ITO/(PVS/PAMAM-Pt) $)_{10}$ não sofrem obstrução pelo metanol para a adsorção de oxigênio como ocorre com o eletrodo de Pt.

Han et al. ${ }^{50}$ construíram um sensor de glicose baseado na modificação de um eletrodo GC com um material híbrido composto de partículas de sílica mesoporosa (MS) e NPsPt encapsuladas em PAMAM. O material híbrido MS/PAMAM-Pt foi obtido em solução aquosa neutra por interações eletrostáticas entre os materiais. O PAMAM-Pt aumenta a condutividade da MS e aumenta a transferência de elétrons entre o centro redox da enzima e a superfície do eletrodo. O eletrodo GC/MS/PAMAM-Pt/GOx foi utilizado na determinação de glicose com um tempo de resposta de menos de $3 \mathrm{~s}$, numa faixa de concentração de glicose de 0,02 a $10 \mathrm{mmol} \mathrm{L}^{-1}$, com limite de detecção de $4 \mu \mathrm{mol} \mathrm{L}{ }^{-1}$. 
Tang et al. ${ }^{51}$ prepararam um sensor baseado em um material nanobiocompósito obtido pela eletropolimerização de polipirrol contendo NPsPt encapsuladas em PAMAM e a enzima GOx. O PAMAM-Pt proporciona condutividade eléctrica. O polipirrol confere ao filme estabilidade, homogeneidade e condutividade elétrica. Ambos, polipirrol e PAMAM podem proporcionar um microambiente favorável para manter a bioatividade de enzimas, como a glicose oxidase. $\mathrm{O}$ biossensor para glicose apresentou sensibilidade de $164 \mu \mathrm{A} \mathrm{mmol}^{-1} \mathrm{~L} \mathrm{~cm}^{-2}$, numa faixa linear de concentração de glicose de 0,2 a $600 \mu \mathrm{mol} \mathrm{L}^{-1}$, com um limite de detecção de $10 \mathrm{nmol} \mathrm{L}{ }^{-1}$ e um tempo de resposta de menos de $3 \mathrm{~s}$.

Ledesma-Garcia et al. ${ }^{52}$ avaliaram o comportamento de um eletrodo disco rotatório modificado com NPsPt encapsuladas em PAMAM G4.0-OH para reação de redução de $\mathrm{O}_{2}$ (ORR) em meio ácido com e sem a adição de metanol. Os estudos mostraram que o eletrodo modificado com PAMAM-Pt mostrou maior seletividade para a ORR que o eletrodo modificado com catalisador de Pt comercial. O dendrímero confere um efeito protetor sobre a Pt na presença de metanol, o que permite a utilização do PAMAM-Pt em catodos de células de combustível.

Ye e Crooks $^{53}$ imobilizaram eletroquimicamente NPsPt encapsuladas em PAMAM G4.0-OH em um eletrodo de carbono vítreo e utilizaram este dispositivo para redução eletrocatalítica do $\mathrm{O}_{2}$. Os filmes obtidos são ativos para redução de $\mathrm{O}_{2}$, estáveis e mantêm suas propriedades eletrocatalíticas mesmo após 50 ciclos consecutivos.

Com os trabalhos apresentados pudemos observar que as NPsPt encapsuladas em PAMAM, associadas ou não a outros materiais, foram utilizadas na obtenção de filmes eletroativos, imobilizadas pela técnica LBL, por interações eletrostáticas ou eletroquimicamente. E em todos os casos apresentaram notável desempenho e atividade eletrocatalítica para redução de $\mathrm{O}_{2}$, detecção de dopamina, $\mathrm{H}_{2} \mathrm{O}_{2}$ e plataforma para biossensores de glicose, com ótimos limites de detecção, estabilidade e rápido tempo de resposta.

O dendrímero utilizado neste trabalho, na síntese das NPsPt encapsuladas por redução química, o PAMAM G4.0- $\mathrm{NH}_{2}$, como já mostrado na Figura 2, possui 62 grupos internos de aminas terciárias e 64 grupos externos (periféricos). Estes grupos funcionais periféricos permitem que a molécula do dendrímero PAMAM G4.0- $\mathrm{NH}_{2}$ seja altamente solúvel em água e sob condições de $\mathrm{pH}$ adequadas, com suas aminas externas protonadas, o PAMAM G4.0- $\mathrm{NH}_{2}$ pode ser facilmente imobilizado sobre superfícies com carga negativa ou utilizado na confecção de filmes automontados com polieletrólitos de carga negativa. Desta 
forma, neste trabalho um eletrodo de ITO foi modicado com camadas do híbrido PAMAM-Pt alternadas com o poliânion PVS.

\subsection{Ativação do eletrodo de ITO modicado com camadas do híbrido PAMAM-Pt alternadas com o poliânion PVS}

Coutanceau et al. ${ }^{54}$ descreveram quatro principais rotas de síntese para a obtenção de NPsPt com forma controlada: método da microemulsão água/óleo (w/o), método do poliacrilato (PA), método do brometo de tetradeciltrimetilamonio (TTAB) e método do etileno glicol (EG). E observaram que os métodos PA, TTAB e w/o permitem a obtenção de NPsPt que podem ser "limpas" para terem suas estruturas superficiais caracterizadas eletroquimicamente por UPD de hidrogênio e pela deposição espontânea e oxidação de bismuto e germânio. As amostras preparadas pelo método EG, na presença ou não de polivinilpirrolidona como surfactante, têm forma e tamanhos controlados, mas não permitem a caracterização eletroquímica de suas superfícies devido à presença de espécies orgânicas remanescentes, fortemente adsorvidas, mesmo após as etapas de limpeza. NPsPt "limpas" podem ser utilizadas no estudo do efeito da estrutura superficial sobre a atividade eletrocatalítica para a reação de redução de oxigênio ou oxidação de pequenas moléculas orgânicas sem interferentes devido ao envenenamento por espécies anteriormente adsorvidas sobre a superfície do catalisador.

Já vimos nos trabalhos apresentados que a obtenção de NPsPt encapsuladas em dendrímero, pela redução química de íons de platina complexados, é um método de síntese relativamente simples e muito eficaz para aplicações dessas NPsPt em estudos eletroquímicos. As NPsPt assim obtidas são utilizadas sem purificação ou são purificadas por dialise, para remoção do precursor metálico ou do agente redutor não cosumidos na síntese. Ledesma-

Garcia et al. ${ }^{55}$ prepararam NPsPt encapsuladas em PAMAM pela redução eletroquímica dos íons $\mathrm{Pt}^{2+}$. Eletrodos de carbono vítreo modificados com PAMAM-Pt, obtidos via redução química (PAMAM-Pt ${ }_{C}$ ) e obtidos por redução eletroquímica (PAMAM-Pt ${ }_{\mathrm{EC}}$ ), foram utilizados para redução eletrocatalítica de $\mathrm{O}_{2}$. O eletrodo GC/PAMAM-Pt $t_{\mathrm{EC}}$ exibiu melhor desempenho para a ORR, atribuido a um melhor controle sobre a presença de impurezas, precursores metálicos ou agentes redutores, que podem contribuir para uma diminuição do desempenho electrocatalítico, obtido pelo método da redução eletroquímica. 
Assim, levando-se em conta a importancia da obtenção de NPs com sítios eletrocatalíticos disponíveis para estudos e aplicações eletroquímicas, e observando os dados experimentais obtidos neste trabalho, durante o processo de otimização dos parametros de preparação do eletrodo ITO/PAMAM-Pt, realizamos um estudo sobre a ativação do eletrodo ITO/PAMAM-Pt por tratamento eletroqúmico. O tratamento eletroquímico é o mesmo utilizado para pré-condicionar eletrodos de Pt e sua influencia no desempenho dos eletrodos ITO/PAMAM-Pt foi avaliada por medidas de EIS e CV.

A possibilidade de se obter um eletrodo modificado com um filme fino nanoestruturado, de estrutura tridimensional atribuída ao PAMAM, com NPsPt com seus sítios eletrocatalíticos ativos por tratamento eletroquímico, motivou a aplicação do eletrodo ITO/PAMAM-Pt em estudos da eletroquímica do citocromo C.

\subsection{Citocromo C}

O citocromo C, cuja estrutura é apresentada na Figura 4, com um grupo prostético heme, é uma proteína redox, transportadora de elétrons, pelo processo de transferência direta de elétrons na redução do $\mathrm{Fe}^{3+}$ a $\mathrm{Fe}^{2+}$, e está presente na cadeia respiratória mitocondrial, que é o sítio da fosforilação oxidativa. A fosforilação oxidativa é o estágio final do mecanismo produtor de energia nos organismos aeróbicos. Todas as etapas oxidativas na degradação dos carboidratos, gorduras e aminoácidos convergem para esse estágio final da respiração celular. O grupo prostético heme (Figura 4) consiste de quatro anéis de cinco átomos, contendo nitrogênio em uma estrutura cíclica chamada de porfirina. Os quatro átomos de $\mathrm{N}$ estão coordenados com um íon Fe central que pode estar na forma de $\mathrm{Fe}^{2+}$ ou $\mathrm{Fe}^{3+}$. No citocromo $\mathrm{C}$ o grupo heme está ligado à sua proteína, covalentemente, por meio de dois resíduos de cisteína $^{56}$. 
Figura 4 - Estrutura do citocromo C de coração bovino.

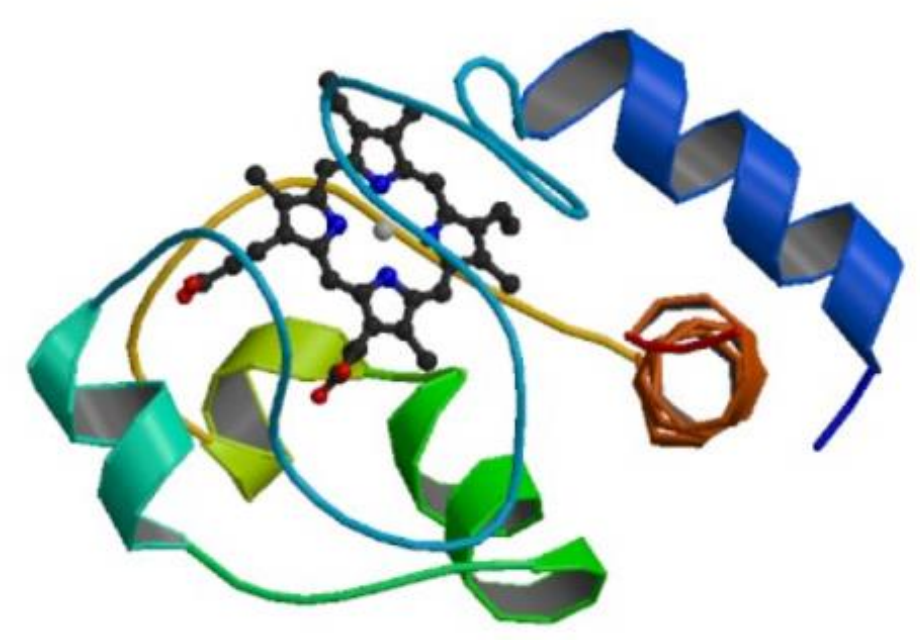

Fonte $^{57}$ : RESEARCH COLLABORATORY FOR STRUCTURAL BIOINFORMATICS. Protein Data Bank Home Page. 1998. Disponível em: 〈http://www.rcsb.org/pdb/explore/images.do?structureId=2B4Z〉. Acesso em: 05 jul. 2013.

O objetivo do estudo de proteínas redox em eletrodos é elucidar os mecanismos de transferência de elétrons das proteínas que estão envolvidas em processos redox biológicos, como a fotossíntese e a cadeia respiratória, e a exploração de enzimas redox para o desenvolvimento de biossensores eletroquímicos, células de biocombustíveis e aplicações em nanotecnologia ${ }^{58}$. A transferência eletrônica direta reversível, sem o uso de mediadores, entre proteína e eletrodo, sob controle difusional, foi descrita em 1977, por Yeh e Kuwana ${ }^{59}$, para o citocromo C em solução com um eletrodo de ITO, e por Eddowes e Hill ${ }^{60}$, para o citocromo C em solução contendo 4,4'-bipiridil com um eletrodo de ouro.

A seguir apresentamos a revisão de alguns trabalhos que estudam a eletroquímica do citocromo C imobilizado sobre diferentes eletrodos, onde as constantes padrão de transferência de carga $\left(k_{s}\right)$ entre o citocromo $\mathrm{C}$ e os eletrodos foram calculadas pelo método de Laviron ${ }^{61}$.

Zhang e Zheng ${ }^{62}$ estudaram a eletroquímica do citocromo $\mathrm{C}$ e sua eletrocatálise para a redução de $\mathrm{H}_{2} \mathrm{O}_{2}$ com um eletrodo de carbono vítreo modificado com um filme compósito de líquidos iônicos à temperatura ambiente (RTIL), quitosana e MWCNTs. O eletrodo GC/MWCNTs-RTIL-CytC-Chi apresentou uma constante de transferência de carga $\left(k_{s}\right)$ de $4,8 \pm 0,1 \mathrm{~s}^{-1}$ em TF 0,1 mol L-1, pH 7,0. 
Chen et al. ${ }^{63}$ prepararam um biossensor para nitrito baseado na modificação de um eletrodo de carbono vítreo com um nanocompósito de MWCNTs, PAMAM e quitosana. O nanocompósito é uma boa plataforma para a imobilização do CytC e o eletrodo GC/Chit-PAMAM-MWCNT/GA/CytC apresentou uma constante de transferência de carga $\left(k_{s}\right)$ de $2,4 \mathrm{~s}^{-1}$ em TF $0,1 \mathrm{~mol} \mathrm{~L}^{-1}, \mathrm{pH} 7,0$.

Liang et al. ${ }^{64}$ estudaram a oxidação de nitrito e a redução de $\mathrm{H}_{2} \mathrm{O}_{2}$ com um eletrodo ITO/NPsPt/CytC. Ions platina foram implantados no ITO para formar um filme de NPsPt. Sobre o eletrodo ITO/NPsPt aplicou-se, por casting, $5 \mu \mathrm{L}$ de uma solução de CytC $5 \mathrm{mmol} \mathrm{L}{ }^{-1}$. O eletrodo ITO/NPsPt/CytC apresentou uma constante de transferência de carga $\left(k_{s}\right)$ de $3,52 \mathrm{~s}^{-1}$ em TF $0,1 \mathrm{~mol} \mathrm{~L}^{-1}$, pH 6,0.

Song et al. ${ }^{65}$ desenvolveram um biossensor para $\mathrm{H}_{2} \mathrm{O}_{2}$ incorporando o CytC em um filme fino de RTIL contendo nanocompósitos de PDDA, grafeno (Gp) e NPsAu sobre um eletrodo de $\mathrm{Au}$ modificado com uma mistura de ácido 11-mercaptoundecanóico (MUA) e 6-marcapto-1-hexanol (MCH). O eletrodo Au/MCH-MUA/NPsAu-Gp-PDDA-RTIL/CytC apresentou uma constante de transferência de carga $\left(k_{s}\right)$ de $3,14 \mathrm{~s}^{-1}$ em TF $0,2 \mathrm{~mol} \mathrm{~L}^{-1}$, $\mathrm{pH} 7,0$.

Xiang et al. ${ }^{66}$ prepararam um biossensor para glicose baseado na eletroquímica direta do citocromo $\mathrm{C}$ em um eletrodo de carbono vítreo modificado com um compósito de NPsAu e nanoesferas de polianilina (PANS). O eletrodo GC/PANS/NPsAu/CytC apresentou uma constante de transferência de carga $\left(k_{s}\right)$ de $2,362 \mathrm{~s}^{-1}$ em TF $0,1 \mathrm{~mol} \mathrm{~L}^{-1}, \mathrm{pH} 7,0$.

Os trabalhos mostram que a imobilização do citocromo C sobre diferentes superfícies, que proporcionam a manutenção da sua atividade, além de permitir o estudo dos mecanismos básicos de transferência de elétrons entre citocromo $\mathrm{C}$ e eletrodos, também permite a obtenção de sensores para glicose, redução de $\mathrm{H}_{2} \mathrm{O}_{2}$ e oxidação de nitrito.

Assim, o objetivo geral deste trabalho é demonstrar a ativação do PAMAM-Pt por tratamento eletroquímico e estudar a eletroquímica do citocromo $\mathrm{C}$ imobilizado em um eletrodo de ITO/PAMAM-Pt ativado eletroquimicamente. 


\section{OBJETIVOS}

Os principais objetivos desta tese são:

1. Síntese e caracterização das NPsPt em capsuladas em dendrímero: sintetizar as NPsPt em meio aquoso, de acordo com método estabelecido na literatura, utilizando o dendrímero PAMAM G4.0- $\mathrm{NH}_{2}$ como template e estabilizador;

2. Preparação e caracterização do eletrodo ITO/PAMAM-Pt: preparar e caracterizar o eletrodo de ITO modificado com filmes nanoestruturados de PAMAM-Pt alternados com camadas do poliânion PVS;

3. Ativação dos eletrodos ITO/(PAMAM-Pt $)_{n}$ por meio de tratamento eletroquímico: Mostrar a influencia do tratamento eletroquímico na resposta eletroquímica dos eletrodos ITO/(PAMAM-Pt) $)_{n}$ para a reação de oxidação do hidrogênio adsorvido;

4. Imobilização e estudo da eletroquímica do citocromo C: imobilizar o citocromo $\mathrm{C}$ sobre o eletrodo ITO/PAMAM-Pt ativado e avaliar a atividade catalítica deste eletrodo para a reação de oxidação e redução do citocromo C. 
3 PARTE EXPERIMENTAL

\subsection{Materiais e Reagentes}

Tabela 2 - Procedência e características dos materiais e reagentes utilizados

\begin{tabular}{|c|c|c|}
\hline Materiais e reagentes & Procedência & Características \\
\hline $\begin{array}{c}\text { Acetona } \\
\left(\left(\mathrm{CH}_{3}\right)_{2} \mathrm{CO}\right)\end{array}$ & Synth & $58,08 \mathrm{~g} \mathrm{~mol}^{-1}$ \\
\hline $\begin{array}{l}\text { Ácido clorídrico } \\
(\mathrm{HCl})\end{array}$ & J. T. Baker & $\begin{array}{l}36,46 \mathrm{~g} \mathrm{~mol}^{-1} \\
\text { Teor } 37 \% \\
\text { d } 1,18 \mathrm{~g} \mathrm{~mL}\end{array}$ \\
\hline $\begin{array}{l}\text { Ácido cloroplatínico hexahidratado } \\
\qquad\left(\mathrm{H}_{2} \mathrm{PtCl}_{6} \cdot 6 \mathrm{H}_{2} \mathrm{O}\right)\end{array}$ & $\begin{array}{l}\text { Sigma-Aldrich } \\
\text { (Cod. 206083) }\end{array}$ & $517,9 \mathrm{~g} \mathrm{~mol}^{-1}$ \\
\hline $\begin{array}{l}\text { Ácido nítrico } \\
\left(\mathrm{HNO}_{3}\right)\end{array}$ & Synth & $\begin{array}{c}63,01 \mathrm{~g} \mathrm{~mol}^{-1} \\
\text { Teor } 65,0 \% \\
\text { d } 1,42 \mathrm{~g} \mathrm{~mL}^{-1}\end{array}$ \\
\hline $\begin{array}{l}\text { Ácido sulfúrico } \\
\qquad\left(\mathrm{H}_{2} \mathrm{SO}_{4}\right)\end{array}$ & Synth & $\begin{array}{l}98,08 \mathrm{~g} \mathrm{~mol}^{-1} \\
\text { Teor } 97,0 \% \\
\text { d } 1,840 \mathrm{~g} \mathrm{~mL}^{-1} \\
\end{array}$ \\
\hline $\begin{array}{l}\text { Álcool etílico } \\
\left(\mathrm{CH}_{3} \mathrm{CH}_{2} \mathrm{OH}\right)\end{array}$ & J.T. Baker & $46,06 \mathrm{~g} \mathrm{~mol}^{-1}$ \\
\hline $\begin{array}{c}\text { Borohidreto de sódio } \\
\qquad\left(\mathrm{NaBH}_{4}\right)\end{array}$ & $\begin{array}{c}\text { Aldrich } \\
(\text { Cod. 480886) }\end{array}$ & $37,83 \mathrm{~g} \mathrm{~mol}^{-1}$ \\
\hline $\begin{array}{c}\text { Citocromo C de coração bovino } \\
\text { (CytC) }\end{array}$ & $\begin{array}{l}\text { Sigma-Aldrich } \\
\text { (Cod. 30398) }\end{array}$ & $\begin{array}{l}\text { Solubilidade em } \mathrm{H}_{2} \mathrm{O}: \\
10 \mathrm{~g} \mathrm{~L}^{-1}\end{array}$ \\
\hline $\begin{array}{l}\text { Cloreto de hexaaminrutênio (II) } \\
\qquad\left[\mathrm{Ru}\left(\mathrm{NH}_{3}\right)_{6}\right] \mathrm{Cl}_{2}\end{array}$ & $\begin{array}{l}\text { Sigma-Aldrich } \\
(\text { Cod. 303690) }\end{array}$ & $273,15 \mathrm{~g} \mathrm{~mol}^{-1}$ \\
\hline $\begin{array}{l}\text { Cloreto de hexaaminrutênio (III) } \\
{\left[\mathrm{Ru}\left(\mathrm{NH}_{3}\right)_{6}\right] \mathrm{Cl}_{3}}\end{array}$ & $\begin{array}{l}\text { Sigma-Aldrich } \\
(\text { Cod. 262005) } \\
\end{array}$ & $309,61 \mathrm{~g} \mathrm{~mol}^{-1}$ \\
\hline $\begin{array}{l}\text { Cloreto de potássio } \\
(\mathrm{KCl})\end{array}$ & Vetec & $74,56 \mathrm{~g} \mathrm{~mol}^{-1}$ \\
\hline $\begin{array}{l}\text { Dendrímero Poli(amidoamino) geração } 4.0 \\
\text { com grupos amino terminais } \\
\left.\text { (PAMAM G4.0-NH } \mathrm{NH}_{2}\right)\end{array}$ & $\begin{array}{l}\text { Sigma-Aldrich } \\
(\text { Cod. 412449) }\end{array}$ & $\begin{array}{c}14.214,17 \mathrm{~g} \mathrm{~mol}^{-1} \\
\text { Concentração } 10,02 \% \\
\text { (em metanol) } \\
\text { d } 0,813 \mathrm{~g} \mathrm{~mL}^{-1}\end{array}$ \\
\hline $\begin{array}{l}\text { Fosfato de potássio dibásico trihidratado } \\
\qquad\left(\mathrm{K}_{2} \mathrm{HPO}_{4} \cdot 3 \mathrm{H}_{2} \mathrm{O}\right)\end{array}$ & $\begin{array}{l}\text { Sigma-Aldrich } \\
\text { (Cod. P9666) }\end{array}$ & $228,22 \mathrm{~g} \mathrm{~mol}^{-1}$ \\
\hline $\begin{array}{l}\text { Fosfato de potássio monobásico } \\
\left(\mathrm{KH}_{2} \mathrm{PO}_{4}\right)\end{array}$ & $\begin{array}{l}\text { Sigma-Aldrich } \\
(\text { Cod. P9791) }\end{array}$ & $136,09 \mathrm{~g} \mathrm{~mol}^{-1}$ \\
\hline $\begin{array}{l}\text { Hexacianoferrato de potássio (II) } \\
\mathrm{K}_{4}\left[\mathrm{Fe}(\mathrm{CN})_{6}\right] \cdot 3 \mathrm{H}_{2} \mathrm{O}\end{array}$ & Mallinckrodt & $422,39 \mathrm{~g} \mathrm{~mol}^{-1}$ \\
\hline $\begin{array}{l}\text { Hexacianoferrato de potássio (III) } \\
\qquad\left(\mathrm{K}_{3}\left[\mathrm{Fe}(\mathrm{CN})_{6}\right]\right)\end{array}$ & J.T. Baker & $329,26 \mathrm{~g} \mathrm{~mol}^{-1}$ \\
\hline $\begin{array}{l}\text { Hidróxido de amônio } \\
\qquad\left(\mathrm{NH}_{4} \mathrm{OH}\right)\end{array}$ & Synth & $35,05 \mathrm{~g} \mathrm{~mol}^{-1}$ \\
\hline $\begin{array}{l}\text { Hidróxido de potássio } \\
\qquad(\mathrm{KOH})\end{array}$ & J.T. Baker & $56,11 \mathrm{~g} \mathrm{~mol}^{-1}$ \\
\hline $\begin{array}{l}\text { L-Cisteína } \\
\text { (Cys) }\end{array}$ & $\begin{array}{l}\text { Sigma-Aldrich } \\
\text { (Cod. C7352) }\end{array}$ & $\begin{array}{l}\text { Solubilidade em } \mathrm{H}_{2} \mathrm{O}: \\
\qquad 25 \mathrm{~g} \mathrm{~L}^{-1}\end{array}$ \\
\hline $\begin{array}{l}\text { Metanol } \\
\left(\mathrm{CH}_{3} \mathrm{OH}\right) \\
\end{array}$ & J.T. Baker & $32,04 \mathrm{~g} \mathrm{~mol}^{-1}$ \\
\hline $\begin{array}{l}\text { Nitrato de prata } \\
\quad(\text { AgNO3) }\end{array}$ & Merk & $169,87 \mathrm{~g} \mathrm{~mol}^{-1}$ \\
\hline
\end{tabular}




\begin{tabular}{|c|c|c|}
\hline Materiais e reagentes & Procedência & Características \\
\hline $\begin{array}{l}\text { Nitrogênio } \\
\left(\mathrm{N}_{2}\right)\end{array}$ & Linde & Concentração 99,997\% \\
\hline $\begin{array}{l}\text { Peróxido de hidrogênio } \\
\qquad\left(\mathrm{H}_{2} \mathrm{O}_{2}\right)\end{array}$ & Synth & $\begin{array}{c}34,01 \mathrm{~g} \mathrm{~mol}^{-1} \\
\text { Teor } 29,0 \% \\
\text { d } 1,476 \mathrm{~g} \mathrm{~mL}^{-1} \\
\end{array}$ \\
\hline $\begin{array}{l}\text { Poli(ácidovinilsulfônico) - PVS } \\
\qquad\left(\mathrm{C}_{2} \mathrm{H}_{3} \mathrm{NaO}_{3} \mathrm{~S}\right)_{\mathrm{n}}\end{array}$ & $\begin{array}{l}\text { Sigma-Aldrich } \\
\text { (Cod. 278424) }\end{array}$ & $\begin{array}{c}\text { 130,02 } \mathrm{g} \mathrm{momomol}^{-1} \\
\text { Concentração } 25,0 \% \\
\text { (em água) } \\
\text { d } 1,267 \mathrm{~g} \mathrm{~mL}^{-1}\end{array}$ \\
\hline Quartzo & $\begin{array}{c}\text { Delta Technologies } \\
\text { (QS-0310) }\end{array}$ & $\begin{array}{c}\text { Dimensões } \\
25 \times 75 \times 1 \mathrm{~mm}\end{array}$ \\
\hline $\begin{array}{c}\text { Vidro recoberto com óxido } \\
\text { de estanho e índio } \\
\text { (ITO) }\end{array}$ & $\begin{array}{l}\text { Delta Technologies } \\
(\text { CG-50IN-S115) }\end{array}$ & $\begin{array}{c}\text { Dimensões } \\
25 \times 75 \times 1,1 \mathrm{~mm} \\
\text { Resistência } 8-12 \Omega\end{array}$ \\
\hline
\end{tabular}

\subsection{Soluções}

Todas as soluções foram preparadas com água ultrapura $(18,2 \mathrm{M} \Omega \mathrm{cm})$ de um sistema de purificação Nanopure Infinity, Barnstead. Para a preparação da solução aquosa de PAMAM $50 \mu \mathrm{mol} \mathrm{L}{ }^{-1}$, o metanol da solução comercial deve ser evaporado em dessecador à vácuo por aproximadamente $30 \mathrm{~min}$ antes da diluição em água deionizada. O polieletrólito PVS foi adsorvido de uma solução aquosa $2,6 \mathrm{~g} \mathrm{~L}^{-1}$ em solução aquosa de $\mathrm{KCl} 0,1 \mathrm{~mol} \mathrm{~L}^{-1}$. O

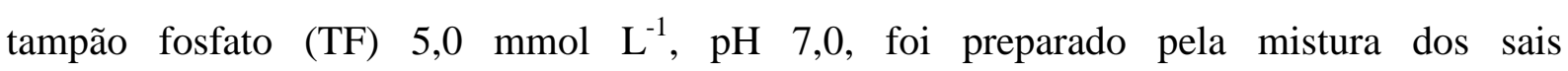
hidrogenofosfato de potássio e dihidrogenofosfato de potássio. As soluções de cisteína 20,0 mmol L ${ }^{-1}$, pH 6,35, e citocromo C $1 \mathrm{~g} \mathrm{~L}^{-1}$, foram preparadas em TF 5 mmol L ${ }^{-1}$, $\mathrm{pH}$ 7,0.

\subsection{Limpeza dos materiais}

Toda a vidraria e o material de politetrafluoretileno (PTFE) foram lavados com água e detergente doméstico, enxaguados exaustivamente, fervidos e armazenados em solução aquosa de ácido nítrico $10 \%$ por no mínimo 30 minutos. Antes de serem utilizados eram novamente enxaguados com água ultrapura.

As placas de ITO e quartzo, de 2,5 $\mathrm{mm}$ x $5,0 \mathrm{~mm}$, foram limpas pelo método $\mathrm{RCA}^{67}$ adaptado e tratadas de acordo com o método de $\mathrm{Xu}$ et $\mathrm{al}^{68}$. Inicialmente as placas foram lavadas com detergente doméstico concentrado, enxaguadas, transferidas para um béquer contendo solução oxidante básica $\mathrm{H}_{2} \mathrm{O}-\mathrm{NH}_{4} \mathrm{OH}-\mathrm{H}_{2} \mathrm{O}_{2}(5: 1: 1)(\mathrm{v} / \mathrm{v})$ e aquecidas a $80{ }^{\circ} \mathrm{C}$ por 10 minutos. No processo de resfriamento, ao atingir $60{ }^{\circ} \mathrm{C}$, as placas foram enxaguadas exaustivamente, transferidas para um béquer contendo água ultrapura e sonicadas por 5 
minutos (2 vezes). As placas limpas foram colocadas em um béquer contendo acetona, sonicadas por 10 minutos e enxaguadas. Em seguida foram transferidas para um béquer contendo solução de $\mathrm{KOH} 10 \%$ em etanol-água (7:3) (v/v), sonicadas por 10 minutos e enxaguadas. Por fim, foram colocadas em um béquer contendo água ultrapura, sonicadas por 10 minutos, secas sob $\mathrm{N}_{2}$ e armazenadas em metanol.

\subsection{Instrumentação utilizada}

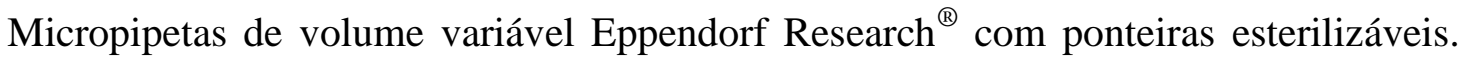
Para as pesagens utilizou-se uma balança analítica Mettler Toledo da Micronal S/A, modelo $\mathrm{AL}$ 204. As soluções tiveram seus valores de $\mathrm{pH}$ ajustados em um $\mathrm{pH}$-metro Qualxtron, modelo 8010. O equipamento de ultrassom utilizado foi um MaxiClean, modelo 1450, da Unique, com frequência de $25 \mathrm{kHz}$.

As imagens de TEM, HRTEM e análise por EDX das NPsPt encapsuladas em PAMAM foram obtidas em um microscópio eletrônico analítico de transmissão FEI TECNAI G²F20 HRTEM do Laboratório de Caracterização Estrutural do Departamento de Engenharia de Materiais da Universidade Federal de São Carlos (LCE-DEMa-UFSCar).

Nas análises de UV-Vis utilizou-se um espectrofotômetro UV-Vis Jasco V-630, com cubetas de quartzo de $1 \mathrm{~cm}$ de caminho ótico e placas de quartzo. As análises de FTIR foram feitas em um espectrofotômetro modelo IRaffnity-1, da Shimadzu Corporation, na Central de Análises Químicas Instrumentais, CAQI, do Instituto de Química de São Carlos, IQSC/USP.

As medidas de CV foram realizadas em um potenciostato/galvanostato PGSTAT 30 da Autolab $^{\circledR}$ acoplado a um microcomputador equipado com o software GPES 4.9. As medidas de EIS foram realizadas em um potenciostato/galvanostato PGSTAT 30 da Autolab ${ }^{\circledR}$ acoplado a um microcomputador equipado com o software FRA. Os espectros de plano complexo foram analisados com o software Electrochemistry-ZView2. Para todas as medidas eletroquímicas, realizadas em temperatura ambiente, utilizou-se uma célula convencional de vidro borossilicato, com compartimento único de $30 \mathrm{~mL}$, com tampa de PTFE contendo orifícios de encaixe para três eletrodos e para a entrada e saída de $\mathrm{N}_{2}$ para desaeração.

Como eletrodo de trabalho utilizou-se ITO, com área geométrica da 0,5 $\mathrm{cm}^{2} . \mathrm{Ag} / \mathrm{AgCl}$ $\left(\mathrm{KCl} 3 \mathrm{~mol} \mathrm{~L}^{-1}\right)$ foi utilizado como referência e uma placa de platina $\left(1,0 \mathrm{~cm}^{2}\right)$ como auxiliar. A área geométrica do eletrodo de trabalho foi isolada com esmalte à base de nitrocelulose e resina tosilamida/formaldeído. 


\subsection{Construção do eletrodo de referência $\mathrm{Ag} / \mathrm{AgCl}\left(\mathrm{KCl} \mathrm{3,0} \mathrm{mol} \mathrm{L}{ }^{-1}\right)$}

O eletrodo de referência é constituído por um tubo de vidro com um contato elétrico em uma das extremidades, feito por um pedaço de fio de platina e uma tampa de PTFE na outra extremidade, cuja função é vedar a saída da solução de $\mathrm{KCl}$ 3,0 $\mathrm{mol} \mathrm{L}^{-1}$ e fixar o fio de prata recoberto com o filme de $\mathrm{AgCl}$. Para obtenção do filme da $\mathrm{AgCl}$ utilizou-se um potenciostato/galvanostato PGSTAT 30 da Autolab $^{\circledR}$ acoplado a um microcomputador equipado com o software GPES 4.9 e uma célula convencional de vidro borossilicato, com compartimento único de $30 \mathrm{~mL}$, com tampa de PTFE contendo orifícios de encaixe para os eletrodos de trabalho (fio de prata de $1 \mathrm{~mm}$ de diâmetro), referência (ERH) e auxiliar (placa de platina de $1 \mathrm{~cm}^{2}$ ). Eletrólito $\mathrm{HCl} 0,3 \mathrm{~mol} \mathrm{~L}^{-1}$. Aplicou-se no fio de prata um potencial de $1 \mathrm{~V}$ por 5 minutos. O fio de prata recoberto com o filme de $\mathrm{AgCl}$ é colocado no tubo de vidro contendo $\mathrm{KCl}$ 3,0 mol L'${ }^{-1}$ e uma gota de solução aquosa de $\mathrm{AgNO}_{3} 0,1 \mathrm{~mol} \mathrm{~L}^{-1}$. O eletrodo de referência $\mathrm{Ag} / \mathrm{AgCl}\left(\mathrm{KCl} 3,0 \mathrm{~mol} \mathrm{~L}^{-1}\right)$, quando não está em uso, é armazenado, totalmente submerso, em solução de $\mathrm{KCl}$ 3,0 mol L ${ }^{-1}$.

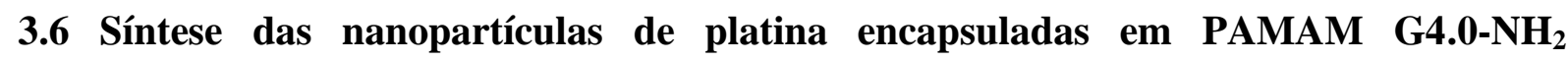 reduzidas com solução aquosa de $\mathrm{NaBH}_{4} 0,5 \mathrm{~mol} \mathrm{~L}^{-1}$}

As NPsPt foram sintetizadas de acordo com o método proposto por Ye e colaboradores $^{36}$, adaptado para as condições e reagentes disponíveis, utilizando-se solução aquosa de PAMAM 50,0 $\mu \mathrm{mol} \mathrm{L}{ }^{-1}$, pH 5,0, solução aquosa de $\mathrm{H}_{2} \mathrm{PtCl}_{6} 0,1$ mol L-1 e solução

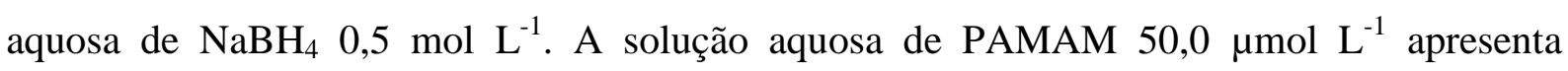
pH 10,0 e este é corrigido para pH 5,0 com solução aquosa de $\mathrm{HCl} \mathrm{0,1} \mathrm{mol} \mathrm{L}{ }^{-1}$. O NaBH granular reage lentamente com água e libera $4 \mathrm{~mol}$ de $\mathrm{H}_{2}$ por mol de $\mathrm{NaBH}_{4}$ em temperatura ambiente, de acordo com a equação 1. Esta reação é acelerada pelo aumento da temperatura ou pela acidificação da solução ${ }^{69}$. Nesta síntese a solução de $\mathrm{NaBH}_{4} 0,5 \mathrm{~mol} \mathrm{~L}^{-1}$ é adicionada à mistura $\mathrm{PAMAM} / \mathrm{H}_{2} \mathrm{PtCl}_{6}$, que após 3 dias de complexação apresenta $\mathrm{pH} 2,3$, e os íons $\mathrm{Pt}^{4+}$ são reduzidos pelo $\mathrm{H}_{2}$ nascente de acordo com a equação 2.

$$
\begin{gathered}
\mathrm{NaBH}_{4(\mathrm{aq})}+2 \mathrm{H}_{2} \mathrm{O}_{(\mathrm{l})} \longrightarrow \mathrm{NaBO}_{2(\mathrm{aq})}+4 \mathrm{H}_{2(\mathrm{~g})} \\
\mathrm{Pt}^{4+}{ }_{(\mathrm{aq})}+2 \mathrm{H}_{2(\mathrm{~g})} \longrightarrow \mathrm{Pt}_{(\mathrm{aq})}^{0}+4 \mathrm{H}^{+}{ }_{(\mathrm{aq})}
\end{gathered}
$$


Em um béquer contendo $5 \mathrm{~mL}$ da solução aquosa de PAMAM 50,0 $\mu \mathrm{mol} \mathrm{L}{ }^{-1}, \mathrm{pH}$ 5,0, sob agitação magnética, adicionou-se $100 \mu \mathrm{L}$ de solução aquosa de $\mathrm{H}_{2} \mathrm{PtCl}_{6} \quad 0,1 \mathrm{~mol} \mathrm{~L}^{-1}$ e manteve-se esta mistura em agitação por 72 horas. Após, ainda sob agitação magnética, adicionou-se, de uma só vez, $200 \mu \mathrm{L}$ da solução aquosa de $\mathrm{NaBH}_{4} 0,5 \mathrm{~mol} \mathrm{~L}^{-1}$ e ajustou-se o pH da solução para 8,0 (para evitar aglomeração das NPs), com solução aquosa de $\mathrm{HCl}$ $0,1 \mathrm{~mol} \mathrm{~L}{ }^{-1}$. Imediatamente após a redução ocorre a formação de um sobrenadante sobre a suspensão de NPsPt, o qual é separado da suspensão, e descartado, quando esta é transferida para tubos safe-lock de $2 \mathrm{~mL}$, para ser armazenada, no escuro, em temperatura ambiente e utilizada após 24 horas, sem purificação.

A reação de complexação PAMAM-Pt ${ }^{4+}$ foi acompanhada por espectroscopia de absorção na região do UV-Vis (UV-Vis) com soluções de concentração $50 \mu \mathrm{mol} \mathrm{L}^{-1}$. As NPsPt encapsuladas em PAMAM (PAMAM-Pt) foram caracterizadas por microscopia de transmissão (TEM), TEM de alta resolução (HRTEM) e o encapsulamento investigado por espectroscopia de infravermelho com transformada de Fourier (FTIR). Para o preparo das amostras, a suspensão teve todo o solvente aquoso evaporado em rotaevaporador e permaneceu em auto vácuo por $1 \mathrm{~h}$. As NPsPt foram ressuspensas em metanol. Para as medidas de TEM e HRTEM preparou-se uma suspensão muito diluída e aplicou-se uma gota em uma grade de cobre recoberta com carbono, aguardou-se que o solvente evaporasse e procedeu-se as medidas. Para as medidas de FTIR preparou-se uma suspensão $2 \%(\mathrm{~m} / \mathrm{v}$ de PAMAM-Pt/metanol) e uma solução $2 \%(\mathrm{~m} / \mathrm{v}$ de PAMAM/metanol). Os filmes foram preparados por cast em substrato de silício.

\subsection{Caracterização eletroquímica dos eletrodos ITO e ITO/PAMAM}

As medidas eletroquímicas foram realizadas em eletrólito $\mathrm{H}_{2} \mathrm{SO}_{4} 0,1 \mathrm{~mol} \mathrm{~L}^{-1}$, saturado com $\mathrm{N}_{2}$. Para isso, borbulhou-se o $\mathrm{N}_{2}$ no eletrólito por pelo menos 20 minutos e manteve-se a atmosfera de $\mathrm{N}_{2}$ na célula eletroquímica durante todas as medidas, feitas a temperatura ambiente de aproximadamente $25^{\circ} \mathrm{C}$.

Os eletrodos de ITO e ITO recoberto com uma camada do dendrímero PAMAM (ITO-PAMAM) foram caracterizados por CV. Para obtenção do eletrodo ITO/PAMAM, o

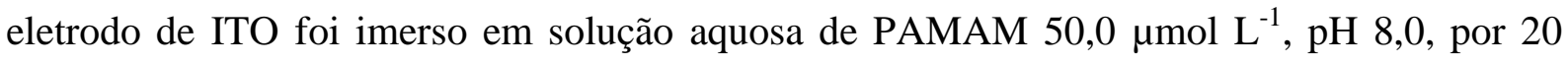
minutos, enxaguado em água ultrapura e seco em fluxo de $\mathrm{N}_{2}$. 


\subsubsection{Construção do eletrodo ITO/PAMAM-Pt}

O eletrodo de ITO foi imerso na suspensão do híbrido PAMAM-Pt por 20 minutos, enxaguado em água ultrapura, seco em fluxo de $\mathrm{N}_{2}$ e inserido na célula eletroquímica para a medida de CV. Após aquisição do voltamograma cíclico a $0,1 \mathrm{~V} \mathrm{~s}^{-1}$, entre os potenciais de $-0,2$ a $0,8 \mathrm{~V}$ (janela de potencial do eletrodo ITO em eletrólito $\mathrm{H}_{2} \mathrm{SO}_{4} 0,1$ mol L ${ }^{-1}$ ), o eletrodo ITO/PAMAM-Pt foi submetido a tratamento eletroquímico empregado para pré-condicionar eletrodos de platina. O tratamento eletroquímico utilizado neste trabalho, consiste de 100 ciclos a $1 \mathrm{~V} \mathrm{~s}^{-1}, 50$ ciclos a $0,5 \mathrm{~V} \mathrm{~s}^{-1}, 25$ ciclos a $0,25 \mathrm{~V} \mathrm{~s}^{-1}$ e 10 ciclos a $0,1 \mathrm{~V} \mathrm{~s}^{-1}$, e foi escolhido para este sistema por apresentar os melhores resultados em termos de estabilidade e reprodutibilidade dos resultados. Após o tratamento registrou-se o voltamograma do primeiro ciclo a $0,1 \mathrm{~V} \mathrm{~s}^{-1}$ entre os potenciais de $-0,2$ a $0,8 \mathrm{~V}$.

\subsubsection{Tempo de adsorção do híbrido PAMAM-Pt sobre o eletrodo de ITO}

Para determinar, por CV, o tempo que o eletrodo de ITO deve ficar imerso na suspensão de PAMAM-Pt para a formação de uma camada, um eletrodo de ITO foi imerso na suspensão de PAMAM-Pt por 30 segundos, enxaguado em água ultrapura, seco em fluxo de $\mathrm{N}_{2}$, inserido na célula eletroquímica e submetido a tratamento eletroquímico. Em seguida registrou-se o primeiro ciclo a $0,1 \mathrm{~V} \mathrm{~s}^{-1}$. O eletrodo foi então retirado da célula eletroquímica, enxaguado em água ultrapura, seco em fluxo de $\mathrm{N}_{2}$, e inserido na suspensão de PAMAM-Pt por mais 30 segundos, enxaguado em água ultrapura, seco em fluxo de $\mathrm{N}_{2}$, inserido na célula eletroquímica e antes da medida de CV foi submetido a tratamento eletroquímico. Procedeuse da mesma forma para os demais tempos de imersão: 1 minuto, 2 minutos, 3 minutos (2 vezes), 5 minutos (4 vezes) e 10 minutos, totalizando 40 minutos de imersão.

Para a determinação do tempo de adsorção do híbrido PAMAM-Pt sobre o substrato de quartzo, por UV-Vis, uma placa de quartzo foi imersa na suspensão de PAMAM-Pt por 30 segundos, enxaguada em água ultrapura, seca em fluxo de $\mathrm{N}_{2}$, e procedeu-se a obtenção do espectro de UV-Vis. Em seguida a placa de quartzo foi imersa na suspensão de PAMAM-Pt por mais 30 segundos, enxaguada em água ultrapura, seca em fluxo de $\mathrm{N}_{2}$, e procedeu-se a obtenção do espectro de UV-Vis. Procedeu-se da mesma forma para os demais tempos de imersão: 1 minuto, 2 minutos, 3 minutos (2 vezes), 5 minutos (4 vezes) e 10 minutos, totalizando 40 minutos de imersão. 


\subsubsection{Tempo de adsorção do poliânion PVS sobre o eletrodo ITO/PAMAM-Pt}

Para a formação de uma camada do poliânion PVS sobre o híbrido PAMAM-Pt adsorvido sobre o eletrodo de ITO, o eletrodo ITO/PAMAM-Pt foi imerso na solução de PVS 2,6 $\mathrm{g} \mathrm{L}^{-1}$ em solução aquosa de $\mathrm{KCl} 0,1 \mathrm{~mol} \mathrm{~L}^{-1}$ por 20 minutos, enxaguado em água ultrapura e seco sob fluxo de $\mathrm{N}_{2}$.

\subsubsection{Número de camadas do híbrido PAMAM-Pt sobre o eletrodo de ITO}

Para determinar, por CV, o número de camadas do híbrido PAMAM-Pt adsorvidas sobre o eletrodo, um eletrodo de ITO foi imerso na suspensão de PAMAM-Pt por 7 minutos (camada 1 - ITO/(PAMAM-Pt) $)_{1}$ ), enxaguado em água ultrapura, seco em fluxo de $\mathrm{N}_{2}$, inserido na célula eletroquímica e submetido a tratamento eletroquímico. Em seguida registrou-se o primeiro ciclo a $0,1 \mathrm{~V} \mathrm{~s}^{-1}$. O eletrodo foi então retirado da célula eletroquímica, enxaguado em água ultrapura, seco em fluxo de $\mathrm{N}_{2}$, inserido na solução do poliânion PVS 2,6

$\mathrm{g} \mathrm{L}^{-1}$ por 20 minutos, enxaguado em água ultrapura, seco em fluxo de $\mathrm{N}_{2}$ e imerso na suspensão de PAMAM-Pt por mais 7 minutos (camada 2 - ITO/PAMAM-Pt/PVS/PAMAMPt). Procedeu-se da mesma forma para as demais camadas 3, 4, 5, 6, 7, 8 e 9.

Para a determinação, por UV-Vis, do número de camadas do híbrido PAMAM-Pt adsorvidas sobre o substrato de quartzo, uma placa de quartzo foi imersa na suspensão de PAMAM-Pt por 7 minutos, enxaguada em água ultrapura, seca em fluxo de $\mathrm{N}_{2}$ e registrou-se o espectro de UV-Vis. Em seguida, a paca de quartzo/PAMAM-Pt foi inserida na solução do poliânion PVS 2,6 $\mathrm{g} \mathrm{L}^{-1}$ por 20 minutos, enxaguada em água ultrapura, seco em fluxo de $\mathrm{N}_{2} \mathrm{e}$ imersa na suspensão de PAMAM-Pt por mais 7 minutos e registrou-se o espectro de UV-Vis. Procedeu-se da mesma forma para as demais camadas 3, 4, 5, 6, 7, 8, 9 e 10.

A nomenclatura utilizada neste trabalho para o eletrodo de ITO modificado com múltiplas camadas do híbrido PAMAM-Pt, alternadas com camadas do poliânion PVS, será ITO/(PAMAM-Pt $)_{n}$, onde n é o número de camadas do híbrido PAMAM-Pt. 


\subsection{Influência do tratamento eletroquímico na resposta eletroquímica dos eletrodos ITO/(PAMAM-Pt $)_{n}$}

A influencia do tratamento eletroquímico na resposta eletroquímica dos eletrodos ITO/(PAMAM-Pt $)_{n}$, para a reação de oxidação do hidrogênio adsorvido, foi investigada por CV e EIS. Para isso, foram utilizados os seguintes eletrodos:

1. ITO/(PAMAM-Pt) $)_{1}$, sem tratamento eletroquímico (ST);

2. ITO/(PAMAM-Pt) $)_{1}$, com tratamento eletroquímico após confecção (CTCo);

3. ITO/(PAMAM-Pt) $)_{1}$, com tratamento eletroquímico entre as imersões (CTIm);

4. ITO/(PAMAM-Pt) $)_{2}$, com tratamento eletroquímico após confecção (CTCo);

5. ITO(PAMAM-Pt $)_{2}$, com tratamento eletroquímico entre camadas (CTCa);

6. ITO/(PAMAM-Pt) $)_{3}, \mathrm{CTCo}$;

7. ITO(PAMAM-Pt $)_{3}, \mathrm{CTCa}$;

8. ITO/(PAMAM-Pt $)_{4}$, CTCo;

9. ITO(PAMAM-Pt $)_{4}, \mathrm{CTCa}$.

Descrição do procedimento para obtenção dos eletrodos:

1. ITO/(PAMAM-Pt $)_{1, \mathbf{S T}}$ : um eletrodo de ITO foi imerso na suspensão do híbrido PAMAM-Pt por 7 minutos, enxaguado em água ultrapura, seco em fluxo de $\mathrm{N}_{2} \mathrm{e}$ inserido na célula eletroquímica para as medidas de CV e EIS;

2. ITO/(PAMAM-Pt $)_{1, \mathbf{C T C o}}$ : um eletrodo de ITO foi imerso na suspensão do híbrido PAMAM-Pt por 7 minutos, enxaguado em água ultrapura, seco em fluxo de $\mathrm{N}_{2}$, submetido a tratamento eletroquímico e inserido na célula eletroquímica para as medidas de CV e EIS;

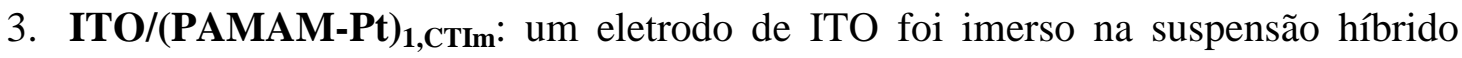
PAMAM-Pt por 30 segundos, enxaguado em água ultrapura, seco em fluxo de $\mathrm{N}_{2}$, inserido na célula eletroquímica e submetido a tratamento eletroquímico. Em seguida o eletrodo foi retirado da célula eletroquímica, enxaguado em água ultrapura, seco em fluxo de $\mathrm{N}_{2}$, inserido na suspensão do híbrido PAMAM-Pt por mais 30 segundos, enxaguado em água ultrapura, seco em fluxo de $\mathrm{N}_{2}$, inserido na célula eletroquímica e submetido a tratamento eletroquímico. Procedeu-se da mesma forma para os demais tempos de imersão, 1, 2 e 3 minutos, totalizando 7 minutos de imersão. 


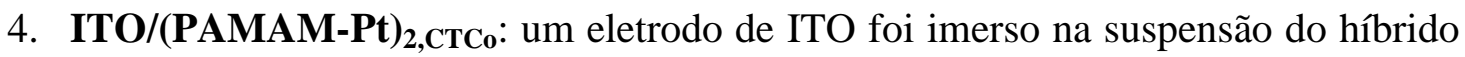
PAMAM-Pt por 7 minutos, enxaguado em água ultrapura, seco em fluxo de $\mathrm{N}_{2}$, inserido na solução do poliânion PVS $2,6 \mathrm{~g} \mathrm{~L}^{-1}$ por 20 minutos, enxaguado em água ultrapura, seco em fluxo de $\mathrm{N}_{2}$, imerso na suspensão do híbrido PAMAM-Pt por mais 7 minutos, enxaguado em água ultrapura, seco em fluxo de $\mathrm{N}_{2}$, inserido na célula eletroquímica e submetido a tratamento eletroquímico. O procedimento é

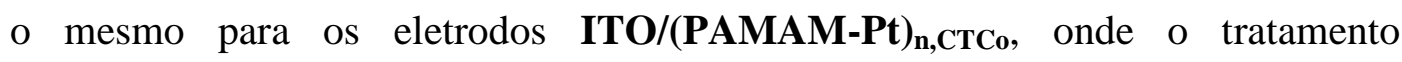
eletroquímico é realizado após o eletrodo estar pronto.

5. ITO/(PAMAM-Pt) 2,CTCa: um eletrodo de ITO foi imerso na suspensão do híbrido PAMAM-Pt por 7 minutos, enxaguado em água ultrapura, seco em fluxo de $\mathrm{N}_{2}$, inserido na célula eletroquímica e submetido a tratamento eletroquímico. Em seguida o eletrodo foi retirado da célula eletroquímica, enxaguado em água ultrapura, seco em fluxo de $\mathrm{N}_{2}$, inserido na solução do poliânion PVS $2,6 \mathrm{~g} \mathrm{~L}^{-1}$ por 20 minutos, enxaguado em água ultrapura, seco em fluxo de $\mathrm{N}_{2}$ e imerso na suspensão do híbrido PAMAM-Pt por mais 7 minutos, enxaguado em água ultrapura, seco em fluxo de $\mathrm{N}_{2}$, inserido na célula eletroquímica e submetido a tratamento eletroquímico. O procedimento é o mesmo para os eletrodos ITO/(PAMAM-Pt) $)_{n, C T C a}$, onde o tratamento eletroquímico é realizado após a deposição de cada camada do híbrido PAMAM-Pt.

Nas medidas de EIS aplicou-se uma onda senoidal com $10 \mathrm{mV}$ de amplitude no potencial de pico de oxidação do hidrogênio adsorvido, observado nos experimentos de CV (nas mesmas condições) em uma faixa de frequência de $65 \mathrm{kHz}$ a $0,1 \mathrm{~Hz}$. Os valores de resistência à transferência de carga, $\mathrm{R}_{\mathrm{tc}}$, foram estimados pelo fitting dos espectros de impedância no plano complexo.

\subsection{Eletroquímica do citocromo $\mathrm{C}$}

As medidas eletroquímicas foram realizadas em eletrólito TF 5,0 mmol L ${ }^{-1}$, pH 7,0, saturado com $\mathrm{N}_{2}$. Para isso, borbulhou-se o $\mathrm{N}_{2}$ no eletrólito por pelo menos 20 minutos e manteve-se a atmosfera de $\mathrm{N}_{2}$ na célula eletroquímica durante todas as medidas, feitas a temperatura ambiente de aproximadamente $25^{\circ} \mathrm{C}$. 
Os eletrodos ITO, ITO/PAMAM e ITO/(PAMAM-Pt) $)_{1, \text { CTIm }}$ foram preparados como descrito anteriormente e caracterizados por CV e EIS. Para os estudos da eletroquímica do citocromo $\mathrm{C}$, foram preparados os seguintes eletrodos:

1. ITO/PAMAM/Cys/CytC: o eletrodo ITO/PAMAM foi imerso na solução de cisteína $20 \mathrm{mmol} \mathrm{L}^{-1}$ por 4 horas a $4{ }^{\circ} \mathrm{C}$, enxaguado em TF 5,0 mmol L ${ }^{-1}$, pH 7,0 e imerso na solução de citocromo $\mathrm{C} 1 \mathrm{~g} \mathrm{~L}^{-1}$ por no mínimo 12 horas a $4{ }^{\circ} \mathrm{C}$;

2. ITO/PAMAM-Pt/Cys/CytC: o eletrodo ITO/PAMAM-Pt foi imerso na solução de cisteína $20 \mathrm{mmol} \mathrm{L}^{-1}$, pH 6,35 por 4 horas a $4{ }^{\circ} \mathrm{C}$, enxaguado em TF 5,0 mmol L ${ }^{-1}$, pH 7,0 e imerso na solução de citocromo $\mathrm{C} 1 \mathrm{~g} \mathrm{~L}^{-1}$ por no mínimo 12 horas a $4{ }^{\circ} \mathrm{C}$.

Quando não estão em uso os eletrodos são armazenados em TF 5,0 mmol L-1, pH 7,0 a $4^{\circ} \mathrm{C}$.

Nas medidas de EIS aplicou-se uma onda senoidal com $10 \mathrm{mV}$ de amplitude em potencial de circuito aberto (OCP) em uma faixa de frequência de $100 \mathrm{kHz}$ a $0,1 \mathrm{~Hz}$. Os valores de resistência à transferência de carga, $\mathrm{R}_{\mathrm{tc}}$, para o processo redox das espécies $\left[\mathrm{Fe}(\mathrm{CN})_{6}\right]^{3-} /\left[\mathrm{Fe}(\mathrm{CN})_{6}\right]^{4-}$ foram estimados pelo fitting dos espectros de impedância no plano complexo. 


\section{RESULTADOS E DISCUSSÃO}

O capítulo 4 será divido em quatro partes. Na parte I abordaremos a síntese e caracterização das nanopartículas de platina encapsuladas em PAMAM. O método utilizado para a síntese foi o proposto por Ye e colaboradores ${ }^{36}$ e foi reproduzido o mais fielmente possível para a obtenção do híbrido PAMAM-Pt utilizado na modificação do eletrodo de ITO.

$\mathrm{Na}$ parte II abordaremos a caracterização eletroquímica dos eletrodos de ITO e ITO/PAMAM em eletrólito $\mathrm{H}_{2} \mathrm{SO}_{4} 0,1 \mathrm{~mol} \mathrm{~L}^{-1}$, que são experimentos de controle para comparação com os dados que serão obtidos com o eletrodo ITO/PAMAM-Pt, e abordaremos também a otimização dos parâmetros de confecção do eletrodo ITO/PAMAM-Pt.

$\mathrm{Na}$ parte III abordaremos a influencia do tratamento eletroquímico na resposta eletroquímica do eletrodo ITO/PAMAM-Pt. Durante a otimização dos parâmetros de confecção do eletrodo ITO/PAMAM-Pt observamos que o eletrodo de ITO com uma camada do híbrido PAMAM-Pt submetido a tratamento eletroquímico durante as etapas de confecção apresenta excelente desempenho sem a necessidade de várias camadas. Desta forma, nesta parte do trabalho, investigamos por CV e EIS a influencia do tratamento eletroquímico na resposta eletroquímica do eletrodo ITO/PAMAM-Pt e o transporte de carga para este eletrodo.

Finalmente, na parte IV abordaremos a aplicação do eletrodo ITO/PAMAM-Pt ativado no estudo da eletroquímica do citocromo $\mathrm{C}$ e apresentaremos a caracterização deste eletrodo em TF 5,0 mmol L ${ }^{-1}$, pH 7,0. 


\subsection{Síntese e caracterização das NPsPt encapsuladas em PAMAM reduzidas com $\mathrm{NaBH}_{4}$ $0,5 \mathrm{~mol} \mathrm{~L}^{-1}$}

No processo de síntese de NPsPt encapsuladas em PAMAM, o tempo de complexação do $\mathrm{PtCl}_{4}^{2-}$ ou $\mathrm{PtCl}_{6}^{2-}$ com os grupos funcionais internos do dendrímero, sob agitação magnética, é em torno de 76 horas e requer ajuste do $\mathrm{pH}$ da solução do dendrímero para pH 5,0 antes da adição da solução de íons, visto que as aminas exteriores (pKa 9,2) são mais básicas que as aminas interiores (pKa 6,3) e em pH 5,0 os íons complexam-se preferencialmente às aminas internas ${ }^{36}$.

Nesta síntese, utilizaram-se quantidades do dendrímero PAMAM e do ácido $\mathrm{H}_{2} \mathrm{PtCl}_{6}$ de forma que a razão íon/dendrímero foi de 40 íons $\mathrm{PtCl}_{6}^{2-}$ por molécula de PAMAM. Zhao e Crooks ${ }^{35}$ mostram em seu trabalho que uma molécula de PAMAM G4.0-OH pode complexar entre 12 e 60 íons $\mathrm{PtCl}_{4}^{2-}$. Para a redução com $\mathrm{NaBH}_{4}$ 0,5 mol L ${ }^{-1}$ utilizou-se um excesso de $\mathrm{NaBH}_{4}$ de 20 vezes. O tempo de complexação íon/dendrímero, sob agitação magnética, foi de 72 horas. A reação de complexação foi acompanhada por espectroscopia de UV-Vis e a Figura 5 mostra os espectros de absorbância da solução aquosa de PAMAM, da solução aquosa de $\mathrm{H}_{2} \mathrm{PtCl}_{6}$, da solução de síntese (PAMAM-40Pt ${ }^{4+}$ ) com 30 minutos, 10, 24, 50 e 72 horas de complexação e 30 minutos após a redução com $\mathrm{NaBH}_{4} 0,5 \mathrm{~mol} \mathrm{~L}{ }^{-1}$. 
Figura 5 - Espectros de UV-Vis da reação de encapsulamento dos íons $\mathrm{PtCl}_{6}^{2-}$ no dendrímero PAMAM.

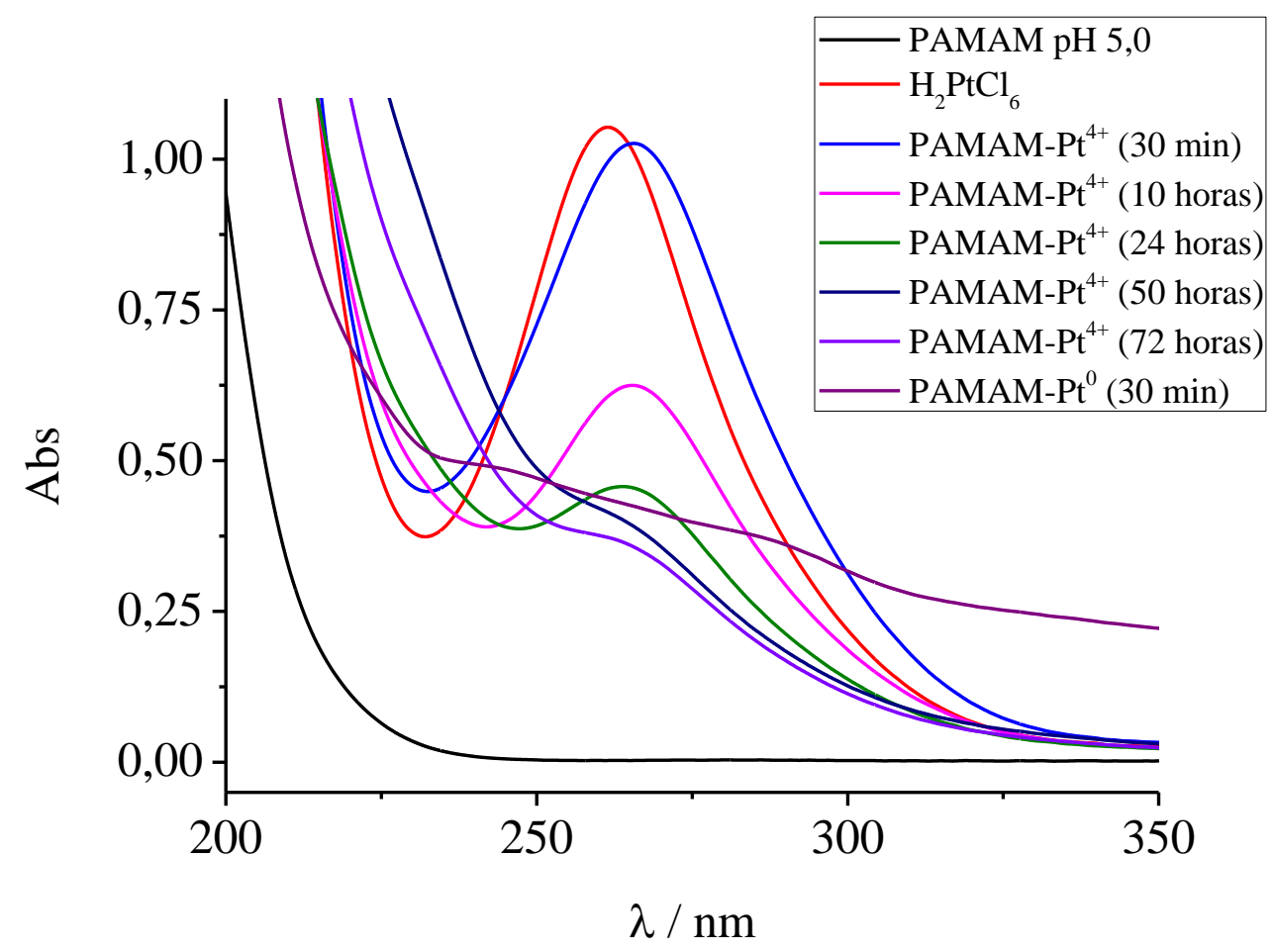

O pico de absorbância em $261 \mathrm{~nm}$ que corresponde ao $\mathrm{PtCl}_{6}^{2-}$ diminui e desloca ligeiramente para $266 \mathrm{~nm}$ quando a solução de $\mathrm{H}_{2} \mathrm{PtCl}_{6}$ é adicionada à solução de PAMAM. Este pico praticamente desaparece a partir de 50 horas de reação, o que sugere que há uma reação lenta de troca de ligantes entre o $\mathrm{PtCl}_{6}^{2-}$ e os grupos amina internos do PAMAM. Após a redução química dos íons encapsulados, com excesso de $\mathrm{NaBH}_{4}$, observa-se a ausência de picos de absorção e um deslocamento da linha de base em relação aos espectros de absorção do PAMAM-Pt ${ }^{4+}$.

Após a redução, a suspensão de NPsPt encapsuladas no dendrímero PAMAM teve seu $\mathrm{pH}$ ajustado para 8,0, pois, de acordo com estudos realizados por Ye e colaboradores ${ }^{36}$, em pHs acima de 8,0, há a aglomeração do dendrímero. A suspensão, como mostrada na Figura 6, foi utilizada sem purificação. 
Figura 6 - Fotografia da suspensão PAMAM-Pt.

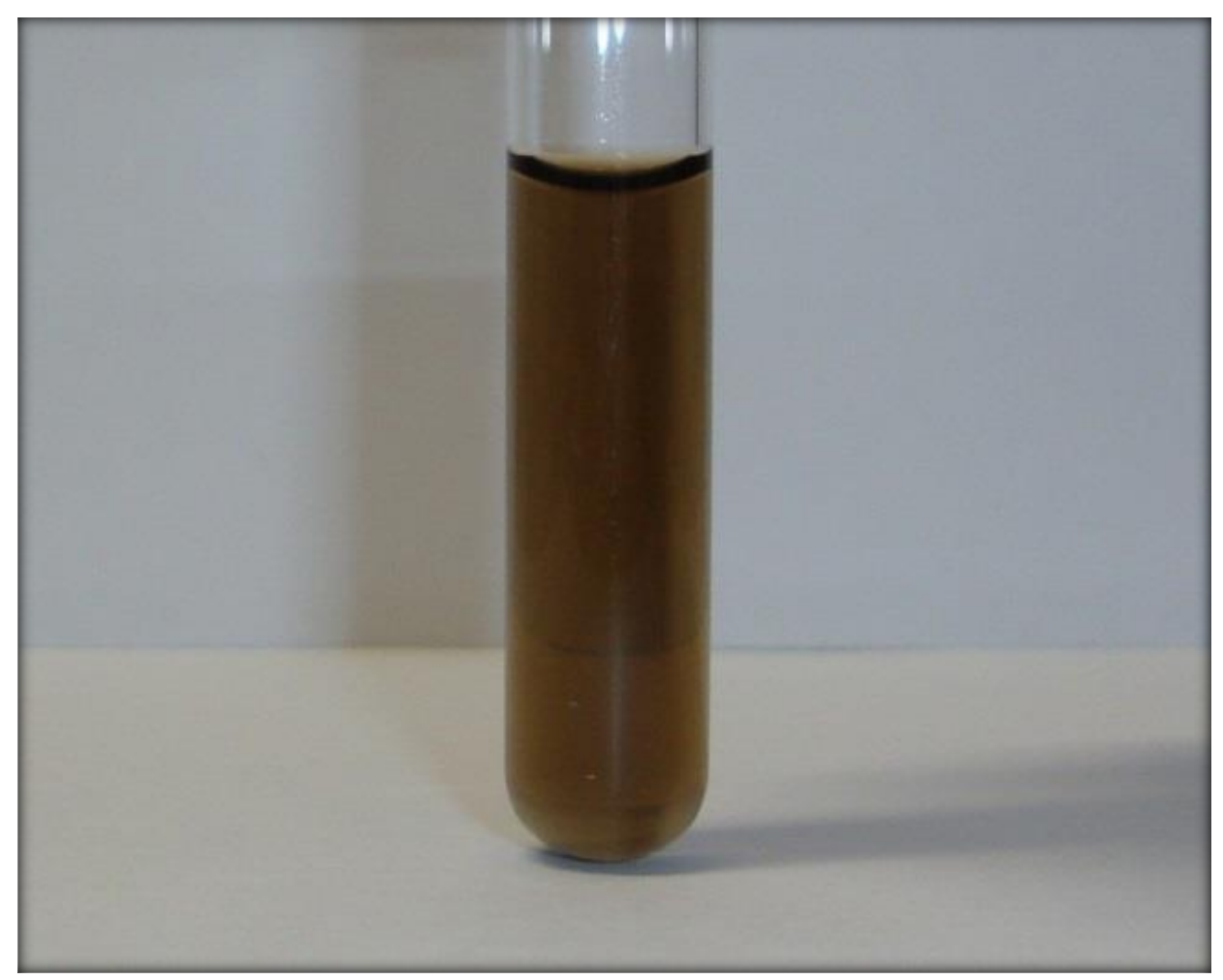

As imagens de TEM da suspensão PAMAM-Pt, em campo claro e escuro

(Figura 7) mostram as NPsPt encapsuladas no dendrímero PAMAM com distribuição homogênea e o espectro de EDX complementa as imagens indicando os picos de energia da Pt. Nas imagens de HRTEM, onde quase é possível visualizar os planos cristalográficos das NPsPt, observa-se NPsPt de morfologia esférica com diâmetro menor que $5 \mathrm{~nm}$. 
Figura 7 - Imagens de TEM em (A) campo claro e (B) campo escuro, com escala de $20 \mathrm{~nm}$, (C) EDX e (D) HRTEM, com escala de $5 \mathrm{~nm}$, das NPsPt (PAMAM-Pt) sem purificação.
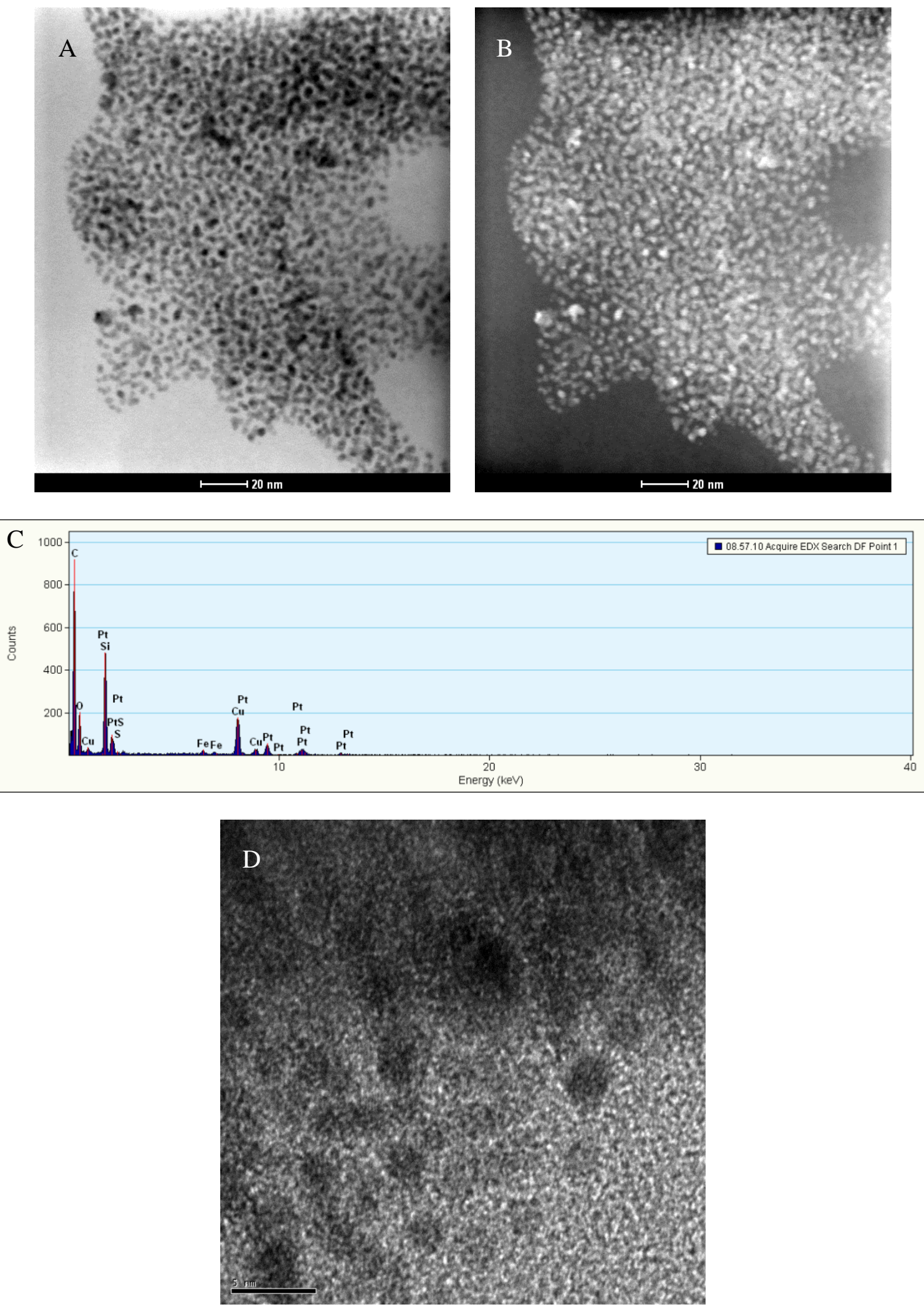
O encapsulamento das NPsPt pelas cavidades internas das moléculas de PAMAM fica evidenciado pelas alterações nos espectros vibracionais da molécula de PAMAM sem e com NPsPt. Os grupos funcionais da molécula de PAMAM podem ser observados na Figura 8.

Figura 8 - (A) Centro da molécula de PAMAM. (B) Ramificações da molécula de PAMAM.<smiles>[R]CCC(=O)NCCN(CCC(=O)NCCCCNCCN)CCC(=O)NCCC(=O)NCCN</smiles>

Os espectros de FTIR no modo transmissão da solução de PAMAM e da suspensão PAMAM-Pt são apresentados na Figura 9.

No espectro do dendrímero observa-se em $1647 \mathrm{~cm}^{-1}$ o pico referente ao grupamento amida I (estiramento $\mathrm{C}=\mathrm{O}$ do $-\mathrm{CH}_{2}-\mathrm{CO}-\mathrm{NH}-\mathrm{CH}_{2}$ ), em $1556 \mathrm{~cm}^{-1} \mathrm{o}$ pico referente à amida II (estiramento C-NH) e em 1460 e $1435 \mathrm{~cm}^{-1}$ os picos referentes ao estiramento $-\mathrm{CH}_{2} \mathrm{~N}$, que são característicos da molécula de PAMAM. No espectro da suspensão de PAMAM-Pt observa-se o deslocamento do pico da amida I para $1656 \mathrm{~cm}^{-1}$, o pico em $1556 \mathrm{~cm}^{-1}$ diminui e há grandes variações entre 1500 e $1000 \mathrm{~cm}^{-1}$, região que engloba estiramentos de amina C-N, os picos em 1460 e $1435 \mathrm{~cm}^{-1}$ não são mais observados e surge uma banda relativamente larga com split em 1400 e $1338 \mathrm{~cm}^{-1}$. Tais perturbações indicam a presença de nanopartículas e confirmam a interação PAMAM-Pt e o encapsulamento das NPsPt pelas cavidades internas do PAMAM ${ }^{39,70-72}$ 
Figura 9 - Espectros de FTIR da solução de PAMAM e da suspensão de PAMAM-Pt.
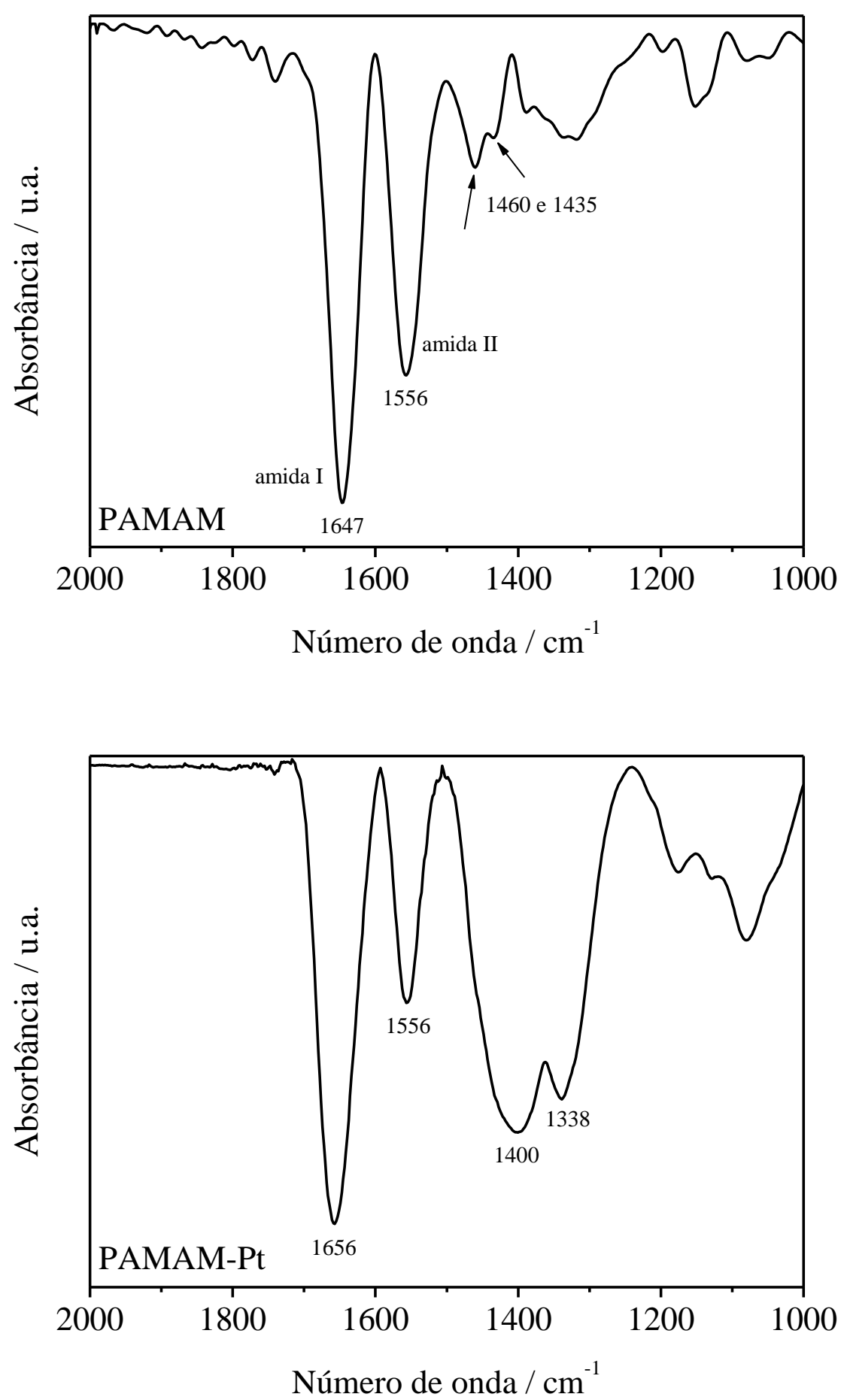

A suspensão de PAMAM-Pt permanece estável por até 60 dias, após este período há adsorção nas paredes do frasco de armazenamento, que ficam escurecidas, embora visualmente a suspensão continue homogênea. 


\subsection{Caracterização eletroquímica dos eletrodos ITO e ITO/PAMAM}

Antes da modificação do eletrodo de ITO com o híbrido PAMAM-Pt foram avaliados os perfis voltamétricos dos eletrodos de ITO e ITO/PAMAM em $\mathrm{H}_{2} \mathrm{SO}_{4}$ $0,1 \mathrm{~mol} \mathrm{~L}{ }^{-1}$. Na Figura 10 são apresentados os voltamogramas cíclicos para os eletrodos de ITO e ITO/PAMAM, onde podemos observar a ausência de processos de oxidação ou redução, até uma região de potenciais superiores a 1,0 V.

Figura 10 - Voltamogramas cíclicos (10 ciclos) para os eletrodos (A) ITO e (B) ITO-PAMAM em $\mathrm{H}_{2} \mathrm{SO}_{4} 0,1$ mol L ${ }^{-1}$, saturado com $\mathrm{N}_{2}$. Velocidade de varredura de $0,1 \mathrm{~V} \mathrm{~s}^{-1}$.
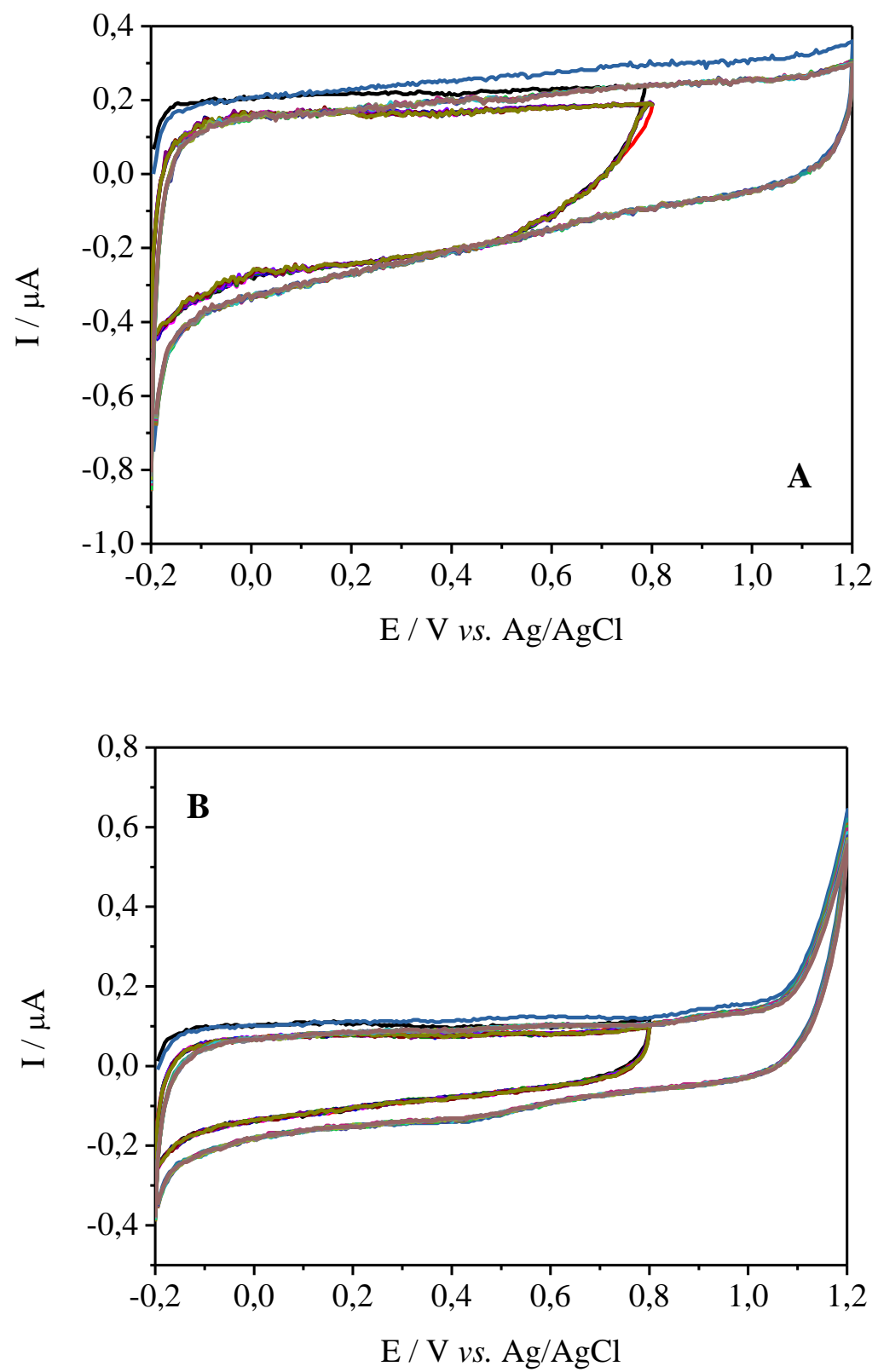
Na Figura 11 tem-se os voltamogramas cíclicos do eletrodo de ITO em solução de

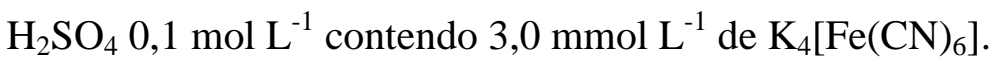

Figura 11 - Voltamogramas cíclicos do eletrodo de ITO nas velocidades de varredura de 10, 25, 50, 75, 100, 150, 200, 250, 300 e $400 \mathrm{mV} \mathrm{s}^{-1}$, em solução de $\mathrm{K}_{4}\left[\mathrm{Fe}(\mathrm{CN})_{6}\right] \quad 3,0 \mathrm{mmol} \mathrm{L}^{-1}$. Eletrólito $\mathrm{H}_{2} \mathrm{SO}_{4} \quad 0,1$ mol $\mathrm{L}^{-1}$, saturado com $\mathrm{N}_{2}$. Inserido: correntes de pico anódica e catódica em função da raiz quadrada da velocidade de varredura.

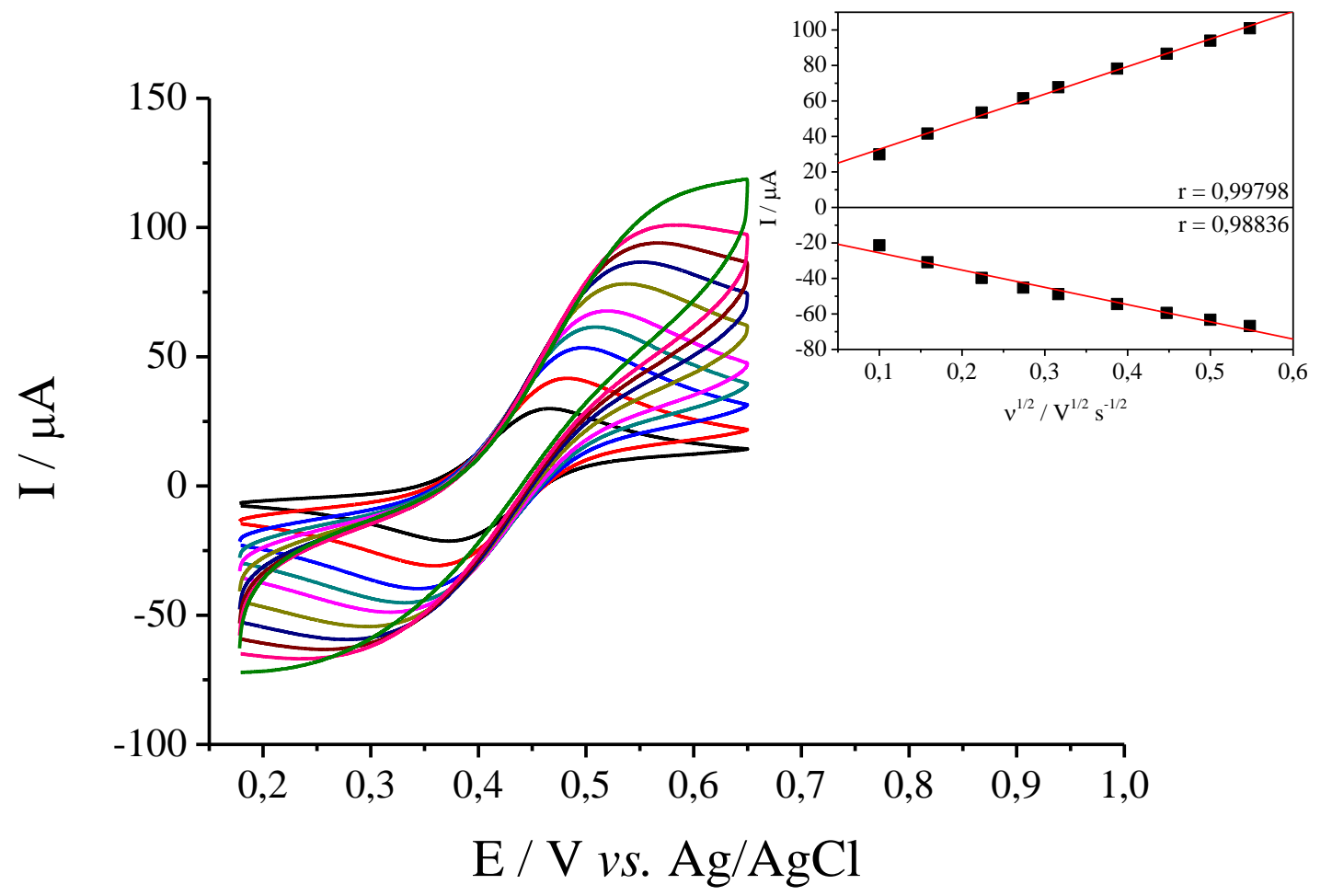

Os voltamogramas foram obtidos em diferentes velocidades de varredura e pode-se observar que as correntes de pico anódica e catódica aumentam de forma linear com a raiz quadrada da velocidade de varredura, indicando, como esperado para as espécies $\left[\mathrm{Fe}(\mathrm{CN})_{6}\right]^{3-} /\left[\mathrm{Fe}(\mathrm{CN})_{6}\right]^{4-}$, reações eletroquímicas limitadas por difusão. Observa-se também que com o aumento da velocidade de varredura, o processo redox sobre o eletrodo de ITO apresenta uma cinética cada vez mais dificultada, com o deslocamento de ambos os picos para valores maiores de sobrepotenciais.

Em velocidades de varredura acima de $0,3 \mathrm{~V} \mathrm{~s}^{-1}$ não é possível avaliar a linearidade do sistema para o processo eletroquímico do par redox $\left[\mathrm{Fe}(\mathrm{CN})_{6}\right]^{3-} /\left[\mathrm{Fe}(\mathrm{CN})_{6}\right]^{4-}$, pois este é inibido pelo processo de formação do hexacianoferrato de ferro $\mathrm{Fe}_{4}\left[\mathrm{Fe}(\mathrm{CN})_{6}\right]_{3}$ (Azul da Prússia), como mostrado na Figura 12, e relatado em alguns trabalhos na literatura, que apresentam o mecanismo de eletrodeposição do Azul da Prússia a partir de uma solução ácida contendo íons ferricianeto ${ }^{73,74}$. 
Figura 12 - Voltamogramas cíclicos do eletrodo de (-) ITO em $\mathrm{H}_{2} \mathrm{SO}_{4} 0,1 \mathrm{~mol} \mathrm{~L}^{-1}$, saturado com $\mathrm{N}_{2} \mathrm{e}(-)$ ITO em $\mathrm{H}_{2} \mathrm{SO}_{4} 0,1 \mathrm{~mol} \mathrm{~L}^{-1}$, saturado com $\mathrm{N}_{2}$, contendo $3,0 \mathrm{mmol} \mathrm{L}^{-1}$ de $\mathrm{K}_{4}\left[\mathrm{Fe}(\mathrm{CN})_{6}\right]$. Velocidade de varredura $0,1 \mathrm{~V} \mathrm{~s}^{-1}$.

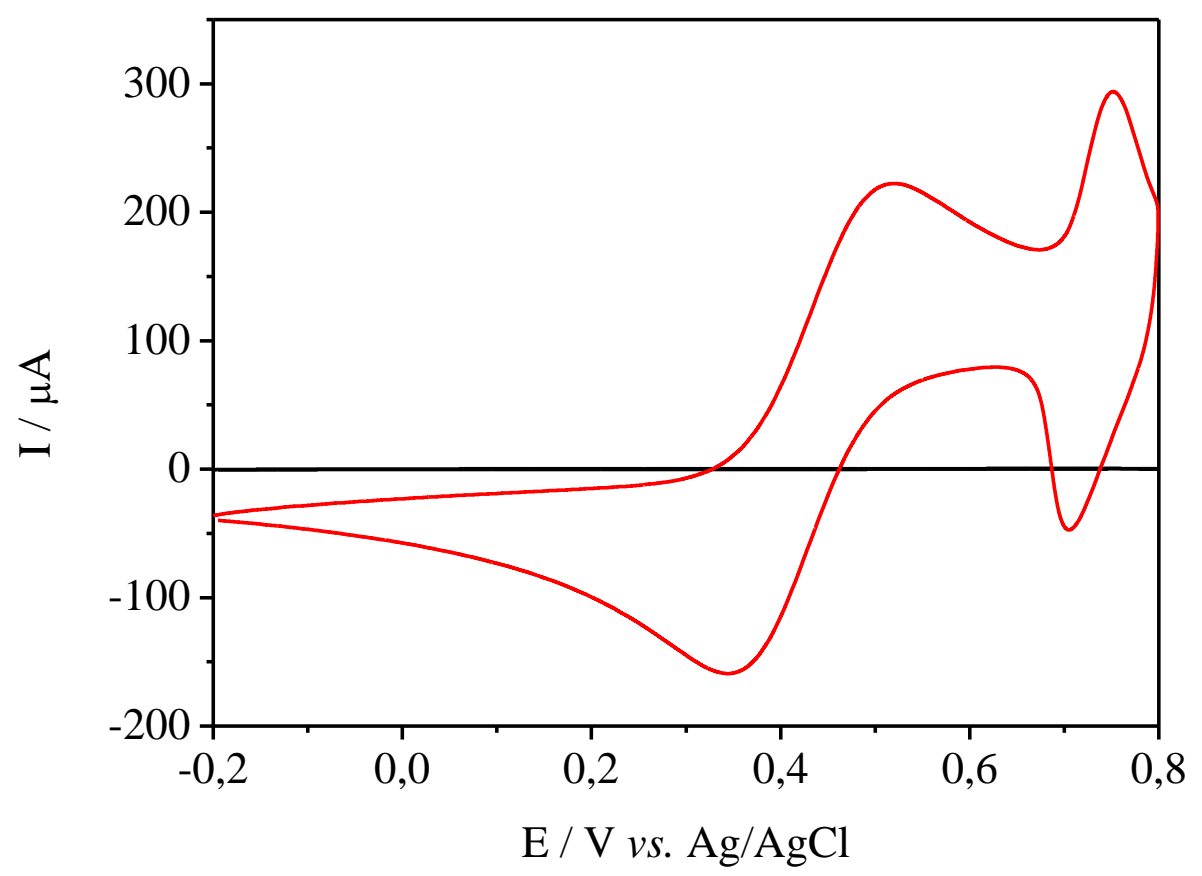

Como os experimentos de caracterização do eletrodo ITO/PAMAM-Pt foram feitas em meio ácido, para eliminar qualquer interferência pela eletrodeposição do Azul da Prússia, as caracterizações dos eletrodos foram então realizadas em $\mathrm{H}_{2} \mathrm{SO}_{4} 0,1 \mathrm{~mol} \mathrm{~L}{ }^{-1}$, contendo o par redox $\left[\mathrm{Ru}\left(\mathrm{NH}_{3}\right)_{6}\right]^{2+} /\left[\mathrm{Ru}\left(\mathrm{NH}_{3}\right)_{6}\right]^{3+}$. Os voltamogramas apresentados na Figura 13 , obtidos em diferentes velocidades de varredura, mostram, de forma análoga aos voltamogramas para o par redox $\left[\mathrm{Fe}(\mathrm{CN})_{6}\right]^{3-} /\left[\mathrm{Fe}(\mathrm{CN})_{6}\right]^{4-}$, que as correntes de pico anódica e catódica aumentam de forma linear com a raiz quadrada da velocidade de varredura, indicando, como também esperado para as espécies $\left[\mathrm{Ru}\left(\mathrm{NH}_{3}\right)_{6}\right]^{2+} /\left[\mathrm{Ru}\left(\mathrm{NH}_{3}\right)_{6}\right]^{3+}$, reações eletroquímicas limitadas por difusão. 
Figura 13 - Voltamogramas cíclicos dos eletrodos (A) ITO e (B) ITO/PAMAM nas velocidades de varredura de $10,25,50,75,100,150,200,250,300,400,500,600,700,800,900$ e $1000 \mathrm{mV} \mathrm{s}^{-1}$ em solução de $\left[\mathrm{Ru}\left(\mathrm{NH}_{3}\right)_{6}\right]^{2+} /\left[\mathrm{Ru}\left(\mathrm{NH}_{3}\right)_{6}\right]^{3+} 3,0 \mathrm{mmol} \mathrm{L}^{-1}$. Eletrólito $\mathrm{H}_{2} \mathrm{SO}_{4} 0,1 \mathrm{~mol} \mathrm{~L}^{-1}$, saturado com $\mathrm{N}_{2}$. Inseridos: correntes de pico anódica e catódica em função da raiz quadrada da velocidade de varredura.
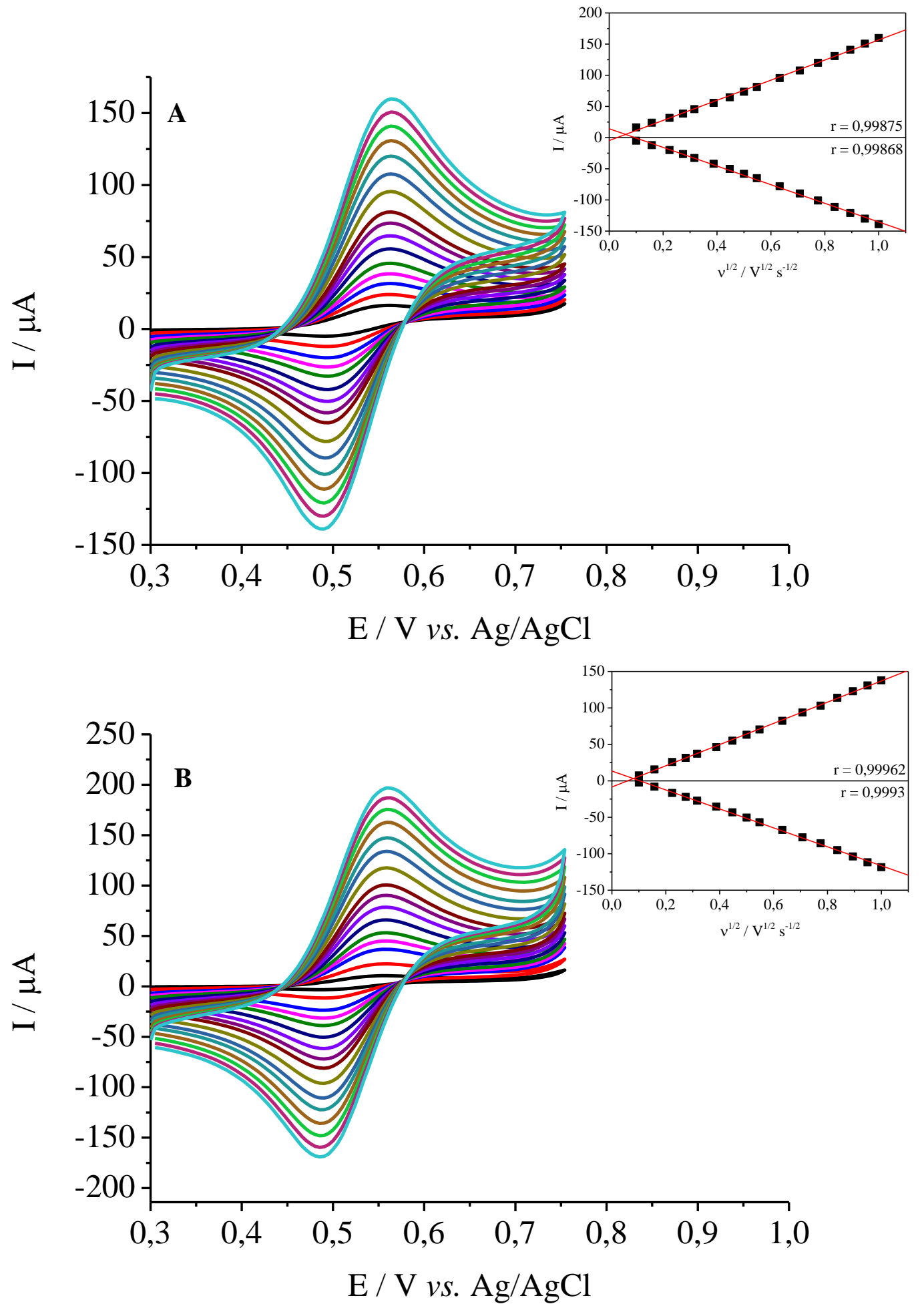


\subsubsection{Construção do eletrodo ITO/PAMAM-Pt}

Avaliados os perfis voltamétricos dos eletrodos de ITO e ITO/PAMAM iniciou-se o processo de obtenção dos filmes automontados de PAMAM-Pt sobre substrato de ITO. Os voltamogramas cíclicos obtidos com o eletrodo ITO/PAMAM-Pt apresentados na Figura 14, apresentam uma resposta muito semelhante, na região de adsorção/dessorção da monocamada de $\mathrm{H}_{\mathrm{ads}}$, à resposta do eletrodo de Pt policristalina ${ }^{75}$, cujo voltamograma está inserido na Figura 14. Pelos processos típicos de adsorção/dessorção de $\mathrm{H}_{2}$ na superfície da $\mathrm{Pt}$ comprovamos a adsorção do híbrido PAMAM-Pt na superfície do eletrodo de ITO.

Figura 14 - Voltamogramas cíclicos do eletrodo ITO/PAMAM-Pt. Eletrólito $\mathrm{H}_{2} \mathrm{SO}_{4} 0,1$ mol L ${ }^{-1}$, saturado com $\mathrm{N}_{2}$. Velocidade de varredura de $0,1 \mathrm{~V} \mathrm{~s}^{-1}$. (-) sem e (-) com tratamento eletroquímico após os 20 minutos de adsorção de PAMAM-Pt. Inserido: Voltamograma cíclico para o eletrodo de platina em $\mathrm{H}_{2} \mathrm{SO}_{4} 0,1 \mathrm{~mol} \mathrm{~L}^{-1}$, saturado com $\mathrm{N}_{2}$. Velocidade de varredura de $0,1 \mathrm{~V} \mathrm{~s}^{-1}$.

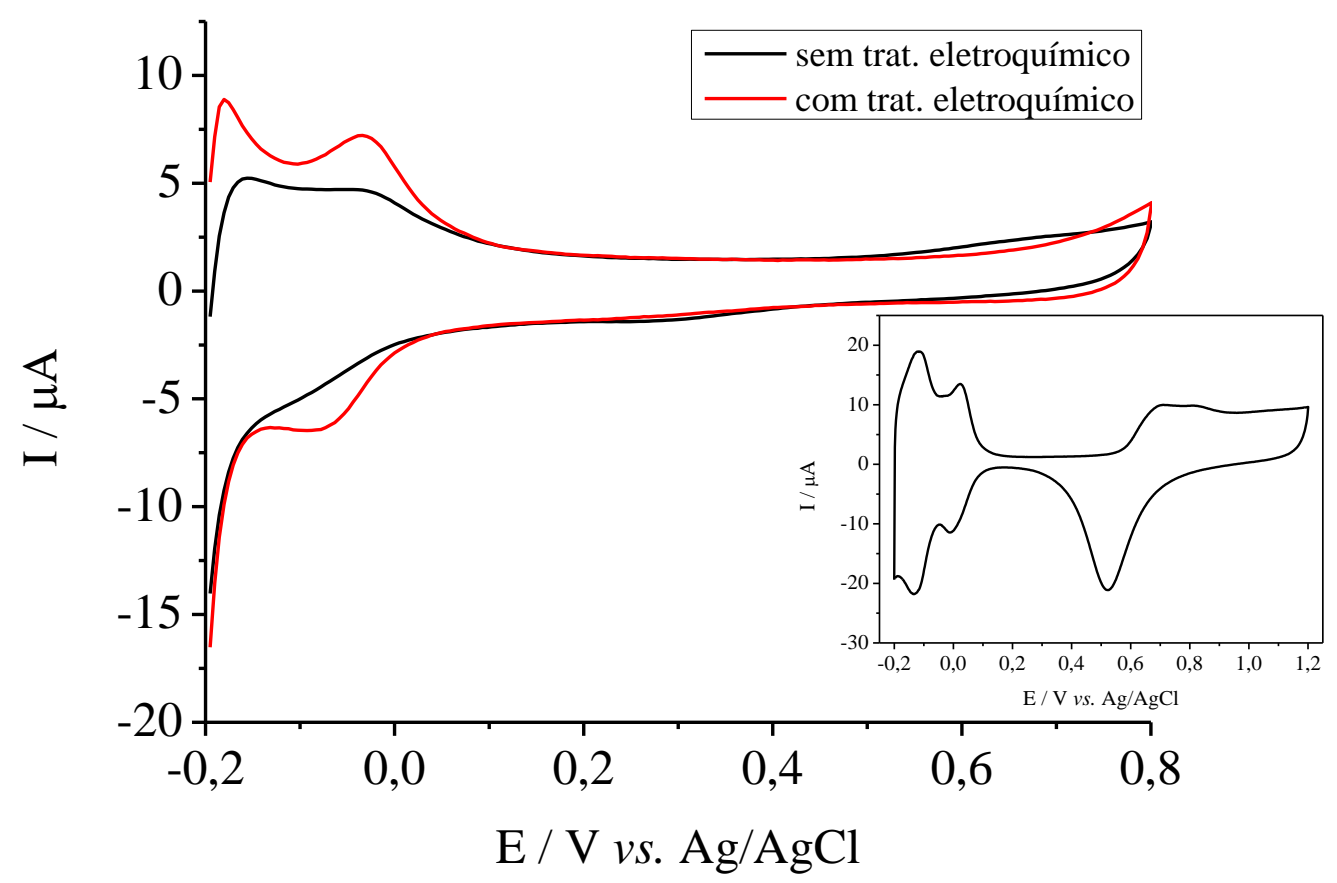

O eletrodo ITO/PAMAM-Pt foi então submetido ao mesmo tratamento eletroquímico utilizado para eletrodos de platina e podemos observar que o tratamento eletroquímico leva a um aumento no valor das correntes de oxidação e redução e melhor definição do voltamograma.

Durante o processo de otimização e caracterização do eletrodo ITO/PAMAM-Pt, todos os voltamogramas foram obtidos entre os potenciais de $-0,2$ e $0,8 \mathrm{~V}$, para evitar a formação e 
redução do óxido de Pt sobre as NPsPt encapsuladas em PAMAM, o que poderia influenciar na estabilidade e reprodutibilidade das medidas eletroquímicas.

\subsubsection{Tempo de adsorção do híbrido PAMAM-Pt sobre o eletrodo de ITO}

Comprovada a adsorção do híbrido PAMAM-Pt sobre o ITO, determinou-se, por CV e espectroscopia de absorção na região do UV-Vis, o tempo que o eletrodo deve ficar imerso na suspensão de PAMAM-Pt para que se forme uma camada. De acordo com os voltamogramas cíclicos da Figura 15 pode-se observar que o híbrido adere rapidamente sobre o eletrodo de ITO e que a partir de 7 minutos de imersão a corrente de oxidação do hidrogênio adsorvido diminui.

Figura 15 - Voltamogramas cíclicos do eletrodo de ITO imerso, por diferentes tempos, na suspensão de PAMAM-Pt. Eletrólito $\mathrm{H}_{2} \mathrm{SO}_{4} 0,1 \mathrm{~mol} \mathrm{~L}^{-1}$, saturado com $\mathrm{N}_{2}$. Velocidade de varredura de $0,1 \mathrm{~V} \mathrm{~s}^{-1}$. Inserido: variação da corrente de oxidação do hidrogênio adsorvido para os diferentes tempos de imersão até 40 minutos.

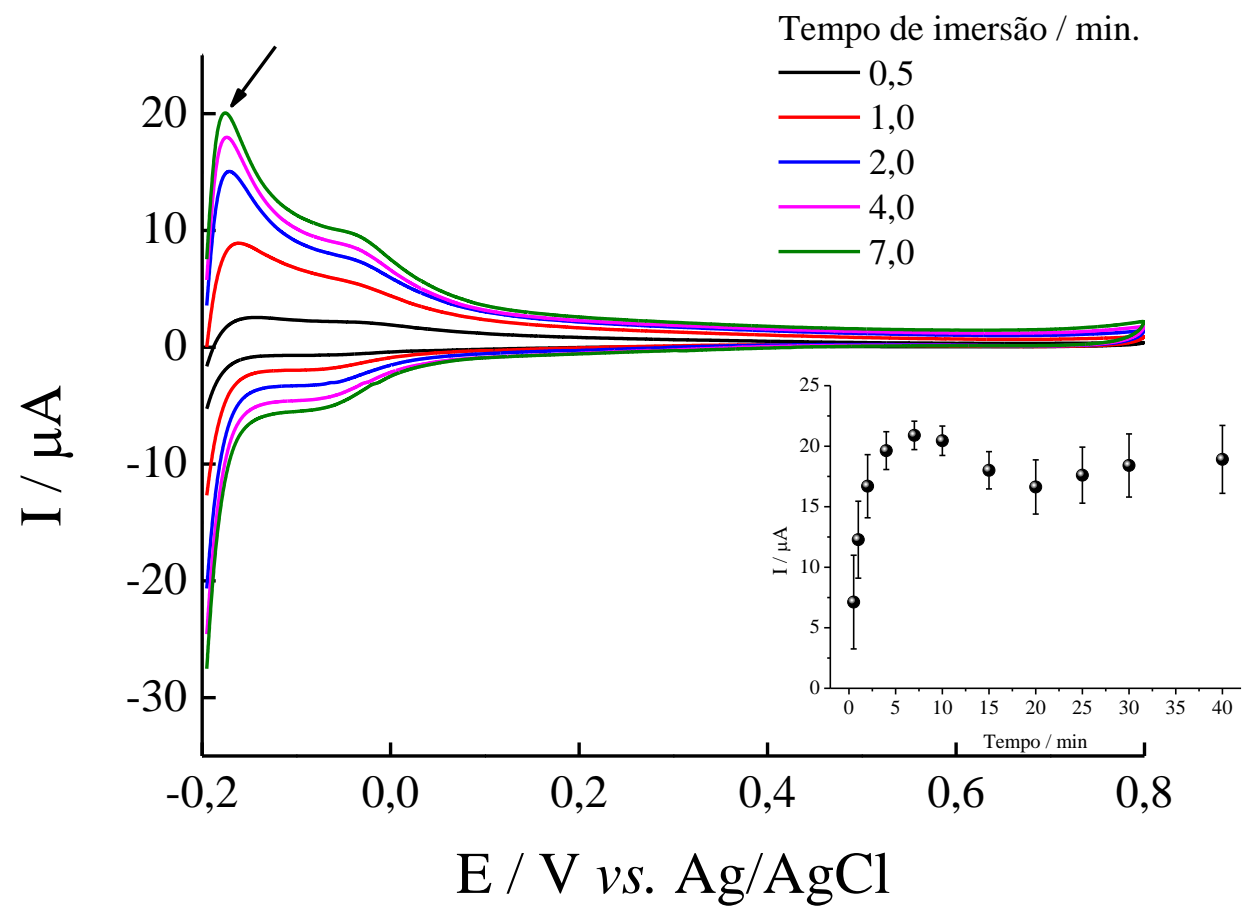

Tais dados são comprovados pelos espectros de UV-Vis da Figura 16, onde o tempo de imersão é monitorado pelo espalhamento de luz, observado pelo aumento da linha de base dos espectros. Inserido na Figura 16 temos a absorbância total, medida em 450 nm, em função do tempo de imersão, onde observamos que a partir de 7 min de imersão não há mais alteração da absorbância total, ou seja, a partir de 7 min a superfície do quartzo está saturada 
de PAMAM-Pt adsorvido. Assim, adotou-se um tempo de 7 minutos para a confecção de uma camada do híbrido PAMAM-Pt sobre substrato de ITO.

Figura 16 - Espectros de UV-Vis do substrato de quartzo imerso, por diferentes tempos, na suspensão de PAMAM-Pt. Inserido: variação da absorbância total, em $450 \mathrm{~nm}$, para os diferentes tempos de imersão, até 40 minutos.

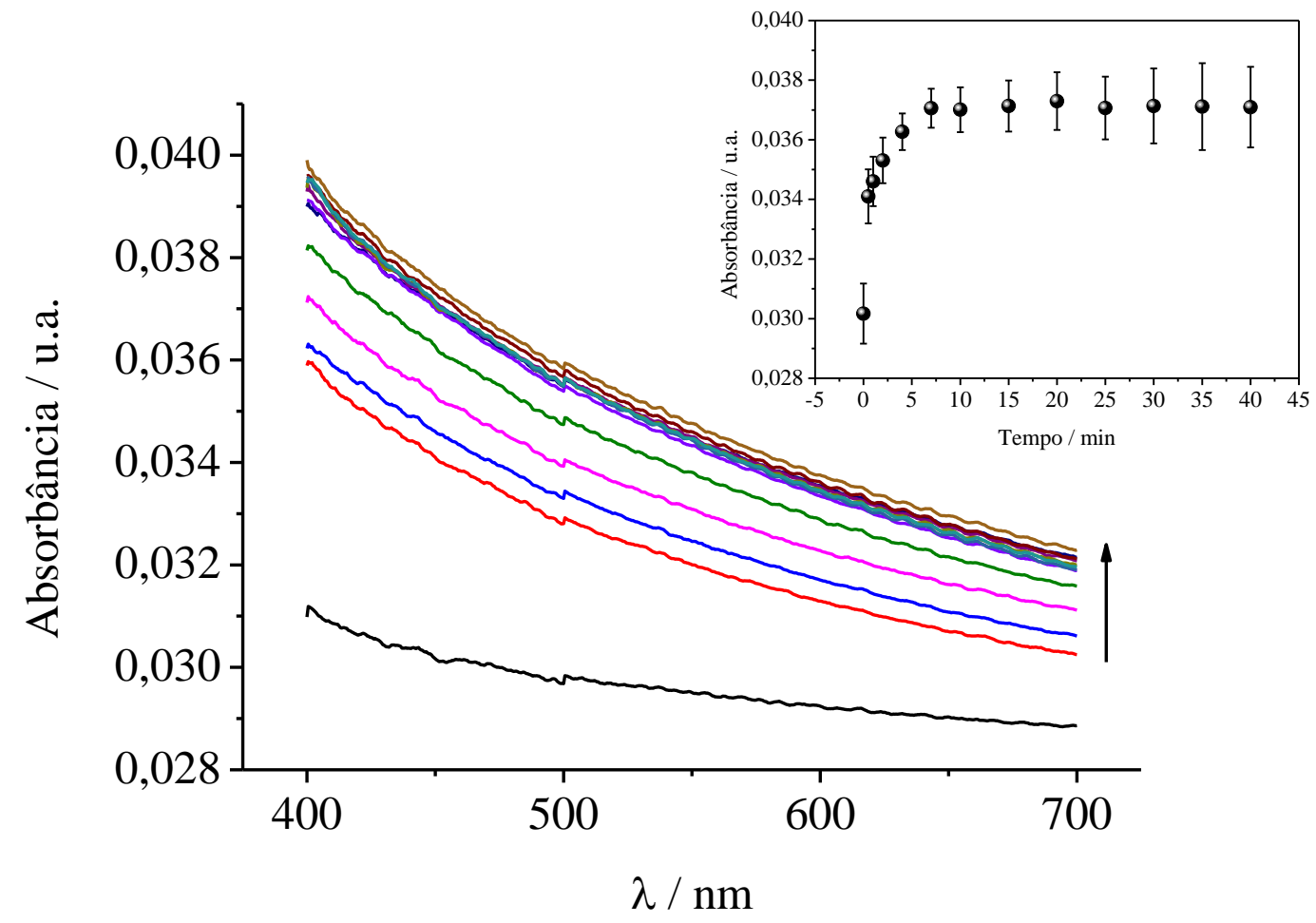

\subsubsection{Tempo de adsorção do poliânion PVS sobre o eletrodo ITO/PAMAM-Pt}

Figura 17 - Estrutura do PVS.

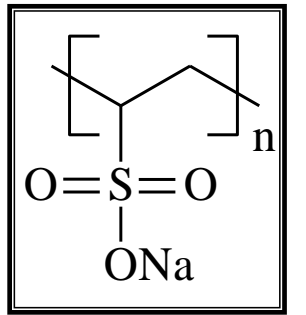

O poliânion PVS, cuja estrutura é apresentada na Figura 17 foi adsorvido sobre a camada de PAMAM-Pt sobre o eletrodo de ITO (ITO/PAMAM-Pt/PVS) a partir de uma solução 2,6 $\mathrm{g} \mathrm{L}^{-1} \mathrm{em} \mathrm{KCl}$ 0,1 mol $\mathrm{L}^{-1}$. A adição de pequenas quantidades de eletrólito à solução de PVS leva a um aumento da espessura da camada do PVS adsorvido e um tempo de adsorção de pelo menos 15 minutos é necessário para a formação da camada do poliânion ${ }^{76}$. Experimentamos se haveria um menor tempo para adsorção do PVS, mas o PVS não apresenta resposta eletroquímica nem absorbância no UV-Vis, utilizou-se o monitoramento indireto, monitorando-se a camada do híbrido PAMAM-Pt sobre a camada de PVS com diferentes tempos de imersão na solução do PVS, como não houve reprodutibilidade, optou-se por 
utilizar o tempo de 20 minutos estabelecido por Mohwald ${ }^{76}$ e colaboradores, utilizando a técnica de espalhamento de Raio-X a baixo ângulo.

\subsubsection{Número de camadas do híbrido PAMAM-Pt sobre o eletrodo de ITO}

O número de camadas de PAMAM-Pt imobilizadas sobre o eletrodo de ITO também foi monitorada por CV e UV-Vis. Os voltamogramas da Figura 18 mostram que a corrente de oxidação do hidrogênio adsorvido aumenta linearmente com a número de camadas de PAMAM-Pt adsorvidas até 4 camadas, indicando que a mesma quantidade de PAMAM-Pt é adsorvida em cada imersão na suspensão de PAMAM-Pt. De 4 a 7 camadas não se observa mais esta linearidade, e a partir de 7 camadas há uma diminuição da corrente.

Figura 18 - Voltamogramas cíclicos do eletrodo de ITO recoberto com diferentes números de camadas do híbrido PAMAM-Pt intercaladas com camadas do poliânion PVS. Eletrólito $\mathrm{H}_{2} \mathrm{SO}_{4} 0,1$ mol L ${ }^{-1}$, saturado com $\mathrm{N}_{2}$. Velocidade de varredura de $0,1 \mathrm{~V} \mathrm{~s}^{-1}$. Inserido: variação da corrente de oxidação do hidrogênio adsorvido em função do número de camadas do híbrido PAMAM-Pt para 9 camadas.

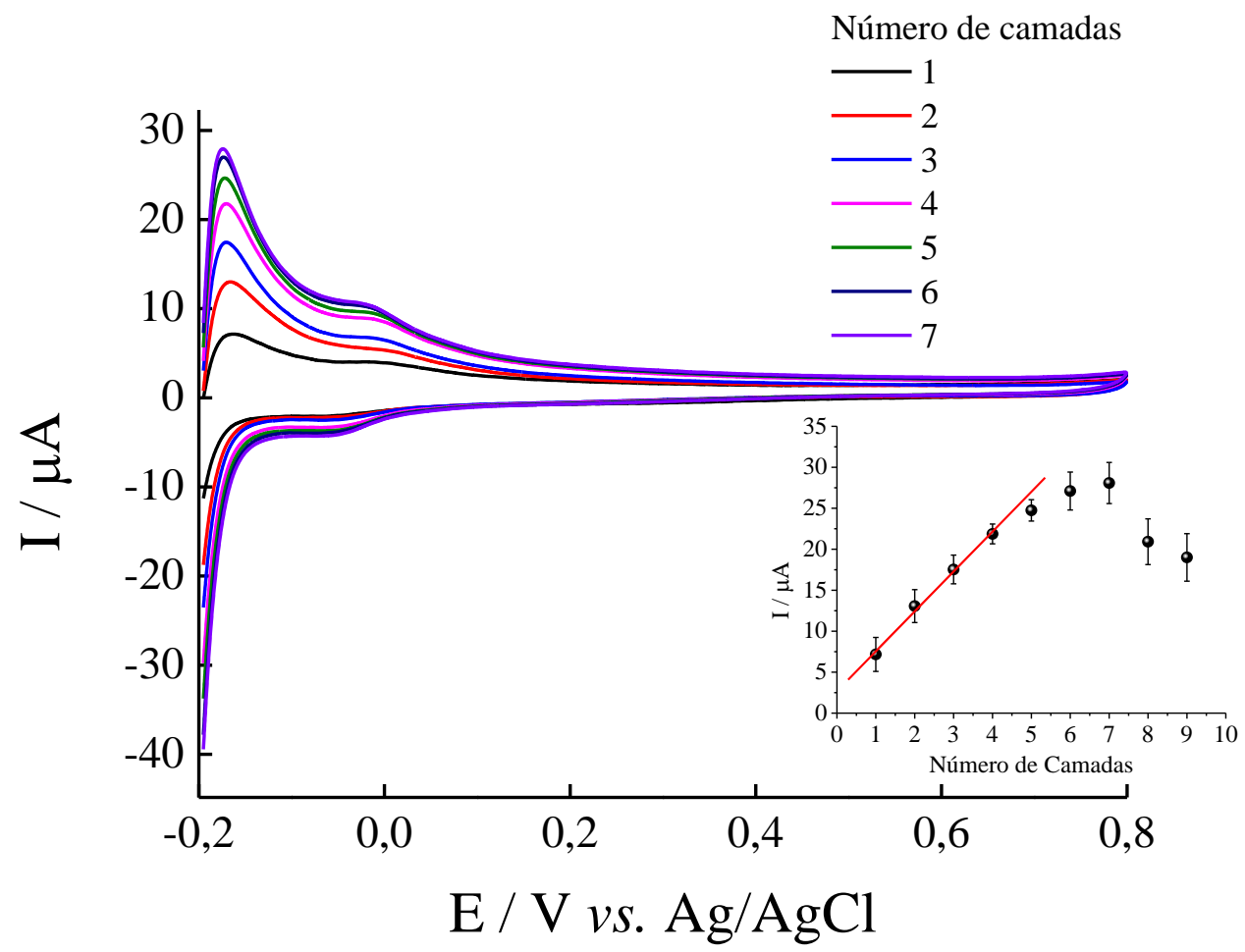

$\mathrm{Na}$ Figura 19 temos os espectros de UV-Vis, onde o número de camadas de PAMAM-Pt imobilizadas sobre o quartzo é também monitorado pelo espalhamento de luz, observado pelo aumento da linha de base dos espectros. Inserido na Figura 19 temos a 
absorbância total, medida em $450 \mathrm{~nm}$, em função do número de camadas, onde podemos observar que a absorbância total aumenta linearmente com o número de camadas do híbrido adsorvidas até 5 camadas e que a partir de 6 camadas a absorbância total permanece constante. Assim considera-se que não haverá aumento na quantidade de PAMAM-Pt adsorvido. Levando-se em conta o desempenho eletroquímico e o tempo de preparação do eletrodo, escolheu-se o eletrodo com 4 camadas de PAMAM-Pt intercaladas com o poliânion PVS.

Figura 19 - Espectros de UV-Vis do substrato de quartzo recoberto com diferentes números de camadas de PAMAM-Pt intercaladas com camadas do poliânion PVS. Inserido: variação da absorbância total, em $450 \mathrm{~nm}$, em função do número de camadas do híbrido PAMAM-Pt para 10 camadas.

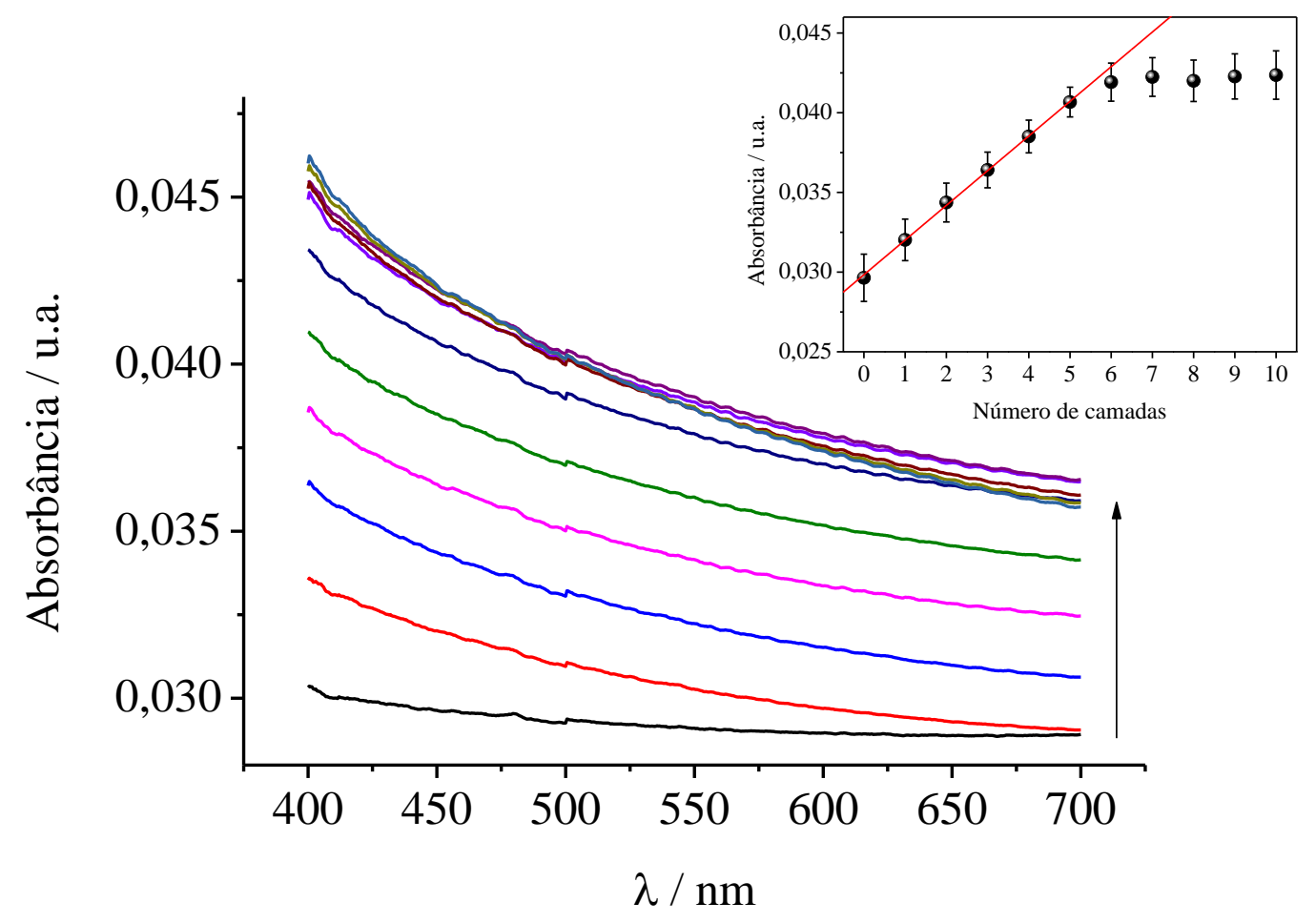

\subsection{Influência do tratamento eletroquímico na resposta eletroquímica dos eletrodos ITO/(PAMAM-Pt)}

Durante os processos de determinação do tempo de adsorção e do número de camadas de PAMAM-Pt sobre o eletrodo de ITO, observando os voltamogramas da Figura 15 nota-se que a corrente de oxidação do hidrogênio adsorvido para o eletrodo de ITO com 7 min de imersão na suspensão de PAMAM-Pt, com tratamento eletroquímico entre as imersões, é 20,2 $\mu \mathrm{A}$. Nota-se também, observando a Figura 18, que corrente semelhante, 21,9 $\mu \mathrm{A}$, é obtida com o eletrodo de ITO com 4 camadas de PAMAM-Pt (ITO/(PAMAM-Pt) ${ }_{4}$, com 
tratamento eletroquímico entre as camadas. Desta forma, decidiu-se investigar, por CV e EIS, a influencia do tratamento eletroquímico na resposta eletroquímica dos eletrodos ITO/(PAMAM-Pt $)_{\mathrm{n}}$. Para isso, vários eletrodos, com diferentes números de camadas, com e sem tratamento eletroquímico, foram avaliados. Todos os espectros de impedância foram obtidos na região de adsorção/dessorção de hidrogênio, medidos nos potenciais indicados nas figuras, de acordo com os respectivos voltamogramas. O circuito equivalente utilizado no fitting dos espectros no plano complexo, obtidos na região de adsorção/dessorção de hidrogênio, é apresentado na Figura 20 e está de acordo com o trabalho de Baranova e Kuznetsov $^{77}$ que realizaram um estudo sobre espectroscopia de impedância de platina em meio de ácido sulfúrico. Segundo o estudo, o circuito em destaque na Figura 20 representa um processo onde o carregamento da dupla camada e a transferência eletrônica ocorrem de maneira independente, ou seja, onde a resistência da solução do eletrólito , $\mathrm{R}_{\Omega}$, está em série com a capacitância da dupla camada, $\mathrm{Cp}$, enquanto a resistência à transferência de elétrons, $\mathrm{R}_{\mathrm{tc}}$, está em paralelo com $\mathrm{Cp}$.

Figura 20 - Circuito equivalente dos espectros no plano complexo, obtidos na região de adsorção/dessorção de hidrogênio, dos eletrodos ITO/(PAMAM-Pt) $)_{n}$, sem e com tratamento eletroquímico.

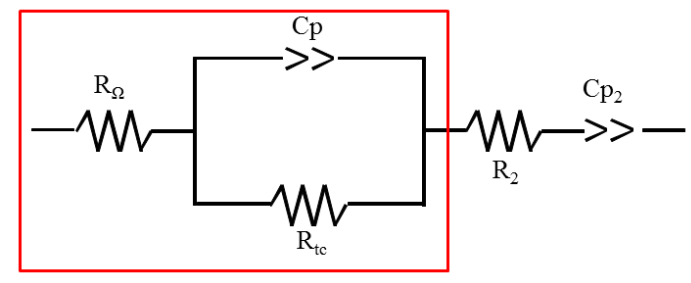

Uma vez que as nanopartículas de platina estejam disponíveis para o processo de adsorção/dessorção do hidrogênio, a partir da solução do eletrólito, a resistência associada a este processo depende inversamente do número de nanopartículas disponíveis. O processo faradaico está associado à oxidação do hidrogênio adsorvido. A resistência à transferência de carga no filme deve ser inversamente proporcional à quantidade de sítios catalíticos (nanopartículas de $\mathrm{Pt}$ ) disponíveis. Os componentes do circuito elétrico equivalente são representados pela resistência da célula, $\mathrm{R}_{\Omega}$, resistência à transferência de carga para a reação de oxidação do hidrogênio adsorvido, $\mathrm{R}_{\mathrm{tc}}$, enquanto $\mathrm{Cp}$ é a capacitância da dupla camada de n-camadas do híbrido PAMAM-Pt.

Segundo Lasia et al. ${ }^{78}$ a adsorção de hidrogênio na superfície da Pt é um processo eletrocatalítico muito rápido e a EIS é uma poderosa técnica que permite estudar processos 
eletroquímicos em um ampla faixa de frequência, no entanto, diferentes grupos obtiveram resultados contraditórios para a $R_{t c}$ para a cinética de deposição do hidrogênio em regime de subtensão. A dificuldade na determinação de $\mathrm{R}_{\mathrm{tc}}$ para reações muito rápidas está relacionada ao fato de a $R_{\Omega}$ ser muito maior que a $R_{t c}$ e a lenta resposta dos potenciostatos a altas frequências. Assim, vale ressaltar, que neste trabalho, os espectros de impedância foram obtidos nas frequências de $65 \mathrm{kHz}$ a $0,1 \mathrm{~Hz}$, todos nas mesmas condições experimentais, e o circuito equivalente utilizado se ajustou perfeitamente aos espectros obtidos, permitindo obtermos valores para a $\mathrm{R}_{\mathrm{tc}}$, que corroboram os dados de intensidade de corrente e área eletroativa obtidos em função do tratamento eletroquímico utilizado, como um parâmetro interno de comparação, não sendo objetivo deste trabalho, determinar valores de $\mathrm{R}_{\mathrm{tc}}$ nem propor metodologia para isto.

Na Figura 21 temos os voltamogramas para os eletrodos de ITO com uma camada de PAMAM-Pt onde se observa maior corrente e melhor definição do picos para o voltamograma do eletrodo com uma camada de PAMAM-Pt com tratamento eletroquímico entre as imersões. Com os espectros no plano complexo podemos observar que o transporte de carga é mais rápido para o eletrodo de ITO com uma camada do híbrido PAMAM-Pt com tratamento eletroquímico entre as imersões e que a resistência à transferência de carga aumenta para o eletrodo com tratamento eletroquímico após a confecção e para o eletrodo sem tratamento eletroquímico. 
Figura 21 - (A) Voltamogramas cíclicos dos eletrodos ITO/(PAMAM-Pt) ${ }_{1}$ em $\mathrm{H}_{2} \mathrm{SO}_{4}$ 0,1 mol L ${ }^{-1}$, saturado com $\mathrm{N}_{2}$. Velocidade de varredura $0,1 \mathrm{~V} \mathrm{~s}^{-1}$. Espectros de impedância no plano complexo, em $\mathrm{H}_{2} \mathrm{SO}_{4} 0,1 \mathrm{~mol} \mathrm{~L}^{-1}$, saturado com $\mathrm{N}_{2}$, para os eletrodos ITO/(PAMAM-Pt) $)_{1}$, (B) sem trat. elet após confecção, (C) com trat. elet. após confecção e (D) com trat. elet. entre imersões. Variação de frequência de $65 \mathrm{kHz}$ a $0,1 \mathrm{~Hz}$.

A
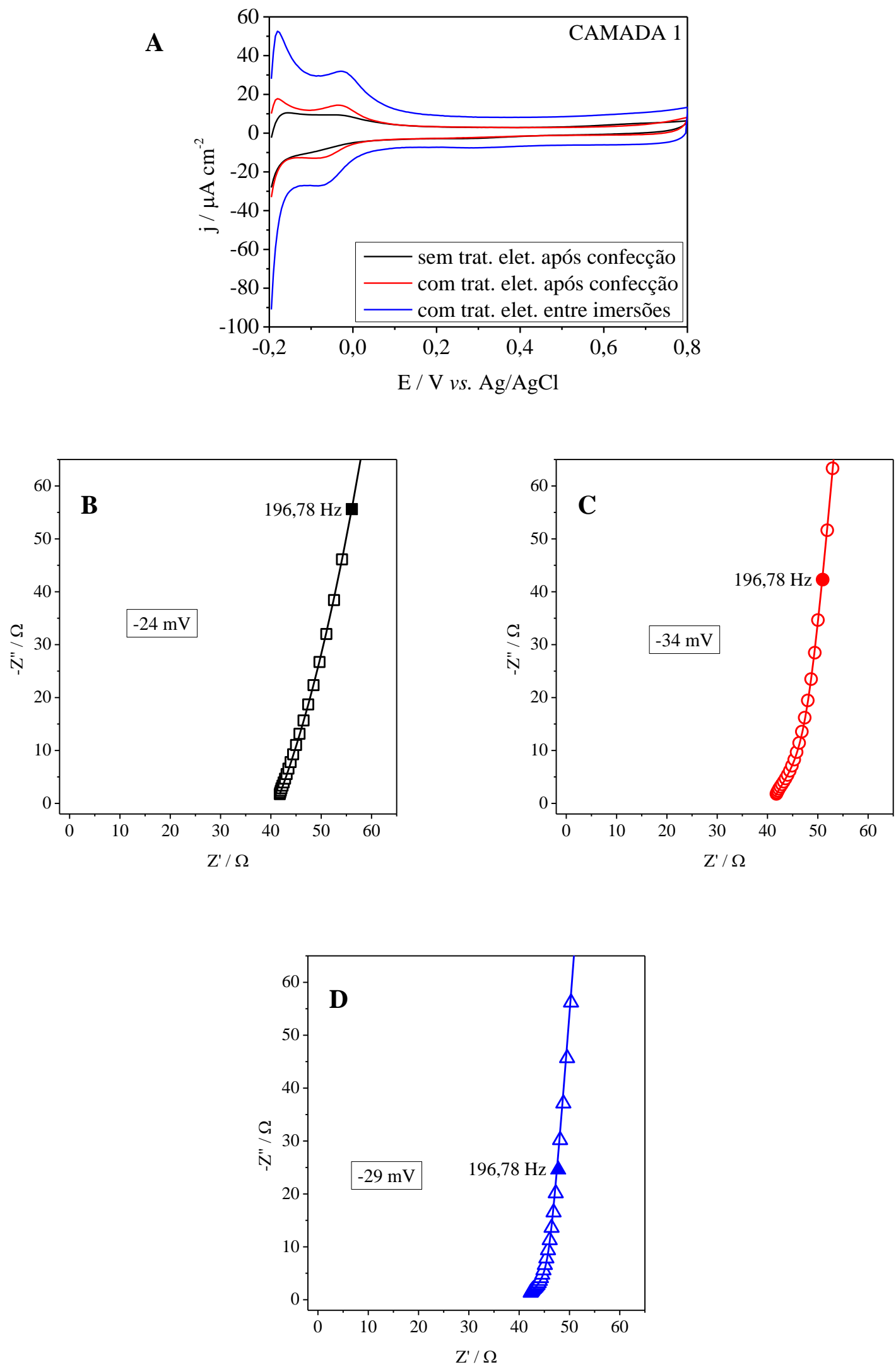
O eletrodo de ITO com uma camada de PAMAM-Pt sem tratamento eletroquímico foi o que apresentou menor corrente de pico para a reação de oxidação do hidrogênio e maior resistência à transferência de carga. Assim, os mesmos experimentos foram feitos para 2, $3 \mathrm{e}$ 4 camadas do híbrido PAMAM-Pt, com tratamento eletroquímico entre camadas e com tratamento eletroquímico após confecção. Na Figura 22 são apresentados o espectro de impedância no plano complexo para o eletrodo de ITO/(PAMAM-Pt) $)_{1}$ sem tratamento eletroquímico, e inseridos as faixas de 0 a $65 \Omega$ e de 0 a $10 \Omega$, sendo que para este ultimo descontou-se a resistência da célula, $\mathrm{R}_{\Omega}=41,8 \Omega$.

Figura 22 - Espectros de impedância no plano complexo, em $\mathrm{H}_{2} \mathrm{SO}_{4} 0,1 \mathrm{~mol} \mathrm{~L}^{-1}$, saturado com $\mathrm{N}_{2}$, para o eletrodo ITO/(PAMAM-Pt) $)_{1}$ sem tratamento eletroquímico. Variação de frequência de $65 \mathrm{kHz}$ a $0,1 \mathrm{~Hz}$.

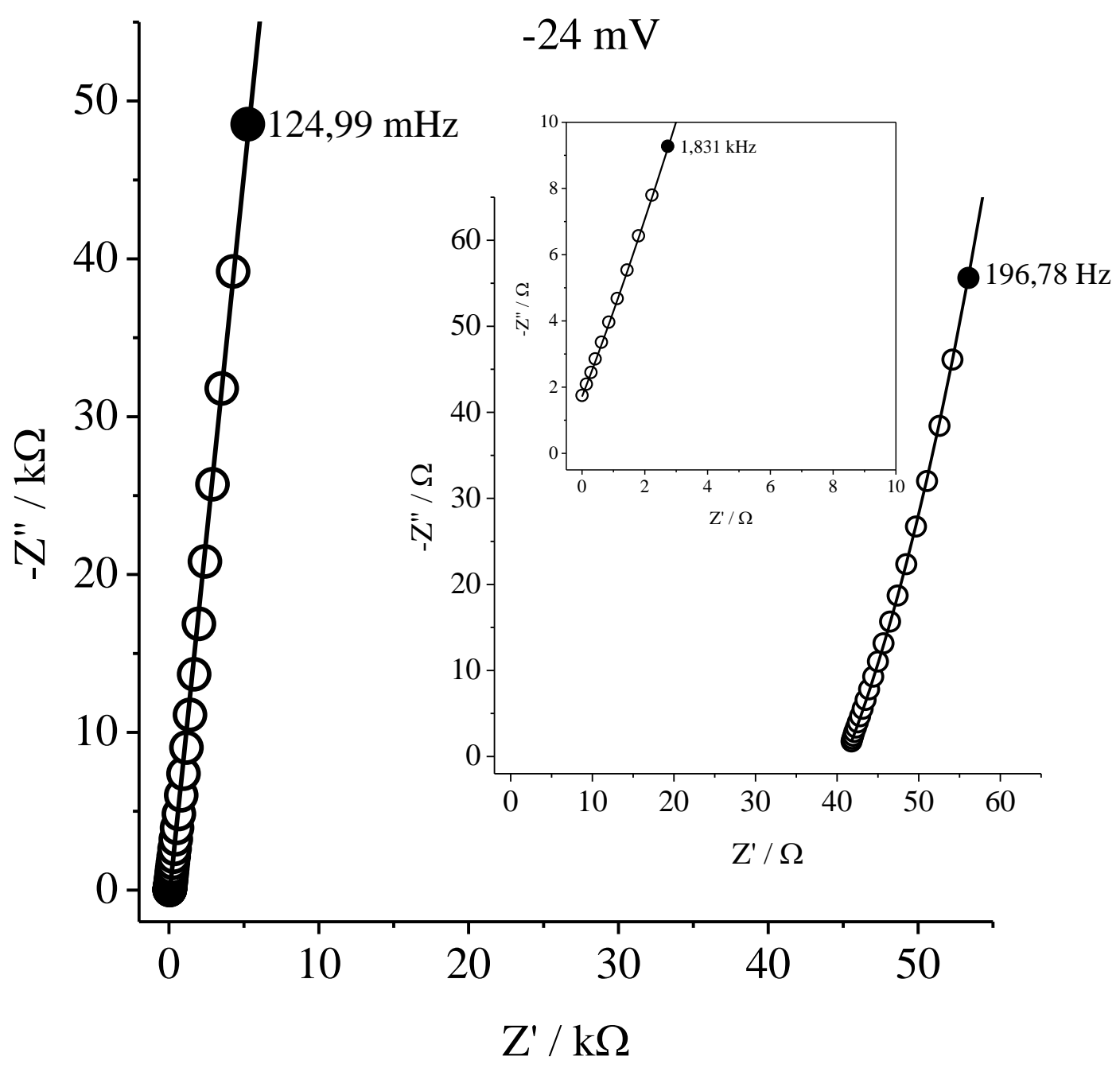


Por apresentarem o mesmo comportamento, todos os espectros de impedância no plano complexo mostrados a seguir foram fitados com o mesmo circuito equivalente apresentado anteriormente, e representam um zoom de 0 a $65 \Omega$.

Nas Figuras 23, 24 e 25 são apresentados os espectros de impedância no plano complexo para os eletrodos de ITO com 2, 3 e 4 camadas do híbrido PAMAM-Pt, com tratamento eletroquímico após confecção e com tratamento eletroquímicos entre camadas, e os respectivos voltamogramas. Observa-se que as correntes de pico para a reação de oxidação do hidrogênio adsorvido são maiores para os eletrodos com tratamento eletroquímico entre as camadas, e que a resistência à transferência de carga é menor para estes eletrodos.

Figura 23 - (A) Voltamogramas cíclicos dos eletrodos ITO/(PAMAM-Pt) em H$_{2} \mathrm{SO}_{4}$ 0,1 mol L-1 , saturado com $\mathrm{N}_{2}$. Velocidade de varredura $0,1 \mathrm{~V} \mathrm{~s}^{-1}$. Espectros de impedância no plano complexo, em $\mathrm{H}_{2} \mathrm{SO}_{4} 0,1 \mathrm{~mol} \mathrm{~L}^{-1}$, saturado com $\mathrm{N}_{2}$, para os eletrodos ITO/(PAMAM-Pt) $)_{2}$, (B) com trat. elet. após confecção e (C) com trat. elet. entre camadas. Variação de frequência de $65 \mathrm{kHz}$ a $0,1 \mathrm{~Hz}$.

A
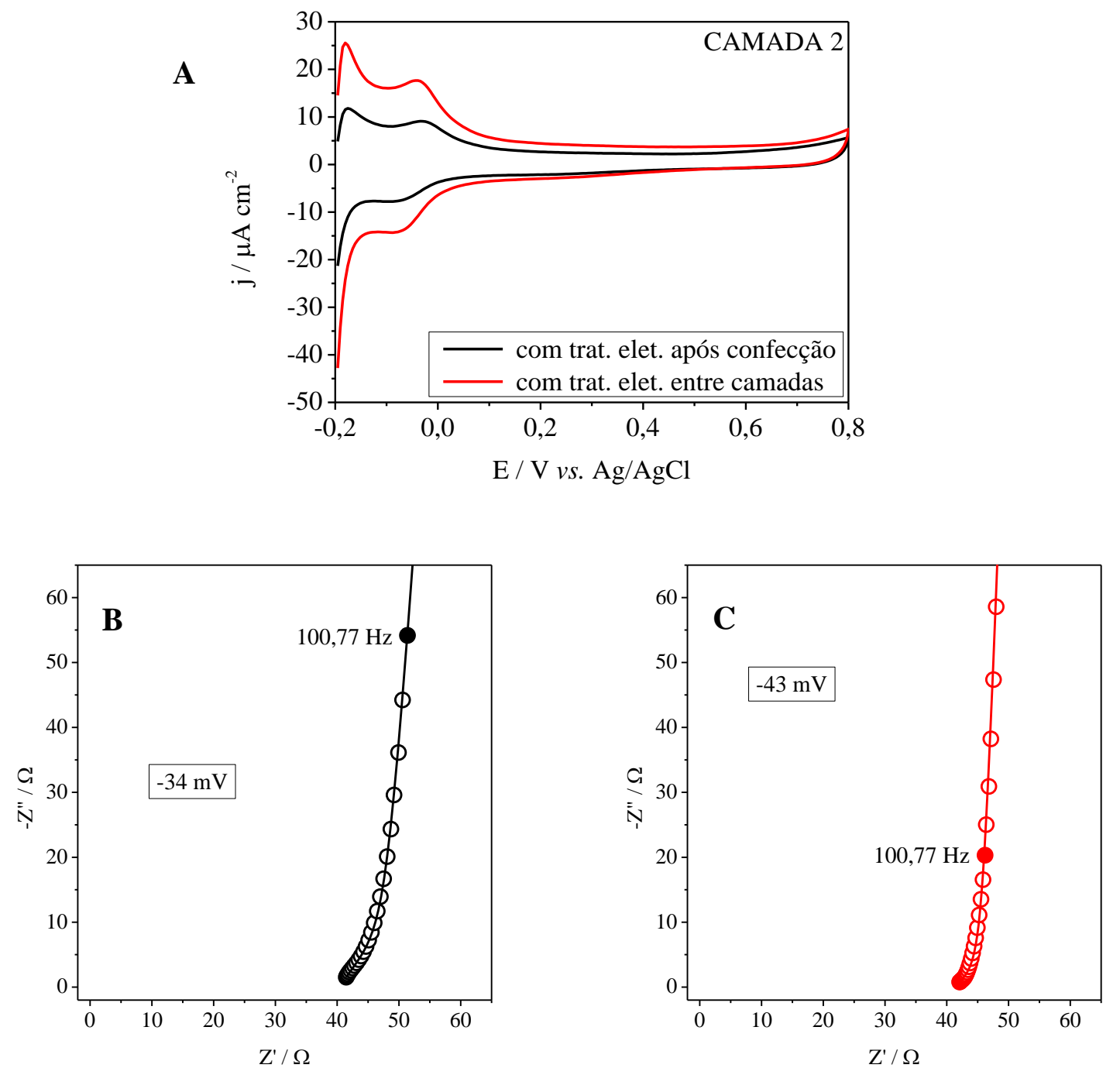
Figura 24 - (A) Voltamogramas cíclicos dos eletrodos ITO/(PAMAM-Pt) ${ }_{3}$ em $\mathrm{H}_{2} \mathrm{SO}_{4}$ 0,1 mol L ${ }^{-1}$, saturado com $\mathrm{N}_{2}$. Velocidade de varredura $0,1 \mathrm{~V} \mathrm{~s}^{-1}$. Espectros de impedância no plano complexo, em $\mathrm{H}_{2} \mathrm{SO}_{4} 0,1 \mathrm{~mol} \mathrm{~L}^{-1}$, saturado com $\mathrm{N}_{2}$, para os eletrodos ITO/(PAMAM-Pt) $)_{3}$, (B) com trat. elet. após confecção e (C) com trat. elet. entre camadas. Variação de frequência de $65 \mathrm{kHz}$ a $0,1 \mathrm{~Hz}$.

\section{A}
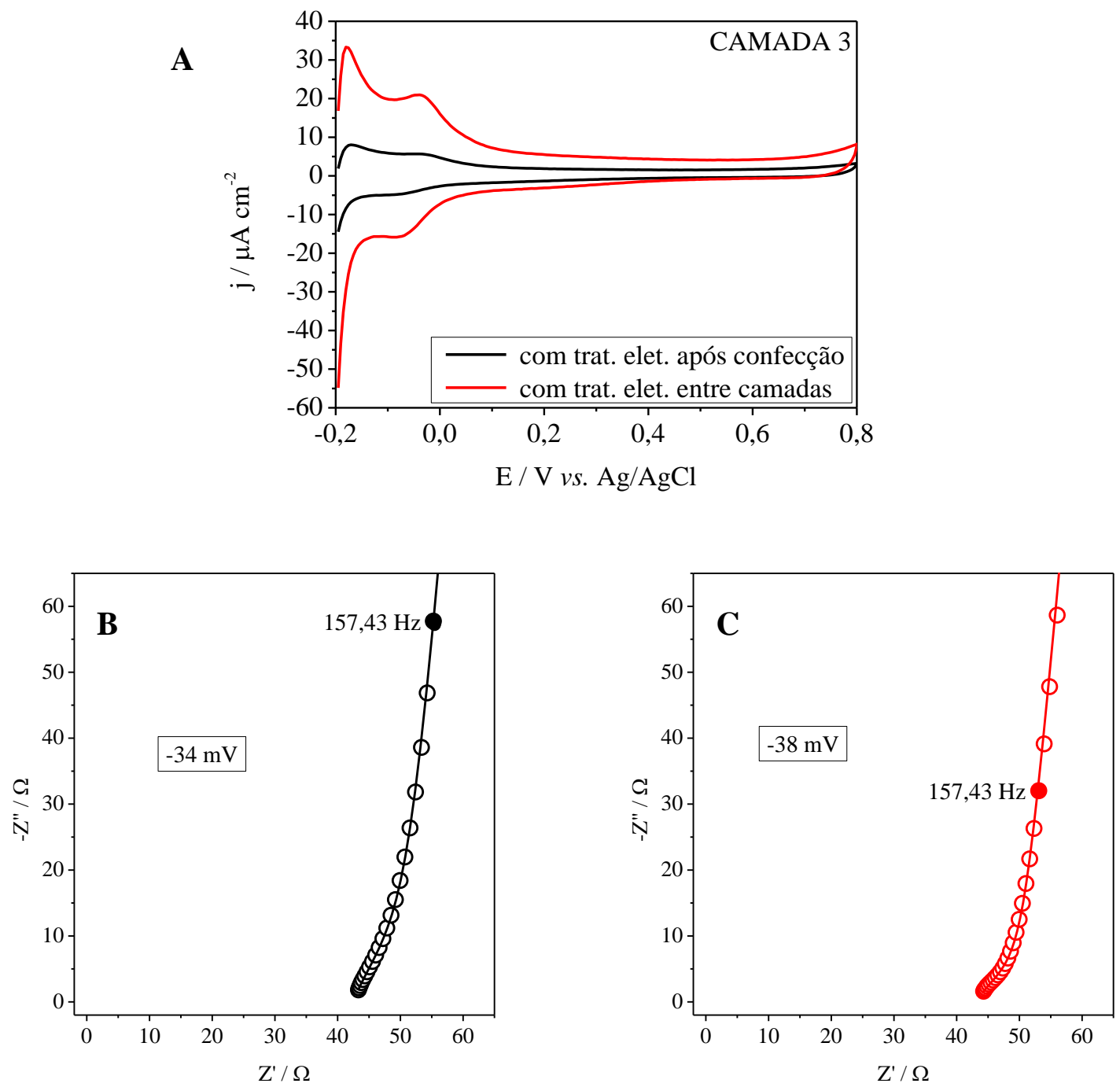


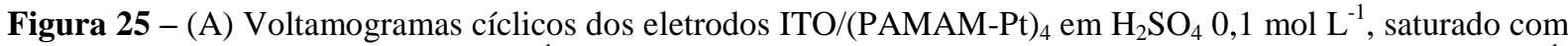
$\mathrm{N}_{2}$. Velocidade de varredura $0,1 \mathrm{~V} \mathrm{~s}^{-1}$. Espectros de impedância no plano complexo, em $\mathrm{H}_{2} \mathrm{SO}_{4} 0,1 \mathrm{~mol} \mathrm{~L}^{-1}$, saturado com $\mathrm{N}_{2}$, para os eletrodos ITO/(PAMAM-Pt) $)_{4}$, (B) com trat. elet. após confecção e (C) com trat. elet. entre camadas. Variação de frequência de $65 \mathrm{kHz}$ a $0,1 \mathrm{~Hz}$.

$\mathbf{A}$
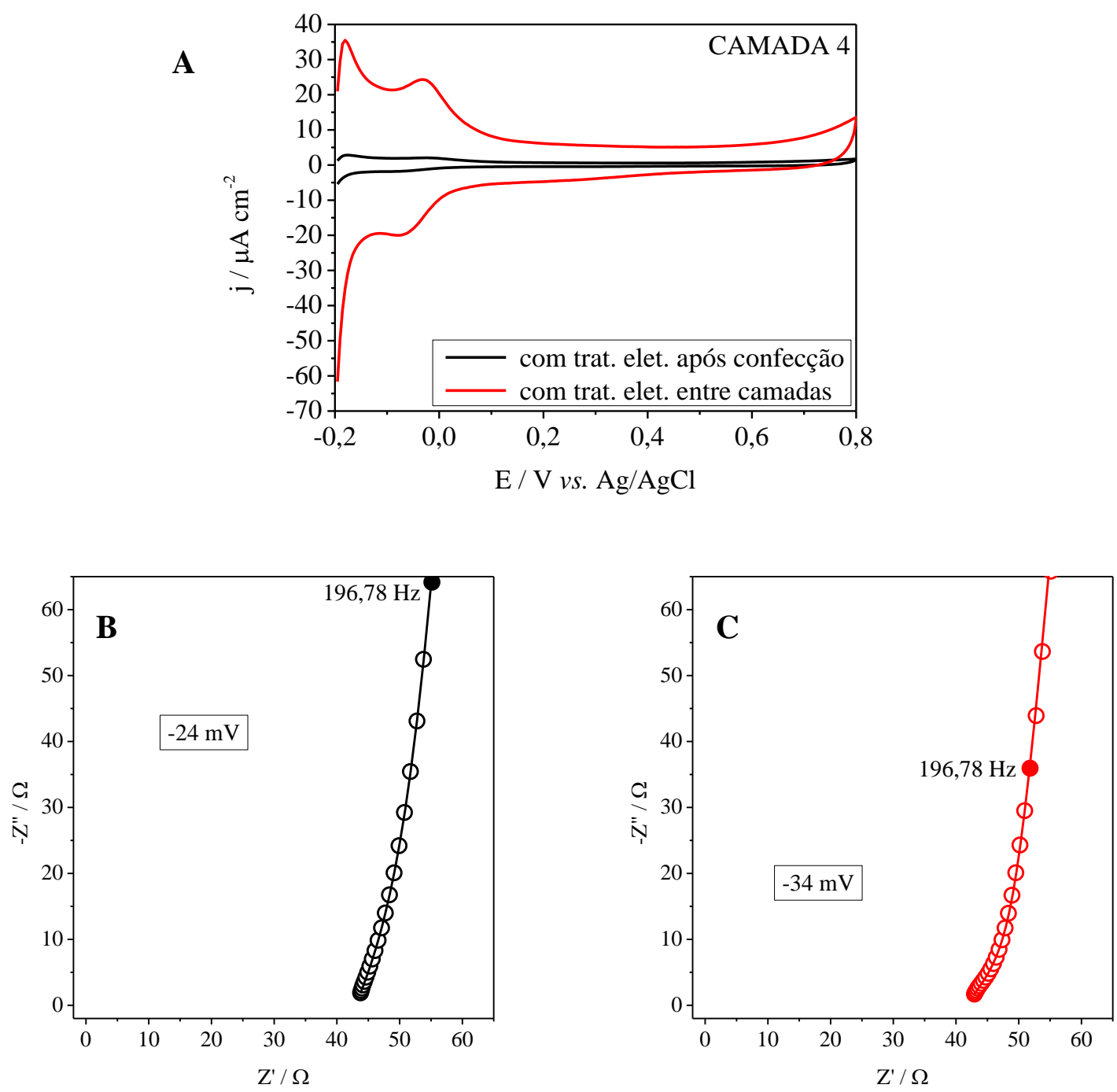

Nas Figuras 26 e 27 são apresentados os mesmos voltamogramas com a intensão de mostrar a influencia do tratamento eletroquímico nas correntes de oxidação do hidrogênio adsorvido. Quando os eletrodos são submetidos a tratamento eletroquímico após a confecção, as correntes de pico diminuem com o aumento do número de camadas, mas quando os mesmos eletrodos são submetidos a tratamento eletroquímico durante a confecção, entre as camadas, as correntes de pico aumentam com o numero de camadas. 
Figura 26 - (A) Voltamogramas cíclicos dos eletrodos ITO/(PAMAM-Pt), com tratamento eletroquímico após confecção, em $\mathrm{H}_{2} \mathrm{SO}_{4} 0,1 \mathrm{~mol} \mathrm{~L}^{-1}$, saturado com $\mathrm{N}_{2}$. Velocidade de varredura $0,1 \mathrm{~V} \mathrm{~s}^{-1}$. (B) Variação das correntes de pico, para a reação de oxidação do hidrogênio adsorvido, em função do número de camadas.

A

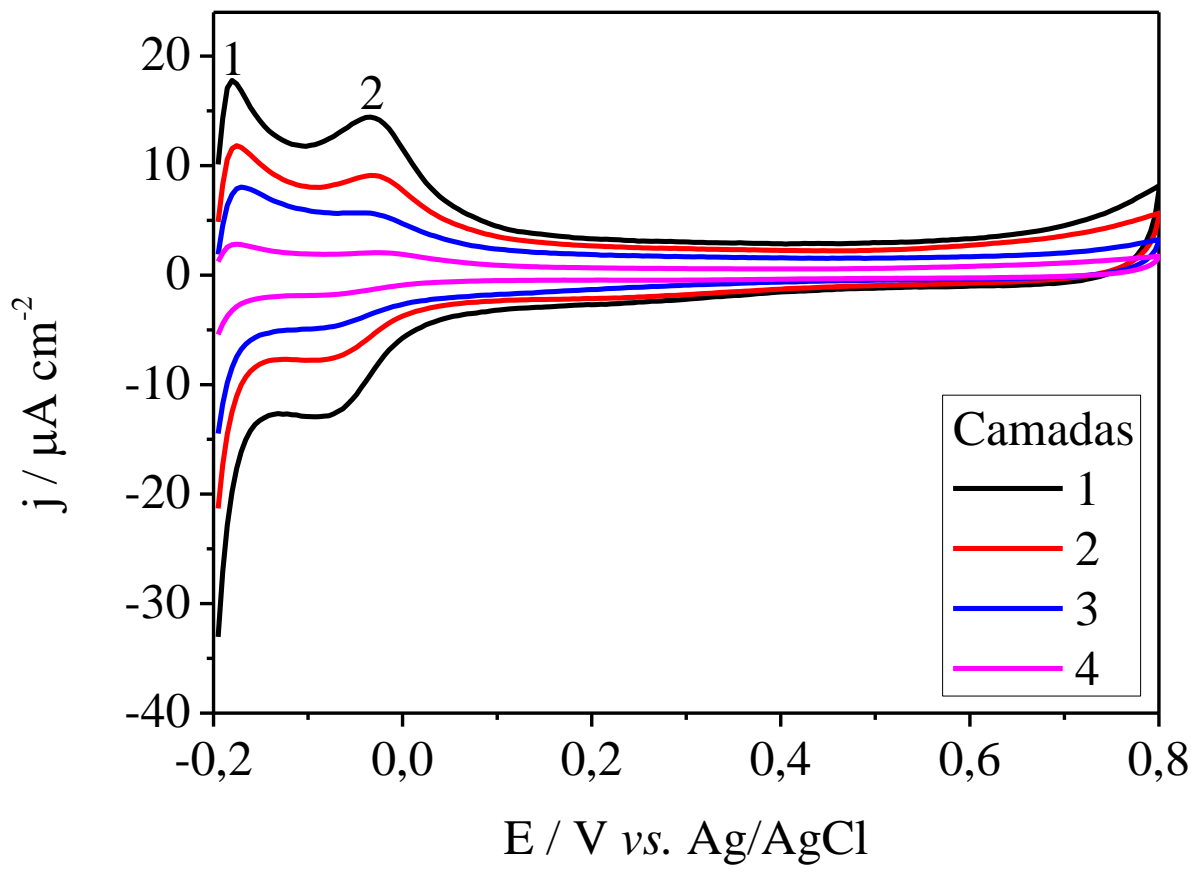

B

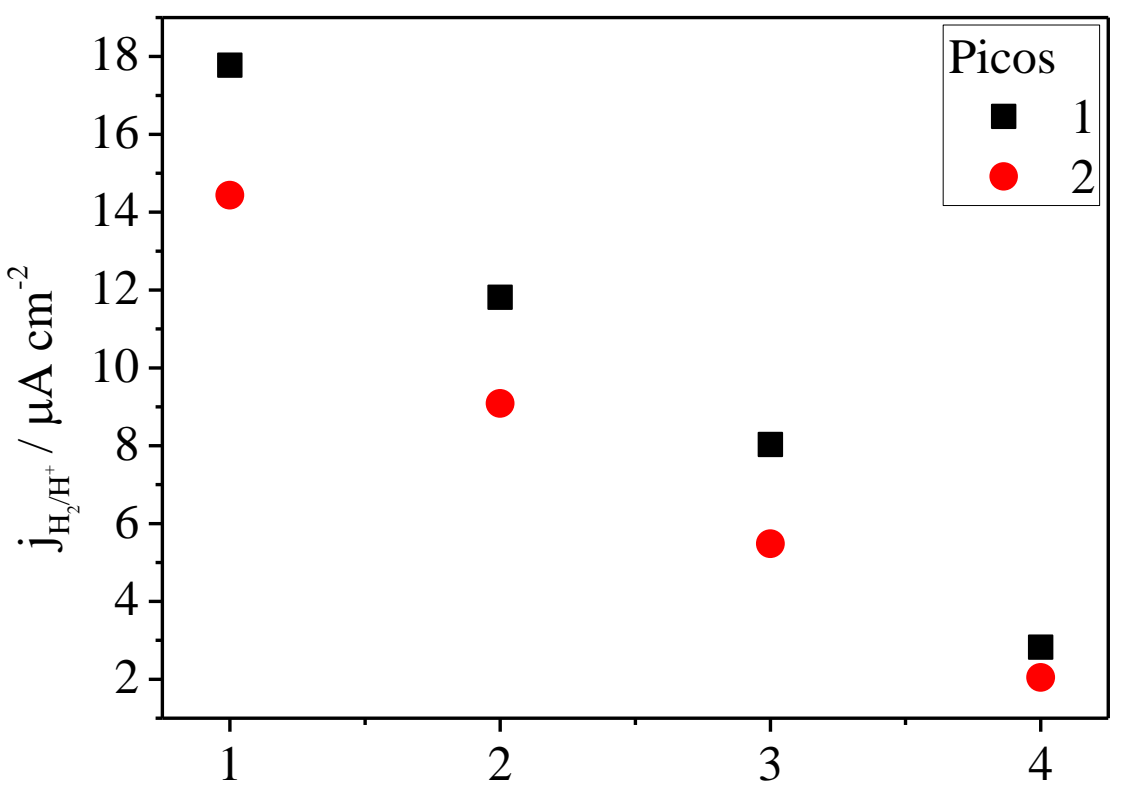

Número de camadas 
Figura 27 - (A) Voltamogramas cíclicos dos eletrodos ITO/(PAMAM-Pt) $)_{n}$, com tratamento eletroquímico entre as camadas, em $\mathrm{H}_{2} \mathrm{SO}_{4} 0,1 \mathrm{~mol} \mathrm{~L}^{-1}$, saturado com $\mathrm{N}_{2}$. Velocidade de varredura $0,1 \mathrm{~V} \mathrm{~s}^{-1}$. (B) Variação das correntes de pico, para a reação de oxidação do hidrogênio adsorvido, em função do número de camadas.

A
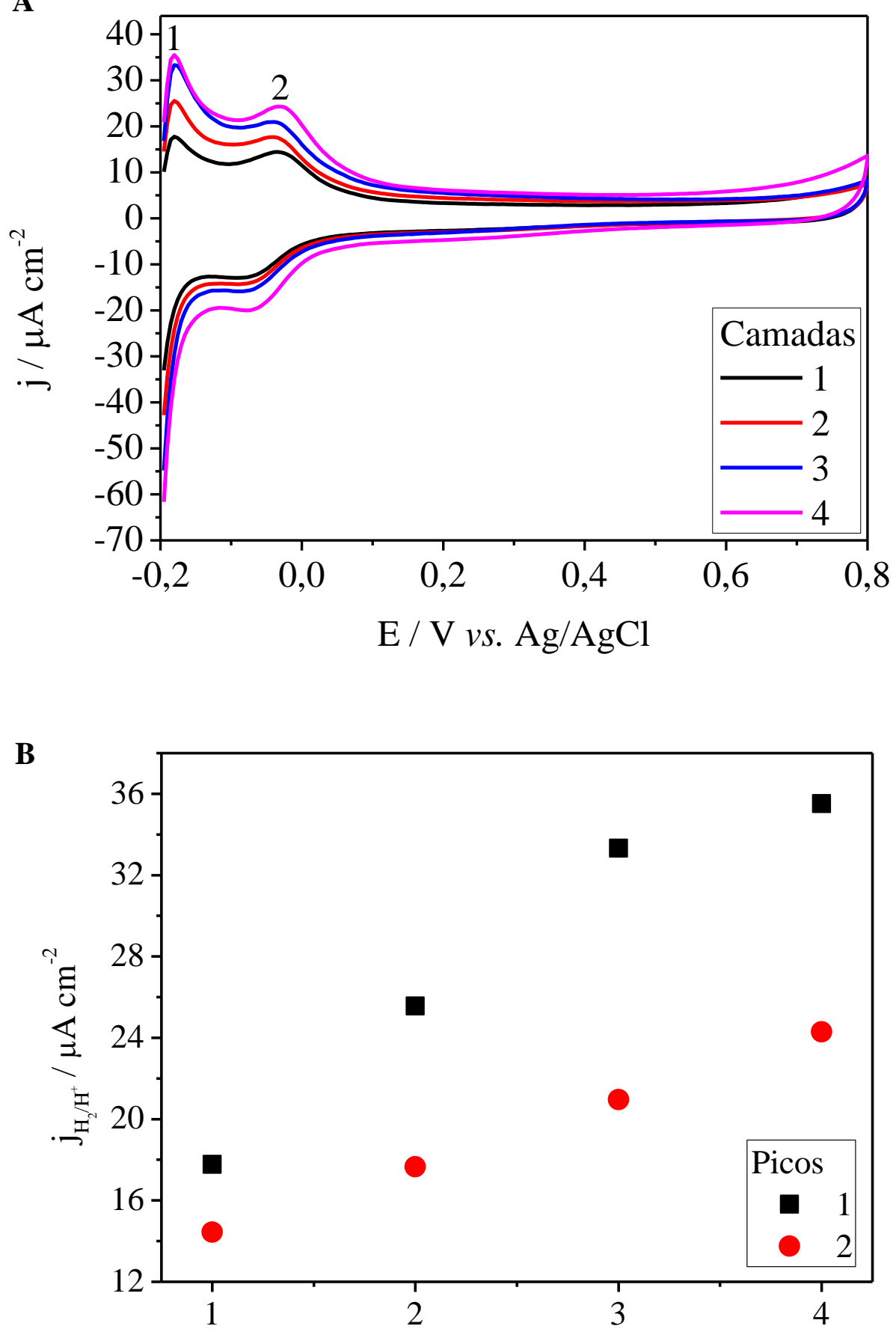

Número de camadas 
A tabela 3 é uma síntese dos resultados apresentados até agora, onde na coluna 1 temos a descrição dos eletrodos estudados. Pode-se observar que de todos os eletrodos avaliados, o que apresenta melhor desempenho é o eletrodo de ITO com uma camada de PAMAM-Pt, com tratamento eletroquímico entre as imersões. Este apresenta densidade de corrente 3 vezes maior que o eletrodo com tratamento eletroquímico após confecção e 5 vezes maior que o mesmo eletrodo sem tratamento eletroquímico. Com relação à resistência à transferência de carga, observam-se as mesmas relações.

Tabela 3 - Correntes de pico e resistência à transferência de carga para a reação de oxidação do hidrogênio adsorvido nos eletrodos ITO/(PAMAM-Pt) $)_{\mathrm{n}}$, e tempo de confecção destes eletrodos.

\begin{tabular}{lccc}
\hline \multicolumn{1}{c}{$\boldsymbol{I T O} /(\boldsymbol{P A M A M - P t})_{n}$} & $\boldsymbol{j}_{\boldsymbol{H}_{2} \mathbf{H}^{+}}\left(\boldsymbol{\mu A} \mathbf{c m}^{-2}\right)$ & $\boldsymbol{R}_{\boldsymbol{T C}}(\boldsymbol{\Omega})$ & Tempo preparo do eletrodo \\
\hline 1 sem trat & 10,48 & 21,03 & $7 \mathrm{~min}$ \\
1 com trat após confecção & 17,78 & 7,384 & $22 \mathrm{~min}$ \\
1 com trat entre imersões & 52,6 & 4,518 & $1 \mathrm{~h} \mathrm{e} 22 \mathrm{~min}$ \\
\hline 2 com trat após confecção & 11,82 & 7,687 & $49 \mathrm{~min}$ \\
2 com trat entre camadas & 25,6 & 4,851 & $1 \mathrm{~h} \mathrm{e} 4 \mathrm{~min}$ \\
\hline 3 com trat após confecção & 8,04 & 9,183 & $1 \mathrm{~h} \mathrm{e} 16 \mathrm{~min}$ \\
3 com trat entre camadas & 33,4 & 7,896 & $1 \mathrm{~h} \mathrm{e} 46 \mathrm{~min}$ \\
\hline 4 com trat após confecção & 2,82 & 12,91 & $1 \mathrm{~h} \mathrm{e} 43 \mathrm{~min}$ \\
4 com trat entre camadas & 35,6 & 8,47 & $2 \mathrm{~h} \mathrm{e} 28 \mathrm{~min}$ \\
\hline
\end{tabular}


Nas Figuras 28, 29 e 30, dá-se ênfase a influencia do tratamento eletroquímico na resposta eletroquímica dos eletrodos de ITO com 1, 2, 3 e 4 camadas de PAMAM-Pt.

$\mathrm{Na}$ Figura 28 tem-se a relação entre a área eletroativa dos eletrodos ITO/(PAMAM-Pt $)_{n}$ e o tratamento eletroquímico. A área eletroativa foi calculada de forma análoga à utilizada para eletrodos de platina. A partir dos voltamogramas dos eletrodos ITO/(PAMAM-Pt $)_{n}$ calculou-se a área eletroativa integrando-se a região de dessorção de hidrogênio. Para os cálculos, considera-se que a oxidação de uma monocamada de hidrogênio nessa região gera uma carga de $210 \mu \mathrm{C} \mathrm{cm}^{-279}$.

Podemos observar que o eletrodo ITO/(PAMAM-Pt $)_{1}$, com tratamento eletroquímico entre as imersões, é o que apresenta maior área eletroativa, maior número de sítios disponíveis para a reação de oxidação do hidrogênio adsorvido. Com relação ao número de camadas, temos que a área eletroativa aumenta com o número de camadas para os eletrodos submetidos a tratamento eletroquímico entre as camadas, e diminui para os eletrodos submetidos a tratamento eletroquímico apenas após a confecção.

Figura 28 - Área eletroativa dos eletrodos ITO/(PAMAM-Pt) em função do tratamento eletroquímico.

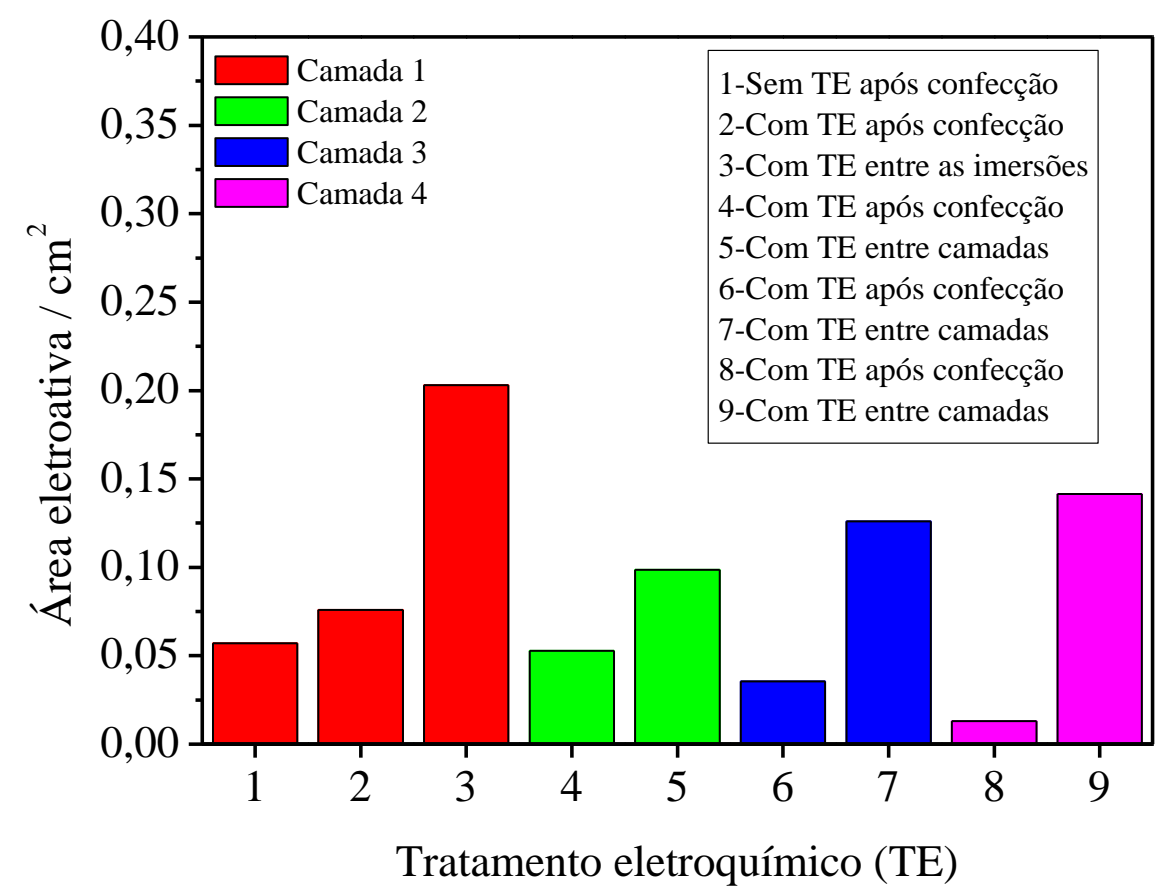


Na Figura 29 tem-se a relação entre a resistência à transferência de carga dos eletrodos ITO/(PAMAM-Pt $)_{n}$ e o tratamento eletroquímico. O eletrodo ITO/(PAMAM-Pt $)_{1}$, com tratamento eletroquímico entre as imersões, é o que apresenta menor resistência à transferência de carga, seguido pelo eletrodo ITO/(PAMAM-Pt) ${ }_{2}$ com tratamento eletroquímico entre as camadas. $\mathrm{A}_{\mathrm{tc}}$ aumenta com o número de camadas e os eletrodos submetidos a tratamento apresentam as menores $\mathrm{R}_{\mathrm{tc}}$.

Figura 29 - Resistência à transferência de carga, nos eletrodos ITO/(PAMAM-Pt) , para a reação de oxidação do hidrogenio adsorvido em função do tratamento eletroquímico.

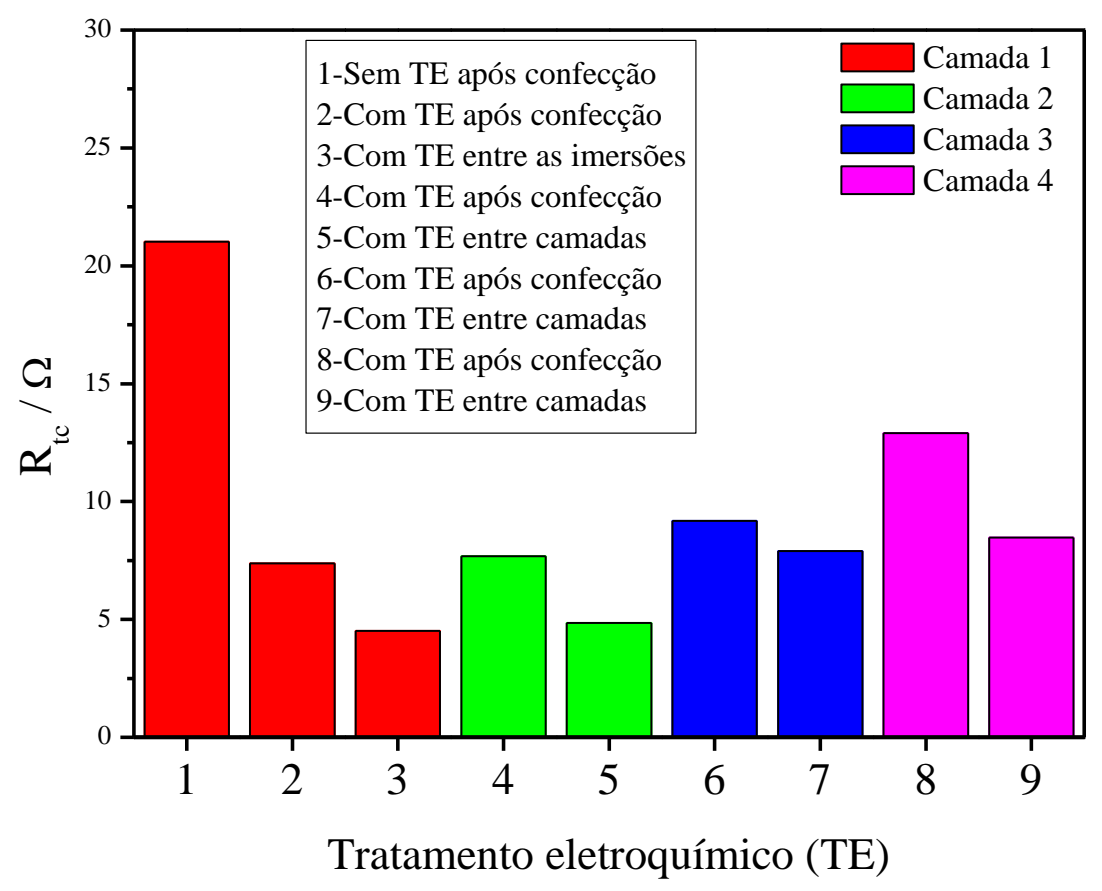


$\mathrm{Na}$ Figura 30, tem-se a relação entre a densidade de corrente dos eletrodos ITO/(PAMAM-Pt $)_{n}$ e o tratamento eletroquímico. O eletrodo ITO/(PAMAM-Pt $)_{1}$, com tratamento eletroquímico entre as imersões, é o que apresenta maior densidade de corrente para a reação de oxidação do hidrogênio adsorvido. A densidade de corrente aumenta com o número de camadas para os eletrodos submetidos a tratamento entre camadas, e diminui com o numero de camadas, para os eletrodos submetidos a tratamento eletroquímico após confecção.

Figura 30 - Correntes de pico, dos eletrodos ITO/(PAMAM-Pt) $)_{\mathrm{n}}$, para a reação de oxidação do hidrogenio adsorvido em função do tratamento eletroquímico.

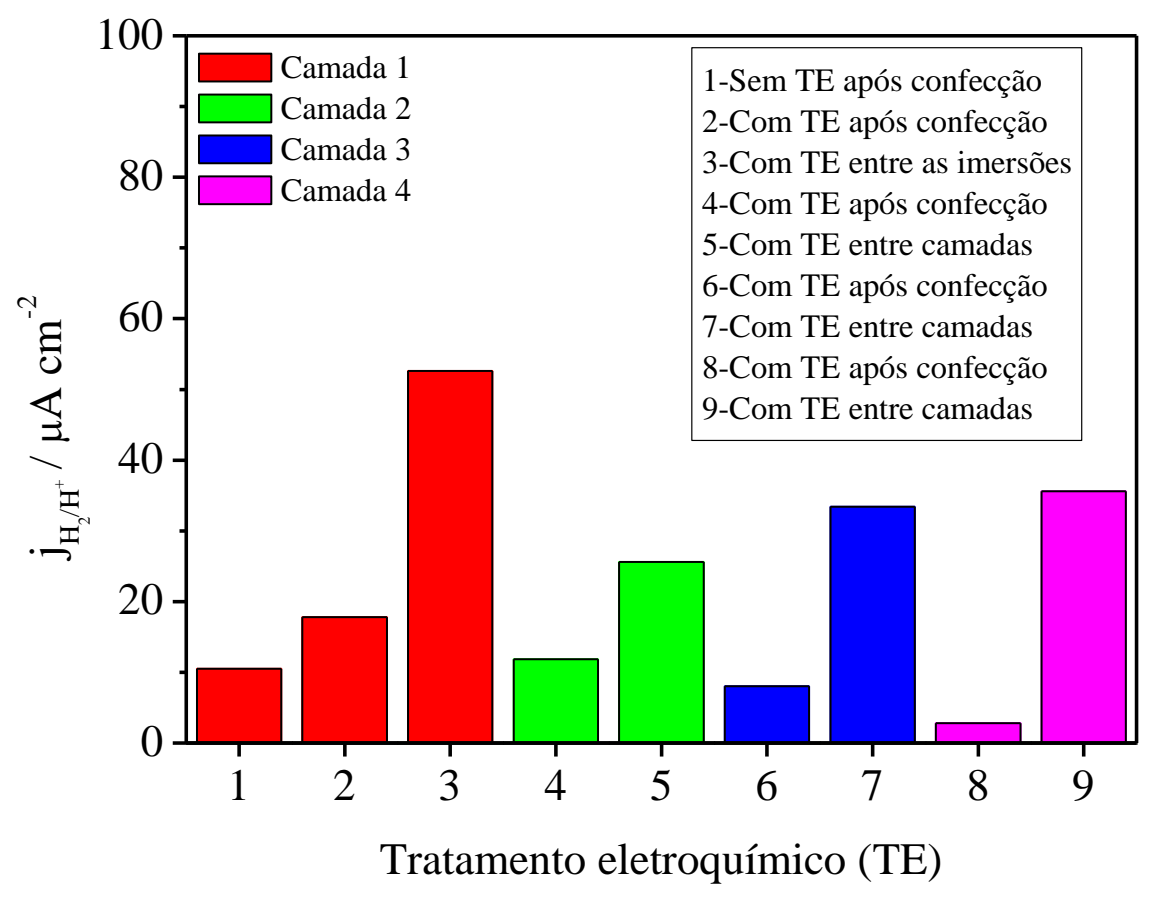

Os dados mostrados até aqui demonstram que as camadas de PAMAM-Pt, adsorvidas sobre o eletrodo de ITO, apresentam boa estabilidade, e que a resposta eletroquímica em termos de intensidade de corrente, resistência à transferência de carga e definição de picos voltamétricos pode ser otimizada mediante o tratamento eletroquímico. Além disso, é possível preparar um eletrodo com ótimo desempenho com apenas uma camada de PAMAM-Pt ativada eletroquimicamente, sem a necessidade de uma membrana com várias camadas. $\mathrm{O}$ eletrodo que será utilizado em todos os estudos feitos a partir daqui é o eletrodo ITO/(PAMAM-Pt $)_{1}$ com tratamento eletroquímico entre as imersões, cuja nomenclatura será ITO/PAMAM-Pt. 


\subsubsection{Transferência de carga no eletrodo ITO/PAMAM-Pt}

A Figura 31-A mostra os voltamogramas para o eletrodo ITO/PAMAM-Pt na janela de potencial utilizada até o momento, - $-0,2$ a 0,8 V. Quando abrimos essa janela de potencial para 1,2 V, a mesma utilizada para o eletrodo de Pt, obtemos os voltamogramas da Figura 31-B, onde para o eletrodo ITO/PAMAM-Pt, temos definidas as regiões adsorção/dessorção de hidrogênio, bem como a região de formação e redução do óxido de Pt. Isso evidencia que as nanopartículas de Pt estão fortemente imobilizadas na superfície do eletrodo e que os sítios eletroquímicos estão muito acessíveis para as reações de oxidação e redução. Voltamograma semelhante ao da Figura 31-B foi obtido por Crooks e colaboradores ${ }^{80}$ com NPsPt encapsuladas em PAMAM G6.0-OH imobilizadas sobre um eletrodo de carbono vítreo. 
Figura 31 - Voltamogramas cíclicos (10 ciclos) para o eletrodo ITO/PAMAM-Pt em $\mathrm{H}_{2} \mathrm{SO}_{4} 0,1$ mol L ${ }^{-1}$, saturado com $\mathrm{N}_{2}$. Velocidade de varredura de $0,1 \mathrm{~V} \mathrm{~s}^{-1}$.

A

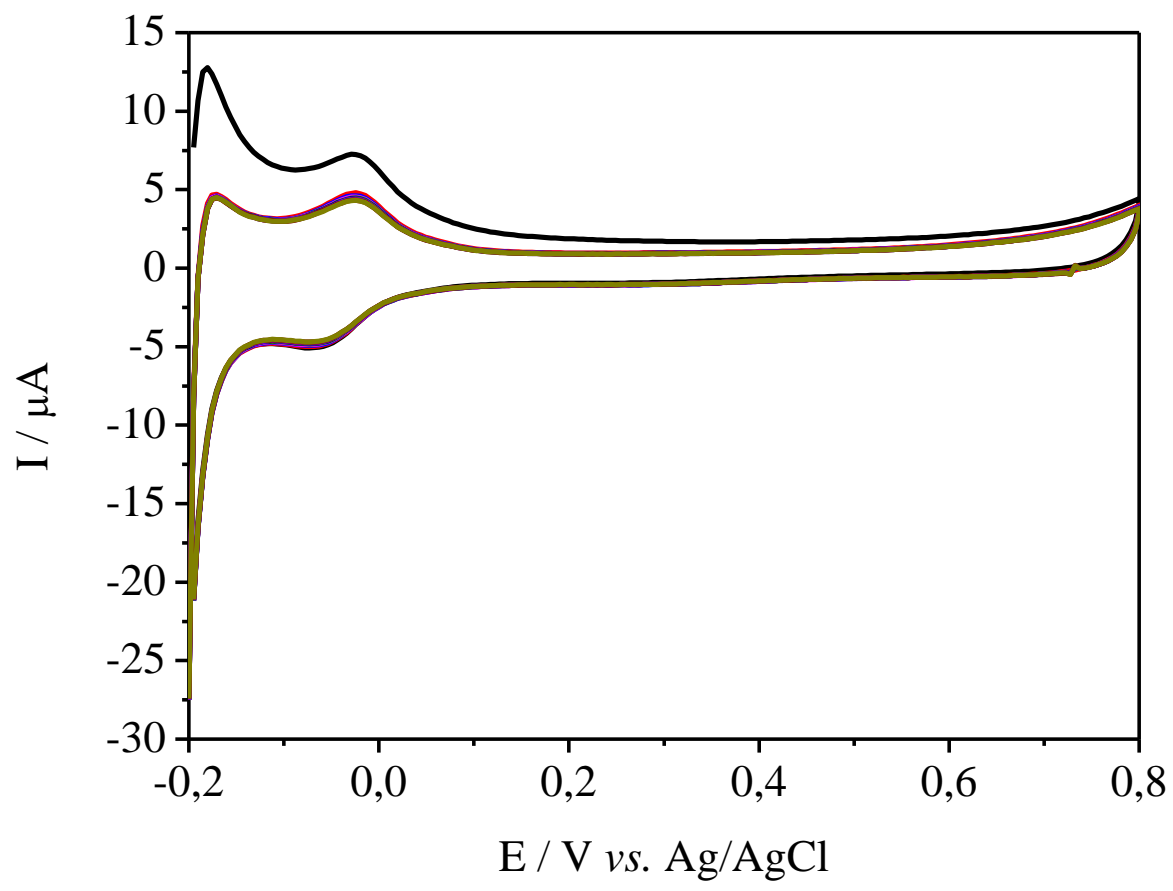

B

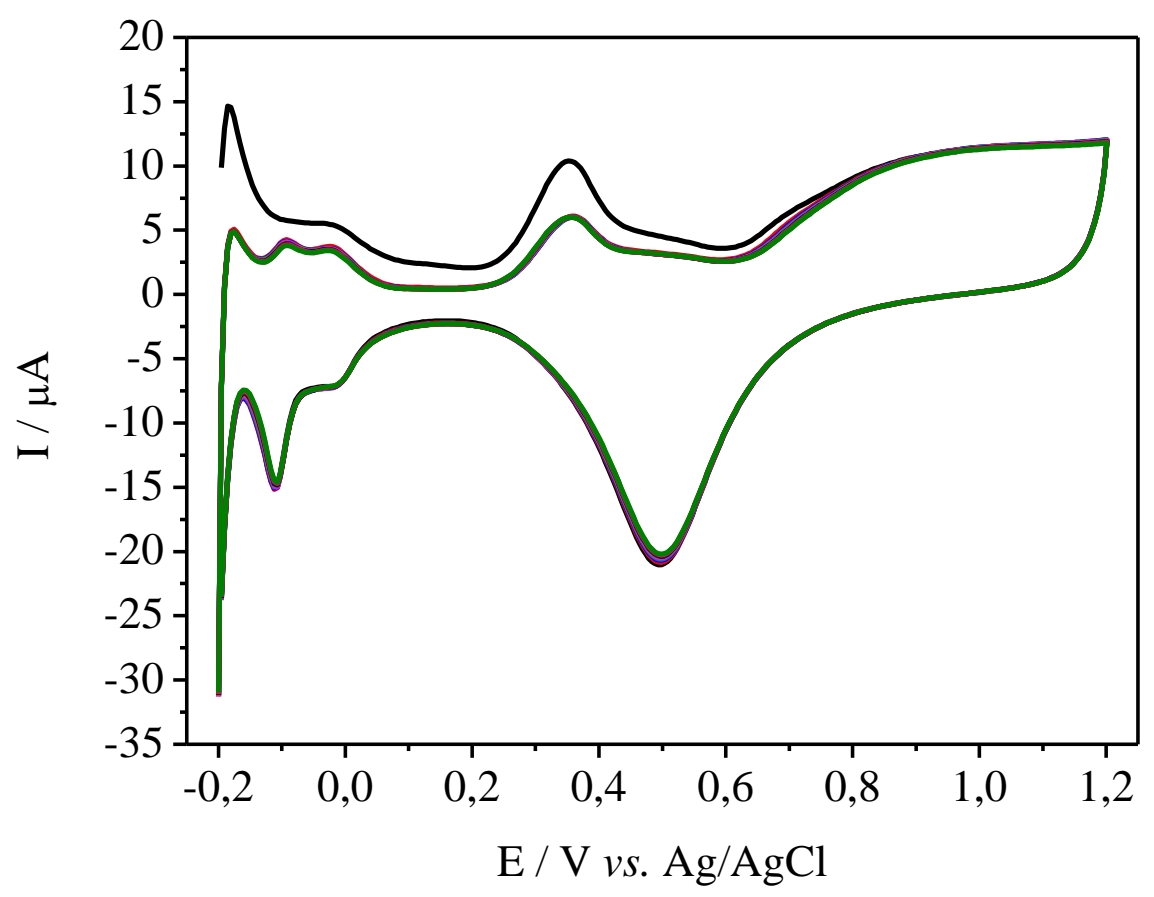

O eletrodo ITO/PAMAM-Pt foi submetido à varredura de potenciais em diferentes velocidades de varredura, e pode-se observar na Figura 32-B que as correntes de pico para a reação de oxidação do hidrogênio adsorvido aumentam linearmente com a velocidade de varredura, indicando que a reação é limitada por transporte de carga. 
Figura 32 - (A) e (C) Voltamogramas cíclicos do eletrodo ITO/PAMAM-Pt nas velocidades de varredura de 10, $25,50,75,100,150,200,250,300,400,500,600,700,800,900$ e $1000 \mathrm{mV} \mathrm{s}^{-1}$. Eletrólito $\mathrm{H}_{2} \mathrm{SO}_{4} 0,1 \mathrm{~mol} \mathrm{~L}^{-1}$, saturado com $\mathrm{N}_{2}$. (B) Variação das correntes de pico anódica e catódica, dos voltamogramas da Figura A, em função da velocidade de varredura.

A

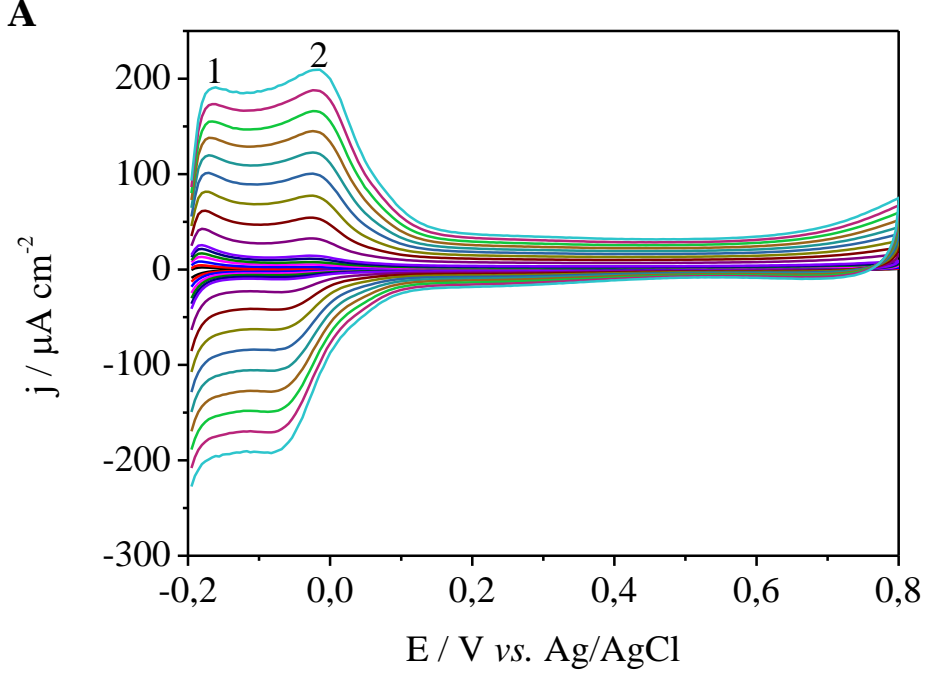

B
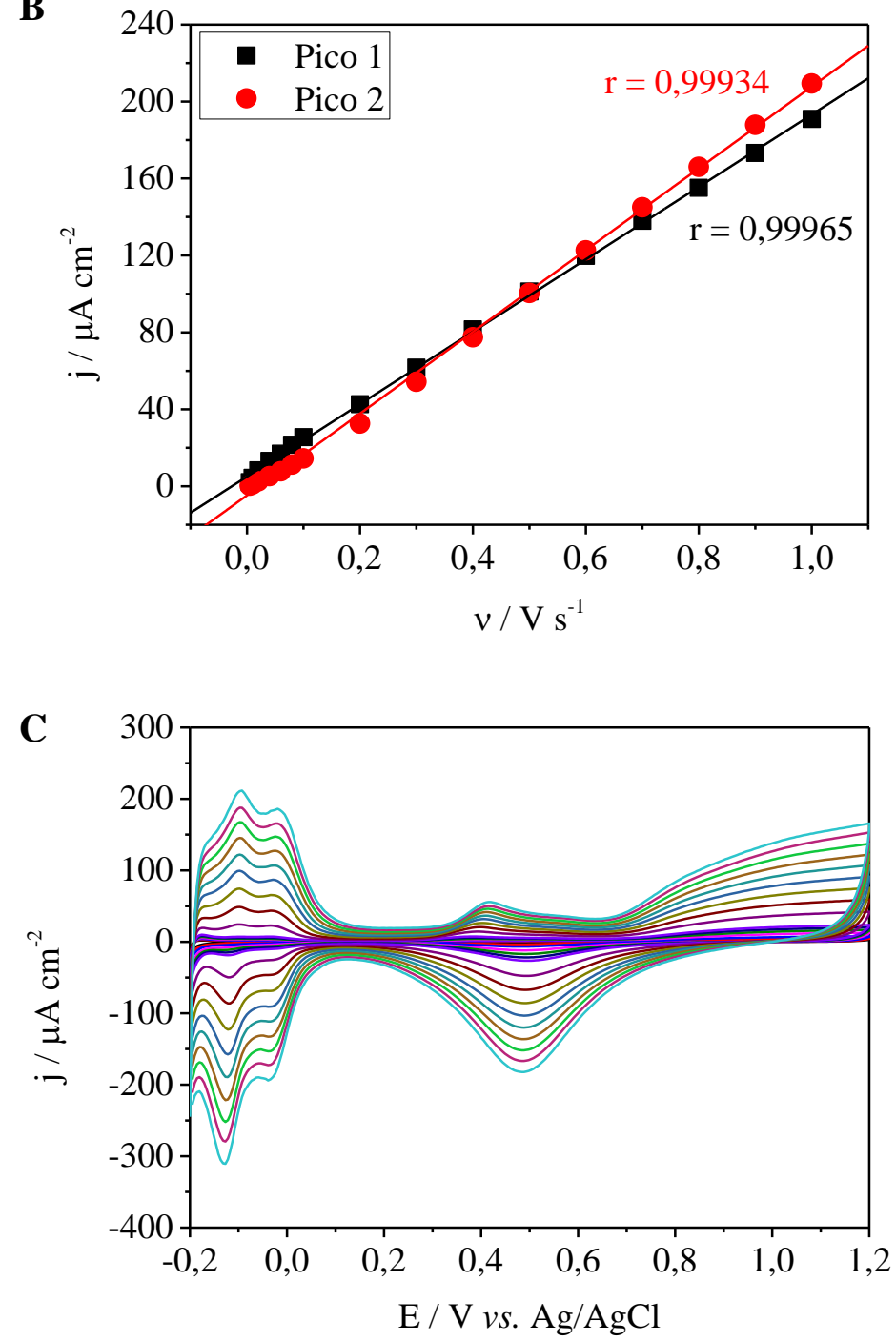
O comportamento eletroquímico do eletrodo ITO/PAMAM-Pt foi avaliado com uma espécie eletroativa em solução, o cloreto de hexaminrutênio (II) e (III). O eletrodo ITO/PAMAM-Pt foi submetido à varredura de potenciais em diferentes velocidades de varredura, e pode-se observar na Figura 33 que as correntes de pico anódica e catódica aumentam linearmente com a raiz quadrada velocidade de varredura, indicando, como esperado para as espécies $\left[\mathrm{Ru}\left(\mathrm{NH}_{3}\right)_{6}\right]^{2+} /\left[\mathrm{Ru}\left(\mathrm{NH}_{3}\right)_{6}\right]^{3+}$, reações eletroquímicas limitadas por difusão.

Figura 33 - Voltamogramas cíclicos do eletrodo de ITO-PAMAM-Pt nas velocidades de varredura de 10, 25, $50,75,100,150,200,250,300,400,500,600,700,800,900$ e $1000 \mathrm{mV} \mathrm{s}^{-1}$ em solução de $\left[\mathrm{Ru}\left(\mathrm{NH}_{3}\right)_{6}\right]^{2+} /\left[\mathrm{Ru}\left(\mathrm{NH}_{3}\right)_{6}\right]^{3+} 3,0 \mathrm{mmol} \mathrm{L}{ }^{-1}$. Eletrólito $\mathrm{H}_{2} \mathrm{SO}_{4} 0,1 \mathrm{~mol} \mathrm{~L}^{-1}$, saturado com $\mathrm{N}_{2}$. Inserido: correntes de pico anódica e catódica em função da raiz quadrada da velocidade de varredura.

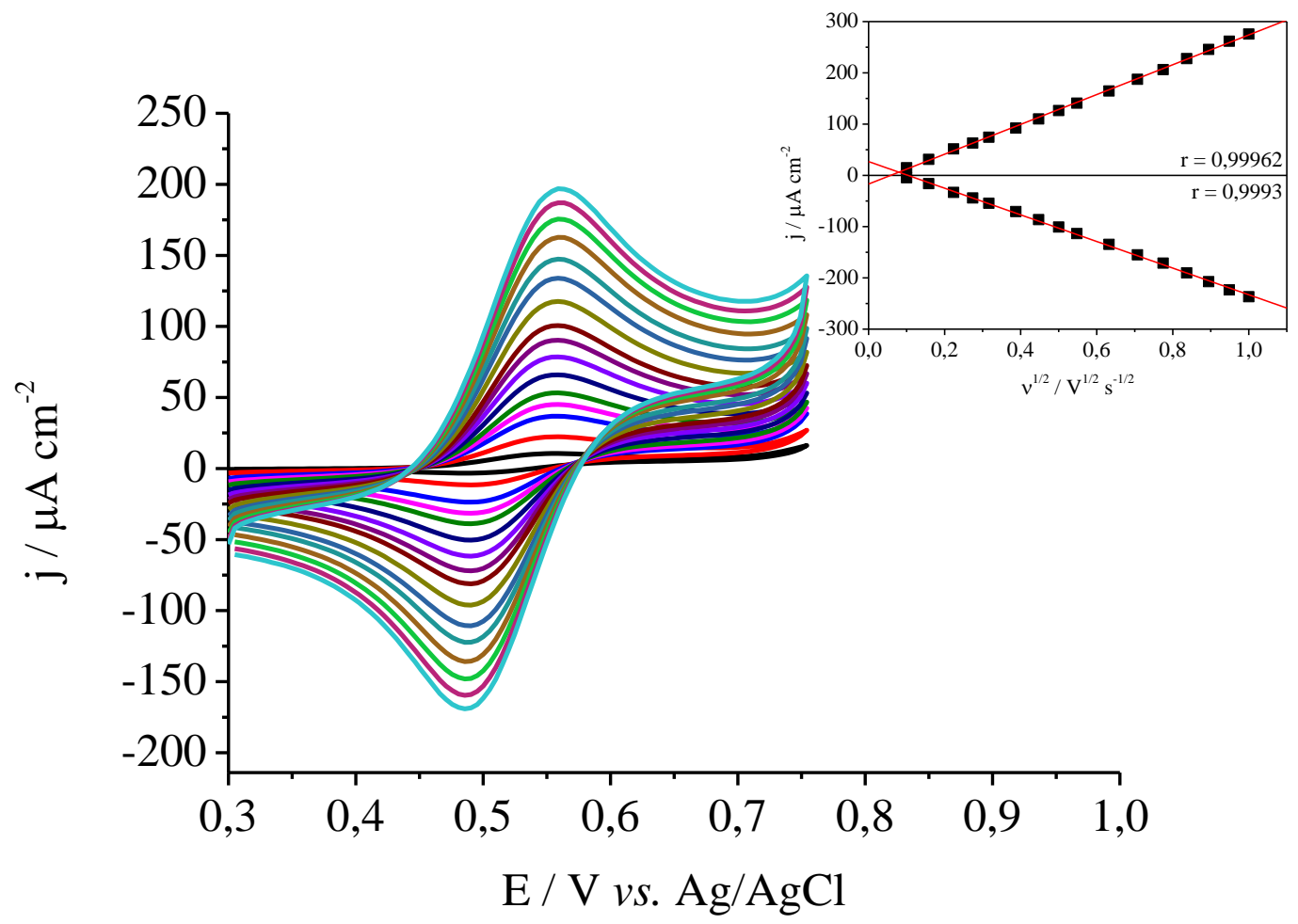

\subsection{Eletroquímica do citocromo $\mathrm{C}$}

A eletroquímica do citocromo $\mathrm{C}$ foi estudada com os eletrodos ITO/PAMAM e ITO/PAMAM-Pt. Inicialmente os eletrodos ITO, ITO-PAMAM e ITO/PAMAM-Pt foram caracterizados em eletrólito tampão fosfato, $5 \mathrm{mmol} \mathrm{L}{ }^{-1}, \mathrm{pH}$ 7,0. Nos voltamogramas das Figuras 34-A e 34-B podemos observar a ausência de processos redox para os eletrodos ITO e ITO-PAMAM. Na Figura 34-C temos o voltamograma para o 
eletrodo ITO/PAMAM-Pt, e inserido, o voltamograma do eletrodo de Pt no mesmo eletrólito, onde podemos observar as regiões de adsorção/dessorção de hidrogênio e a região de formação e redução do óxido de Pt.

Figura 34 - Voltamogramas cíclicos (10 ciclos) para os eletrodos (A) ITO, (B) ITO/PAMAM e (C) ITO/PAMAM-Pt em TF 5,0 mmol L $\mathrm{L}^{-1}, \mathrm{pH} 7,0$, saturado com $\mathrm{N}_{2}$. Inserido: Voltamograma do eletrodo de Pt em TF 5,0 mmol L ${ }^{-1}$, pH 7,0, saturado com $\mathrm{N}_{2}$. Velocidade de varredura de $0,1 \mathrm{~V} \mathrm{~s}^{-1}$.
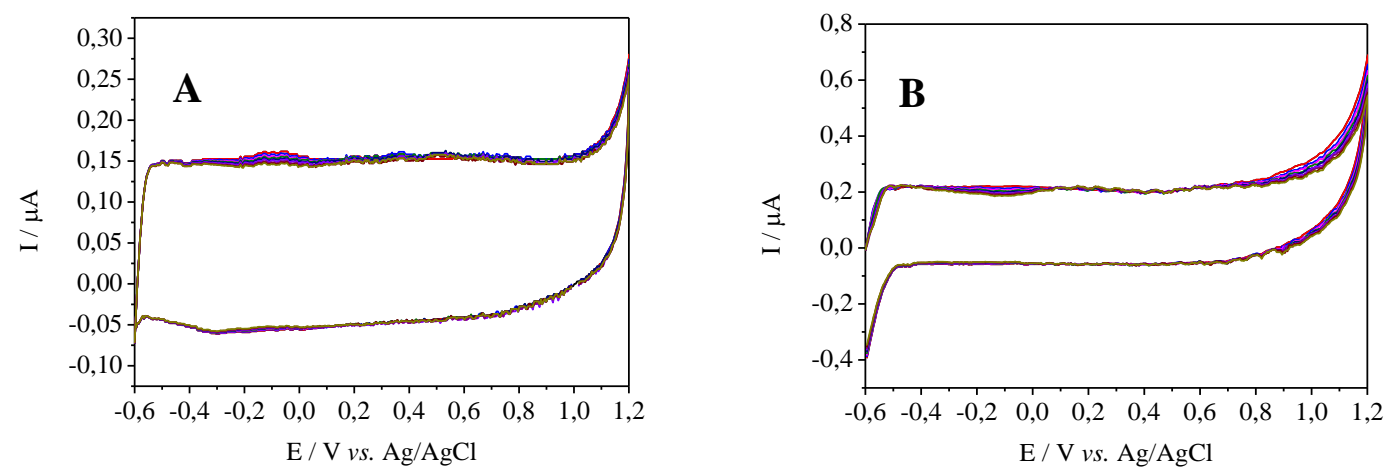

C

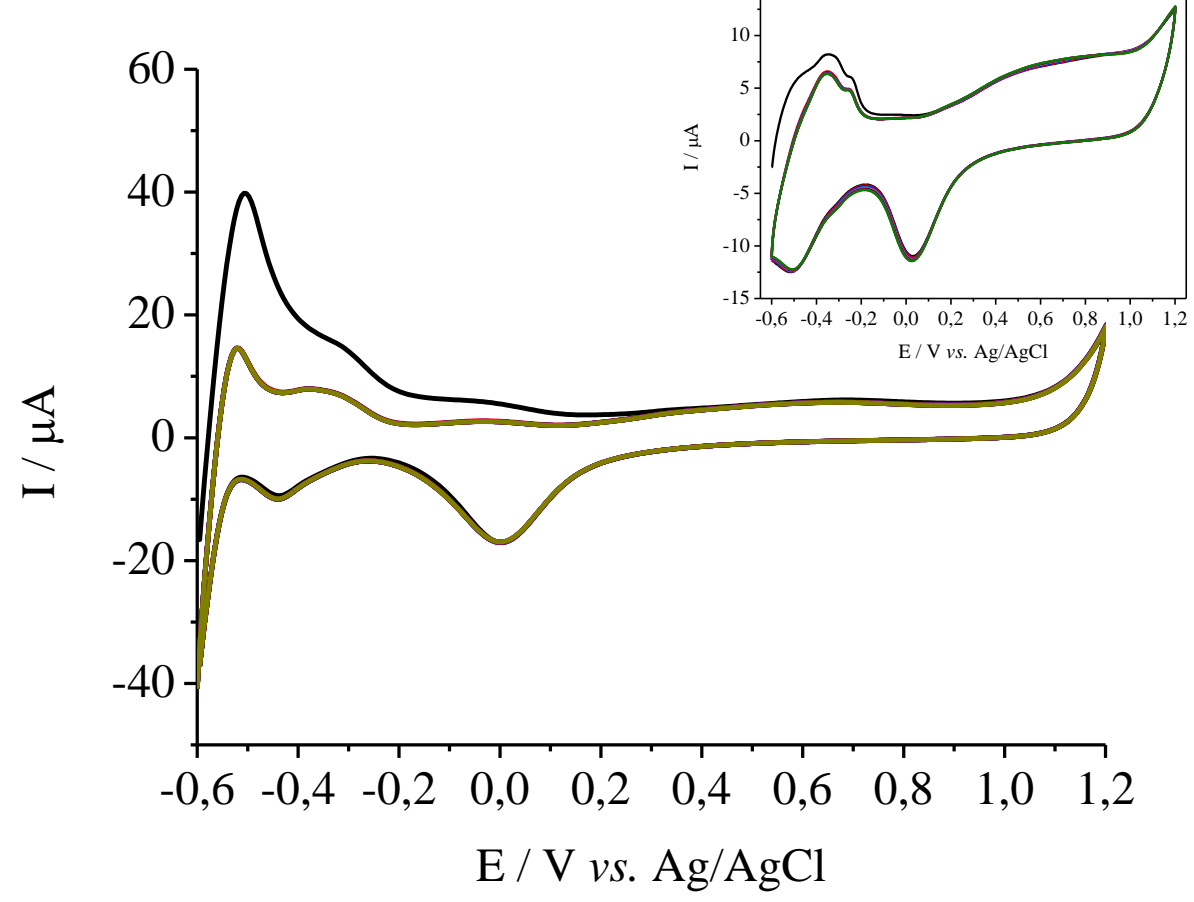

O par redox $\left[\mathrm{Fe}(\mathrm{CN})_{6}\right]^{3-/} /\left[\mathrm{Fe}(\mathrm{CN})_{6}\right]^{4-}$ foi o utilizado para avaliar a performance dos eletrodos ITO, ITO-PAMAM e ITO/PAMAM-Pt que foram submetidos à varredura de potenciais em diferentes velocidades de varredura, e pode-se observar nas Figuras 35, 36 e 37 que as correntes de pico anódica e catódica aumentam linearmente com a raiz quadrada velocidade de varredura, indicando, como esperado para as espécies $\left[\mathrm{Fe}(\mathrm{CN})_{6}\right]^{3-} /\left[\mathrm{Fe}(\mathrm{CN})_{6}\right]^{4-}$, reações eletroquímicas limitadas por difusão. 
Figura 35 - Voltamogramas cíclicos do eletrodo ITO nas velocidades de varredura de 10, 25, 50, 75, 100, 150, 200, 250 e $300 \mathrm{mV} \mathrm{s}^{-1}$, em solução de $\mathrm{K}_{4}\left[\mathrm{Fe}(\mathrm{CN})_{6}\right]$ 3,0 $\mathrm{mmol} \mathrm{L}^{-1}$. Eletrólito TF 5,0 mmol L-1, pH 7,0, saturado com $\mathrm{N}_{2}$. Inserido: correntes de pico anódica e catódica em função da raiz quadrada da velocidade de varredura.

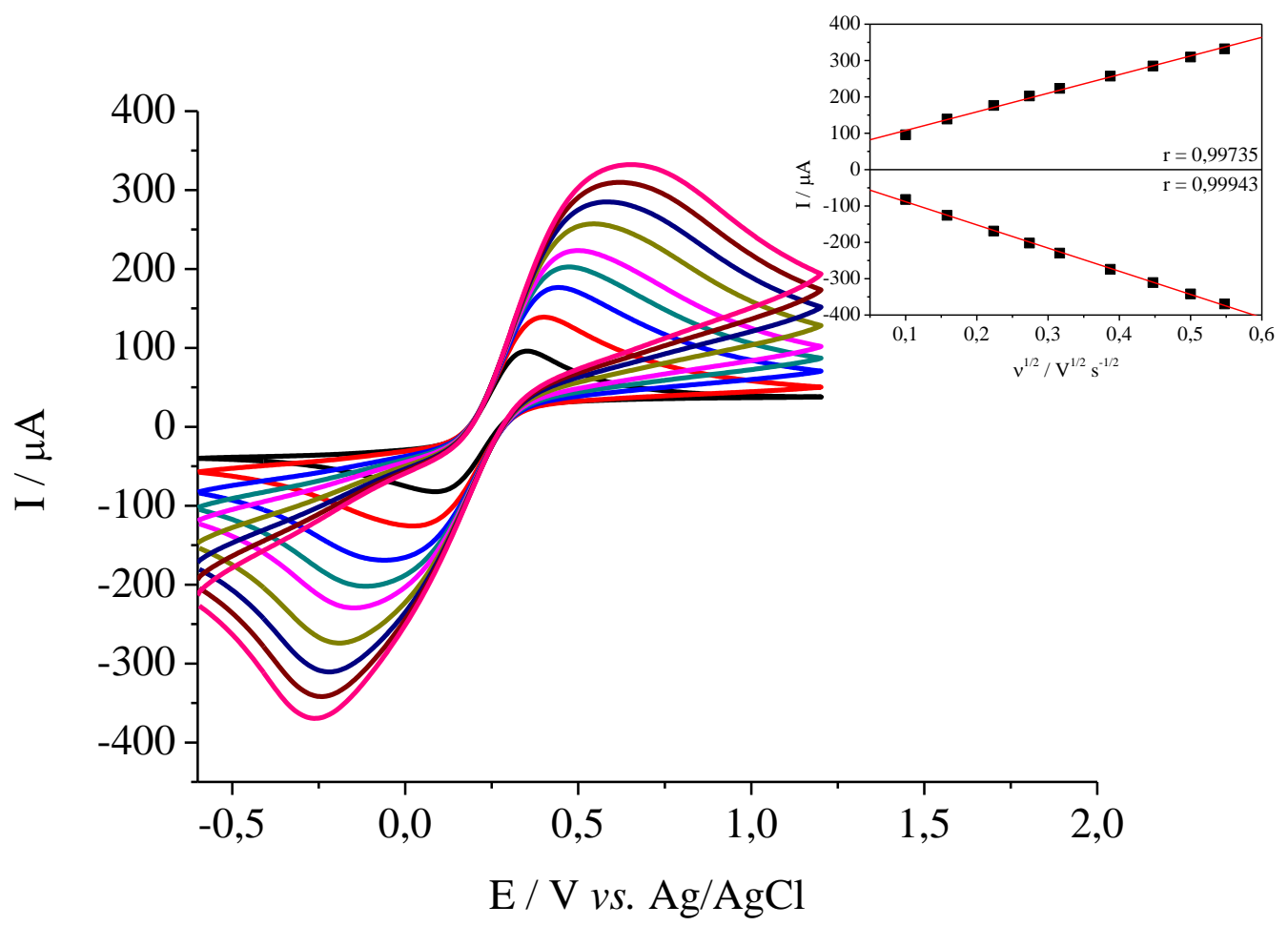


Figura 36 - Voltamogramas cíclicos do eletrodo ITO/PAMAM nas velocidades de varredura de 10, 25, 50, 75, $100,150,200,250$ e $300 \mathrm{mV} \mathrm{s}^{-1}$, em solução de $\mathrm{K}_{4}\left[\mathrm{Fe}(\mathrm{CN})_{6}\right] 3,0 \mathrm{mmol} \mathrm{L}^{-1}$. Eletrólito TF $5,0 \mathrm{mmol} \mathrm{L}^{-1}, \mathrm{pH} \mathrm{7,0,}$ saturado com $\mathrm{N}_{2}$. Inserido: correntes de pico anódica e catódica em função da raiz quadrada da velocidade de varredura.

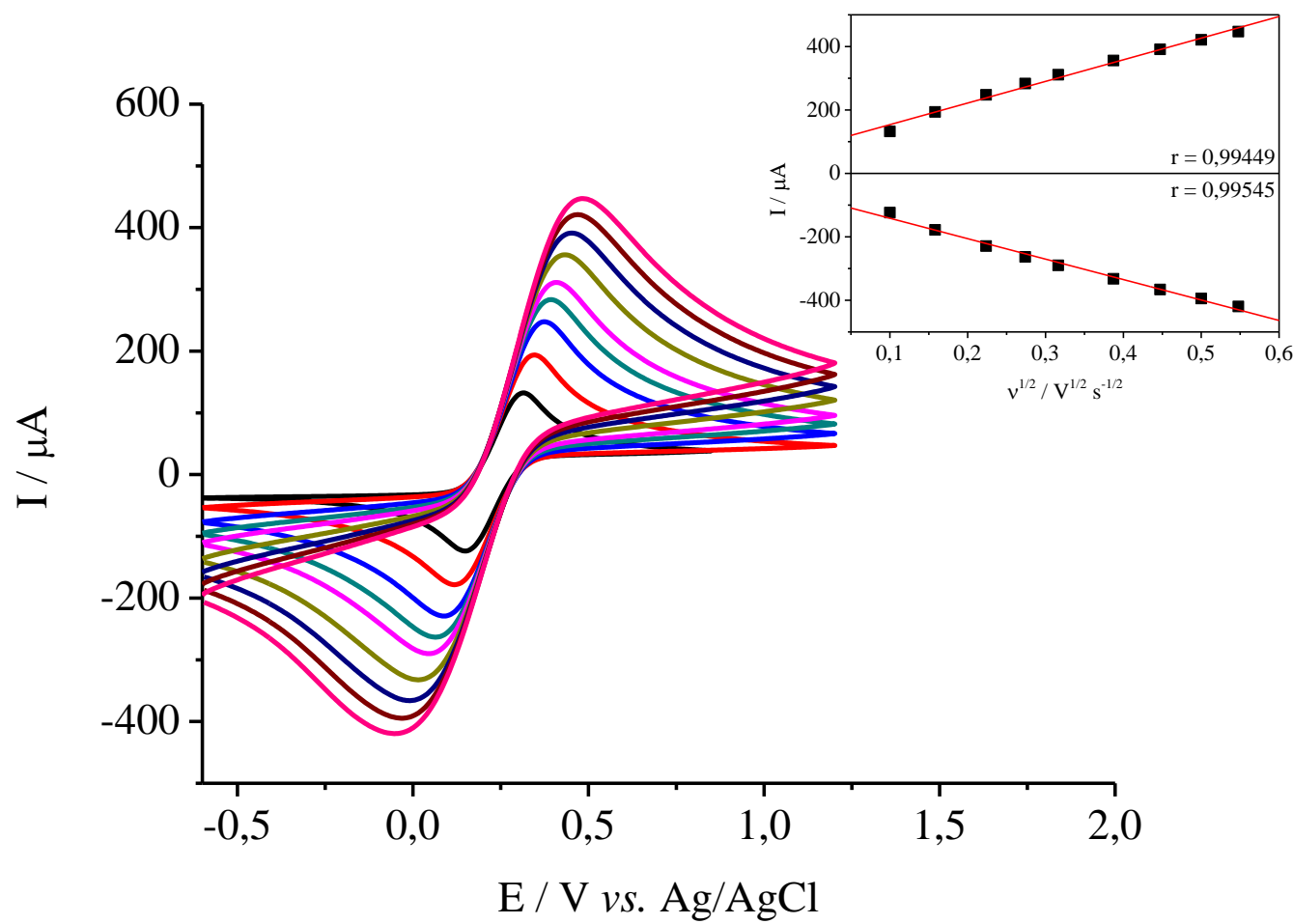

Figura 37 - Voltamogramas cíclicos do eletrodo ITO/PAMAM-Pt nas velocidades de varredura de 10, 25, 50, $75,100,150,200,250$ e $300 \mathrm{mV} \mathrm{s}^{-1}$, em solução de $\mathrm{K}_{4}\left[\mathrm{Fe}(\mathrm{CN})_{6}\right] 3,0 \mathrm{mmol} \mathrm{L}^{-1}$. Eletrólito TF 5,0 mmol L ${ }^{-1}$, pH 7,0, saturado com $\mathrm{N}_{2}$. Inserido: correntes de pico anódica e catódica em função da raiz quadrada da velocidade de varredura.

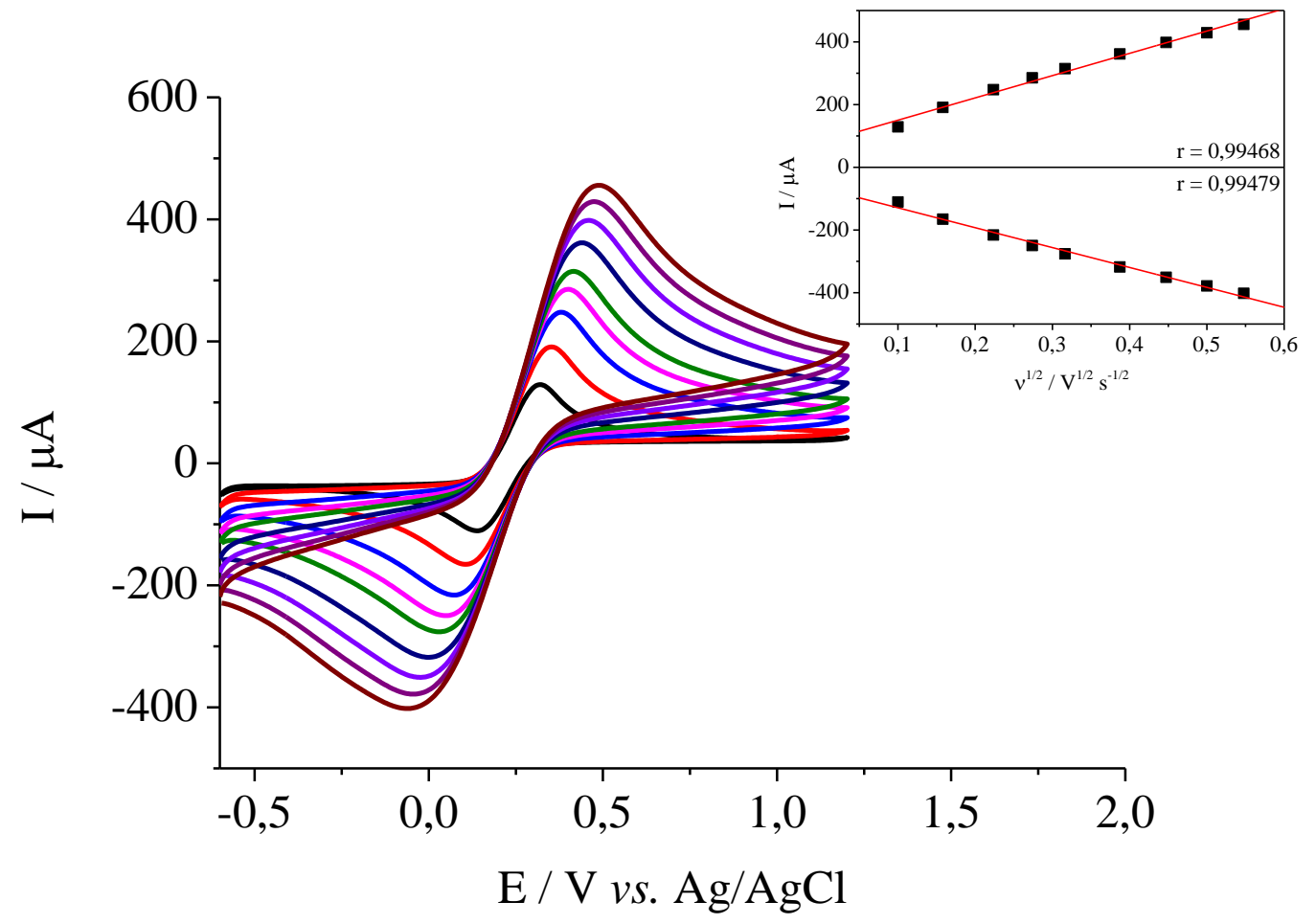


Os eletrodos ITO, ITO/PAMAM e ITO/PAMAM-Pt foram também caracterizados por EIS e na Figura 38 temos os espectros de impedância no plano complexo, obtidos OCP. O circuito equivalente utilizado no fitting dos espectros no plano complexo é o circuito de Randles, inserido na Figura 38, onde $\mathrm{R}_{\Omega}$ é a resistência da solução, $\mathrm{R}_{\mathrm{tc}}$ a resistência à transferência de carga, $\mathrm{Z}_{\mathrm{w}}$ a impedância de Warburg e $\mathrm{Cp}$ a capacitância da dupla camada. De acordo com os dados obtidos pelo fitting dos espectros, o eletrodo ITO/PAMAM-Pt é o que apresenta menor $R_{t c}$, 240,5 $\Omega$, seguido pelo eletrodo ITO/PAMAM que apresentou $R_{t c}$ de $262,9 \Omega$, valores de $\mathrm{R}_{\mathrm{tc}}$ cerca de 3 vezes menores que o apresentado pelo eletrodo ITO, 686,4 $\Omega$. Indicando que a interação entre a probe do par redox $\left[\mathrm{Fe}(\mathrm{CN})_{6}\right]^{3-} /\left[\mathrm{Fe}(\mathrm{CN})_{6}\right]^{4-}$ e o PAMAM facilita a transferência eletrônica para a reação redox dessas espécies.

Figura 38 - Espectros de impedância no plano complexo obtidos em OCP em solução de $\left[\mathrm{Fe}(\mathrm{CN})_{6}\right]^{3-} /\left[\mathrm{Fe}(\mathrm{CN})_{6}\right]^{4-} 3,0 \mathrm{mmol} \mathrm{L}{ }^{-1}$ em TF 5,0 mol L-1 $\mathrm{pH} \mathrm{7,0,} \mathrm{saturado} \mathrm{com} \mathrm{N}_{2}$. Variação de frequência de $100 \mathrm{kHz}$ a 0,1 Hz. Inserido: Circuito de Randles.

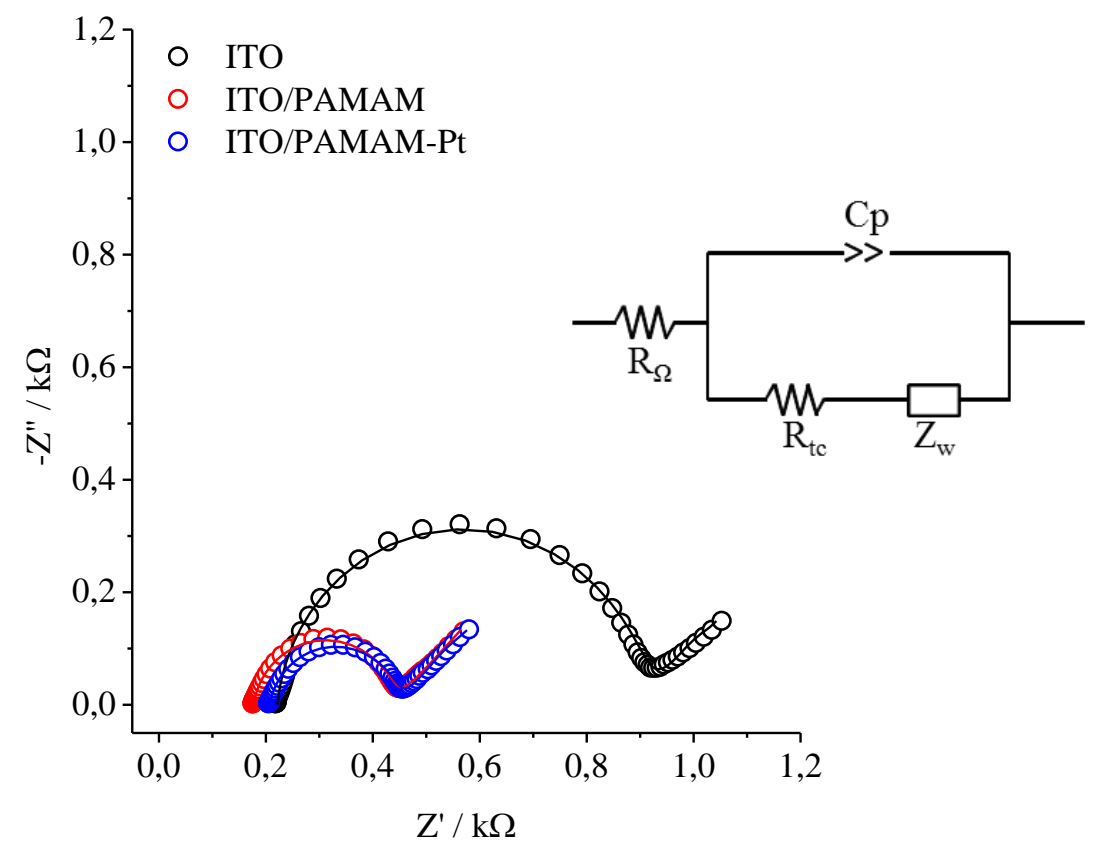

Após as caracterizações procedeu-se os estudos do citocromo C imobilizado sobre os eletrodos ITO/PAMAM e ITO/PAMAM-Pt.

O citocromo C é uma molécula aproximadamente esférica com diâmetro de 34 A. Com massa molecular de 11.703,5 $\mathrm{g} \mathrm{mol}^{-1}$ e ponto isoelétrico, pI, 9,52, é constituído por uma única cadeia polipeptídica de 105 resíduos de aminoácidos e possui em sua estrutura externa 18 resíduos de lisina positivamente carregados em $\mathrm{pH} 7,0^{81}$. 
A cisteína, um aminoácido cuja estrutura é apresentada na Figura 39, possui pI 5,07, estando carregada negativamente em $\mathrm{pH} 7,0^{56}$.

Figura 39 - Estrutura do aminoácido cisteína e os valores de pka de seus grupos funcionais.<smiles>N[C@@H](CS)C(=O)O</smiles>

$$
\begin{aligned}
& \mathrm{pk}_{\mathrm{a} 1}(-\mathrm{COOH})=1,96 \\
& \mathrm{pk}_{\mathrm{a} 2}\left(-\mathrm{NH}_{3}^{+}\right)=10,28 \\
& \mathrm{pk}_{\mathrm{a} 3}(-\mathrm{SH})=8,18
\end{aligned}
$$

Para que haja uma reação de transferência eletrônica eficiente entre o citocromo $\mathrm{C}$ e a superfície do eletrodo, o citocromo $\mathrm{C}$ deve estar imobilizado com uma orientação que minimize a distância entre o seu cofator eletroquimicamente ativo e a superfície do eletrodo. Esta orientação é obtida por interação eletrostática entre os resíduos de lisina do citocromo C, carregados positivamente, e o aminoácido cisteína, carregado negativamente, em pH 7,0. Como visto anteriormente, as aminas externas do PAMAM possuem pka 9,2, estando carregadas positivamente em $\mathrm{pH} 7,0$.

Desta forma, os eletrodos ITO/PAMAM e ITO/PAMAM-Pt, com suas superfícies positivas em $\mathrm{pH}$ 7,0 foram modificados, por interação eletrostática, com o aminoácido cisteína e em seguida com o citocromo C. Os eletrodos, assim obtidos, ITO/PAMAM/Cys/CytC e ITO/PAMAM-Pt/Cys/CytC foram utilizados no estudo da eletroquímica do citocromo $\mathrm{C}$.

A Figura 40 mostra os voltamogramas cíclicos dos eletrodos ITO/PAMAM/Cys e ITO/PAMAM/Cys/CytC onde observa-se, para o eletrodo ITO/PAMAM/Cys/CytC, um par de picos bem definidos e simétricos do processo redox do citocromo $\mathrm{C}$, com um $\Delta \mathrm{Ep}$ de $22 \mathrm{mV}$, indicando um processo eletroquímico reversível para a reação de transferência de elétrons direta entre o citocromo $\mathrm{C}$ e a superfície do eletrodo ITO/PAMAM. 
Figura 40 - Voltamogramas cíclicos em TF 5,0 $\mathrm{mmol} \mathrm{L}^{-1}, \mathrm{pH}$ 7,0, saturado com $\mathrm{N}_{2}$. Velocidade de varredura $0,1 \mathrm{~V} \mathrm{~s}^{-1}$.

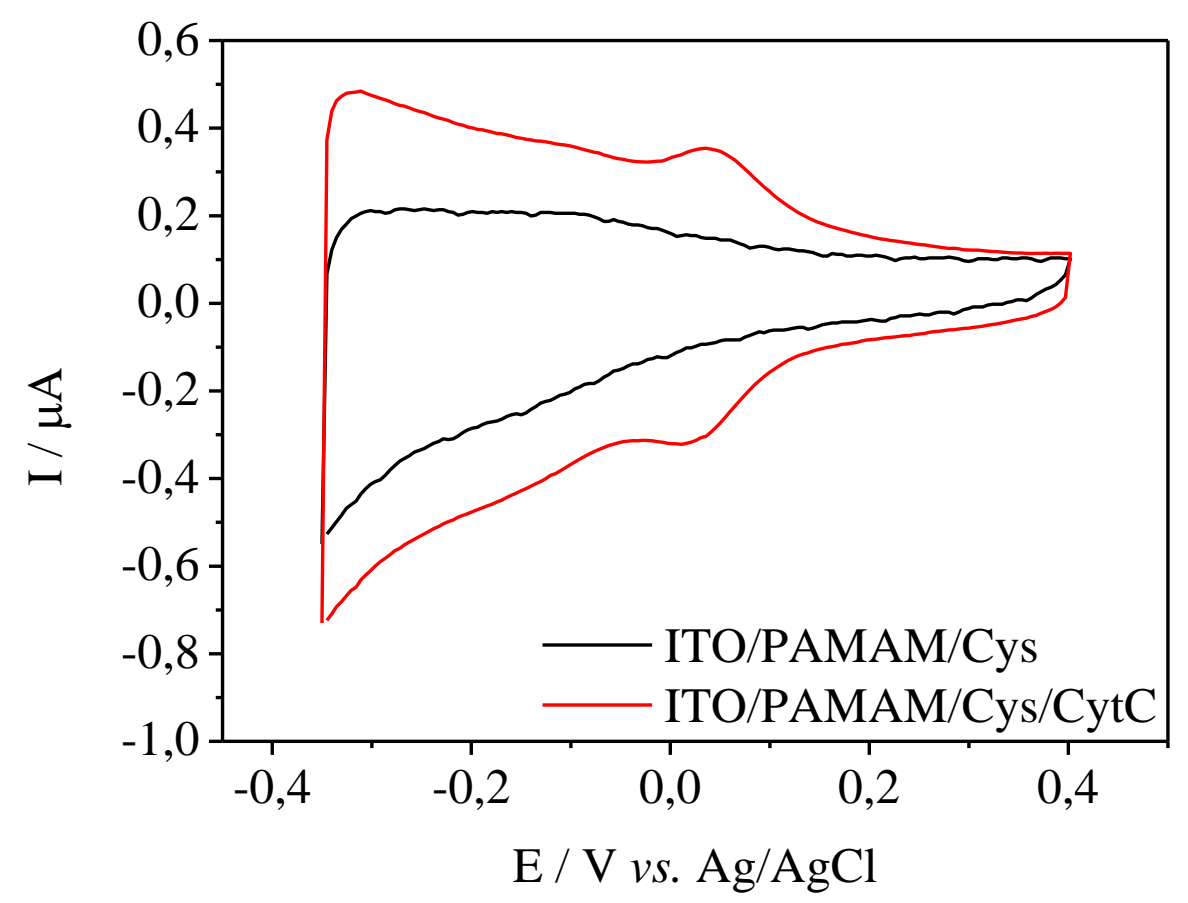

O eletrodo ITO/PAMAM/Cys/CytC foi submetido à varredura de potenciais em diferentes velocidades de varredura e os voltamogramas cíclicos são apresentados na Figura 41. Dos voltamogramas cíclicos obtiveram-se as correntes e potencias de pico de oxidação e redução do citocromo C e na Figura 42 observa-se que as correntes de pico anódica e catódica aumentam linearmente com a velocidade de varredura, indicando que a reação é limitada por transporte de carga, e que o $\Delta$ Ep também aumenta com o aumento da velocidade de varredura, indicando que a reversibilidade do processo redox do citocromo $\mathrm{C}$ é prejudicada. 
Figura 41 - Voltamogramas cíclicos do eletrodo ITO/PAMAM/Cys/CytC em TF 5,0 mmol L ${ }^{-1}$, pH 7,0, saturado com $\mathrm{N}_{2}$
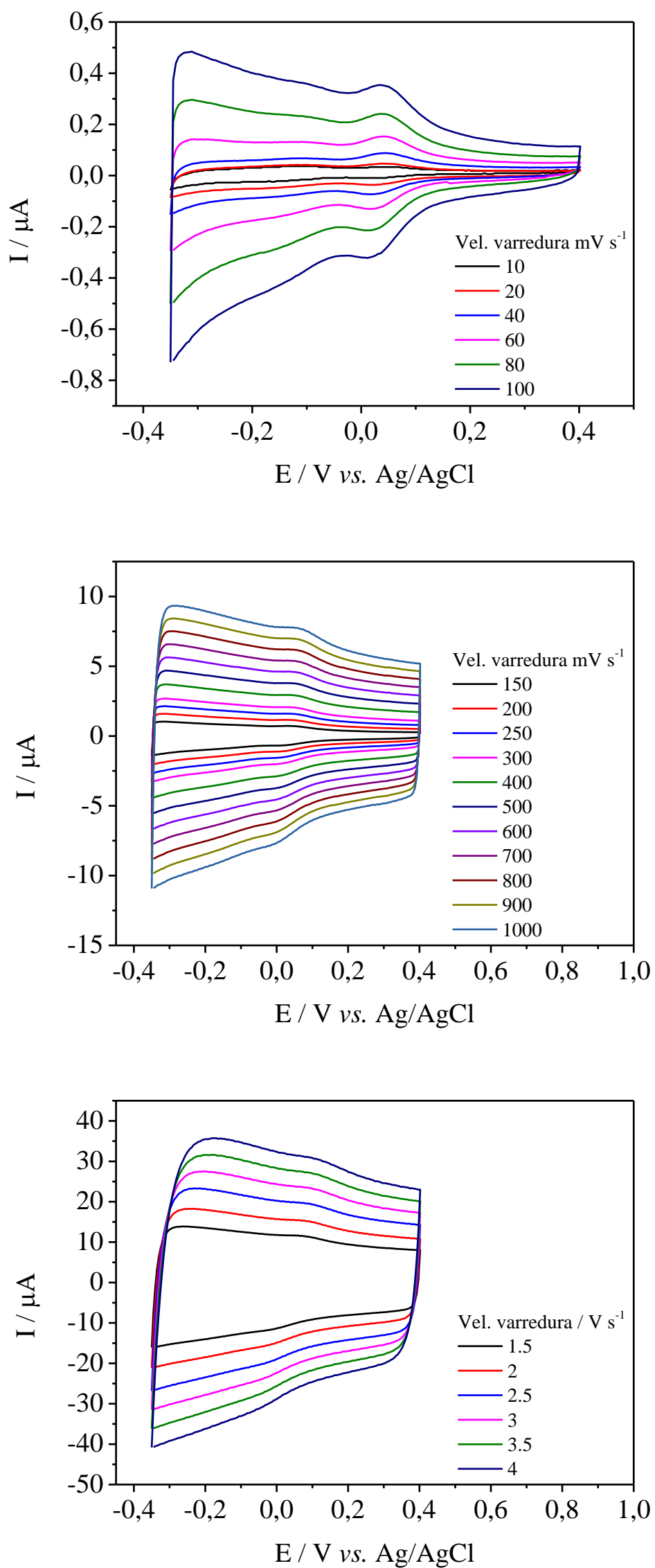
Figura 42 - (A) Variação das correntes de pico anódica e catódica, dos voltamogramas cíclicos da Figura 41, em função da velocidade de varredura. (B) Variação dos potenciais de pico anódico e catódico, dos voltamogramas cíclicos da Figura 41, em função da velocidade de varredura.
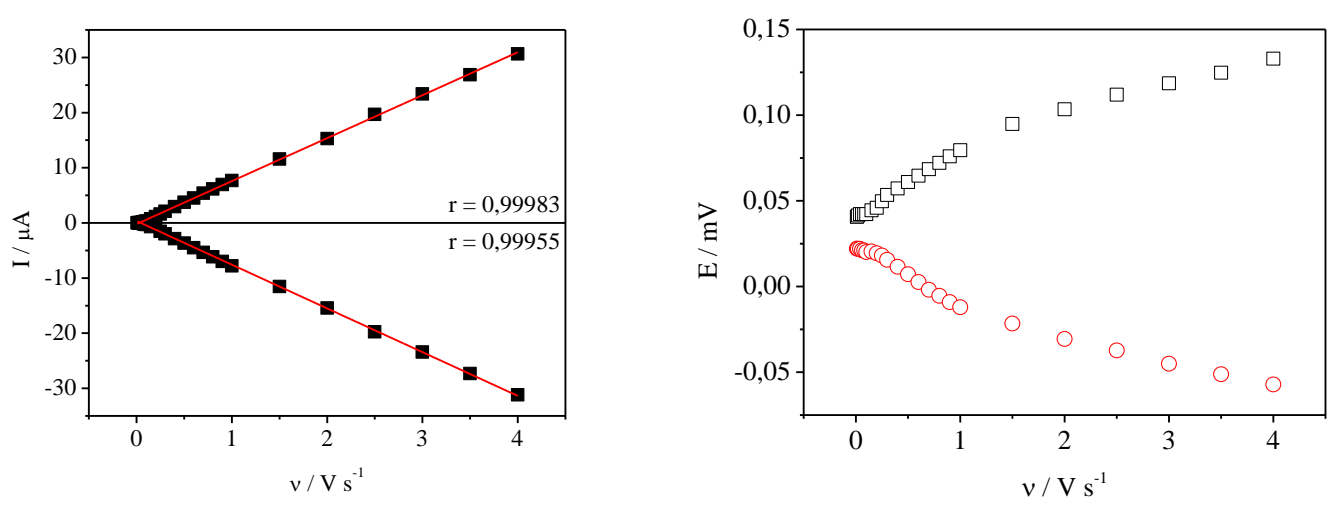

Na voltametria de filmes de proteína, a cinética de transferência eletrônica tem que ser rápida o suficiente para que a razão entre as moléculas oxidadas e reduzidas variem de acordo com o potencial do eletrodo; ou seja, a reversibilidade eletroquímica depende da velocidade de varredura aplicada. Quando o potencial de eletrodo varia muito rápido, a razão entre as moléculas oxidadas e reduzidas da proteína deixa de estar em equilíbrio com o potencial de eletrodo, o que resulta em uma maior diferença entre os potencias de pico anódico e catódico. Com o aumento da velocidade de varredura a reação deixa de ser reversível, e pelo estudo da variação dos potencias de pico com a velocidade de varredura, pode-se deduzir o valor da constante de transferência de carga $\left(k_{s}\right)$, entre proteína e eletrodo, pelo método de Laviron ${ }^{58,61}$.

Assim, nas reações como a do citocromo C, limitada por transporte de carga, a cinética de transferência eletrônica pode ser obtida pela abordagem de Laviron ${ }^{61}$, onde a relação entre o potencial de pico e a velocidade de varredura pode ser expressa pela equação:

$$
E_{p}=f(\log v)
$$


Na Figura 43 temos o gráfico dos potenciais de pico em função do logaritmo da velocidade de varredura, para o eletrodo ITO/PAMAM/Cys/CytC em TF 0,5 mmol L $\mathrm{m}^{-1}$, pH 7,0 , saturado com $\mathrm{N}_{2}$, onde observamos duas linhas retas que extrapolam no eixo $\mathrm{y}=0$. Do slope igual a $-2,3 \mathrm{RT} / \alpha \mathrm{nF}$ para os picos catódicos, e 2,3RT/(1- $\alpha) \mathrm{nF}$ para os picos anódicos, estimamos o valor do coeficiente de transferência eletrônica, $\alpha$, em 0,54 . O valor da constante de transferência de carga, expressa pela equação 4 , foi de $4,6 \mathrm{~s}^{-1}$.

$$
k_{s}=\frac{\alpha n F v_{c}}{R T}=\frac{(1-\alpha) n F v_{a}}{R T}
$$

onde $\alpha$ é o coeficiente de transferência de carga, n o número de elétrons envolvidos na reação e $v_{\mathrm{a}}$ e $v_{\mathrm{c}}$ as velocidades de varredura.

Figura 43 - Relação entre os potenciais de pico e o logaritmo da velocidade de varredura.

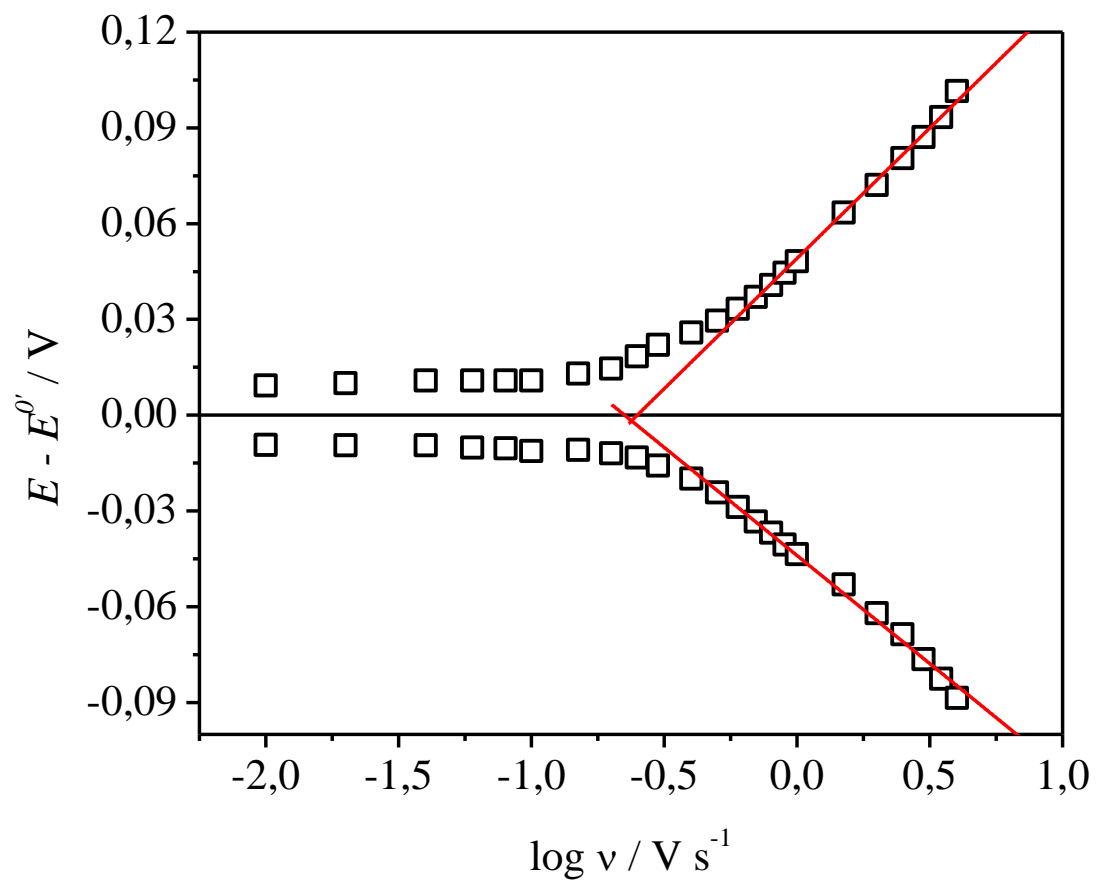


Os mesmos estudos foram realizados para o eletrodo ITO/PAMAM-Pt/Cys/CytC e a Figura 44 mostra os voltamogramas cíclicos dos eletrodos ITO/PAMAM-Pt/Cys e ITO/PAMAM-Pt/Cys/CytC onde observa-se um par de picos bem definidos e simétricos do processo redox do citocromo $\mathrm{C}$, com um $\Delta \mathrm{Ep}$ de $25 \mathrm{mV}$, indicando um processo eletroquímico reversível para a reação de transferência de elétrons direta entre o citocromo $\mathrm{C}$ e a superfície do eletrodo ITO/PAMAM-Pt.

Figura 44 - Voltamogramas cíclicos em TF 5,0 $\mathrm{mmol} \mathrm{L}^{-1}$, pH 7,0, saturado com $\mathrm{N}_{2}$. Velocidade de varredura $0,1 \mathrm{~V} \mathrm{~s}^{-1}$.

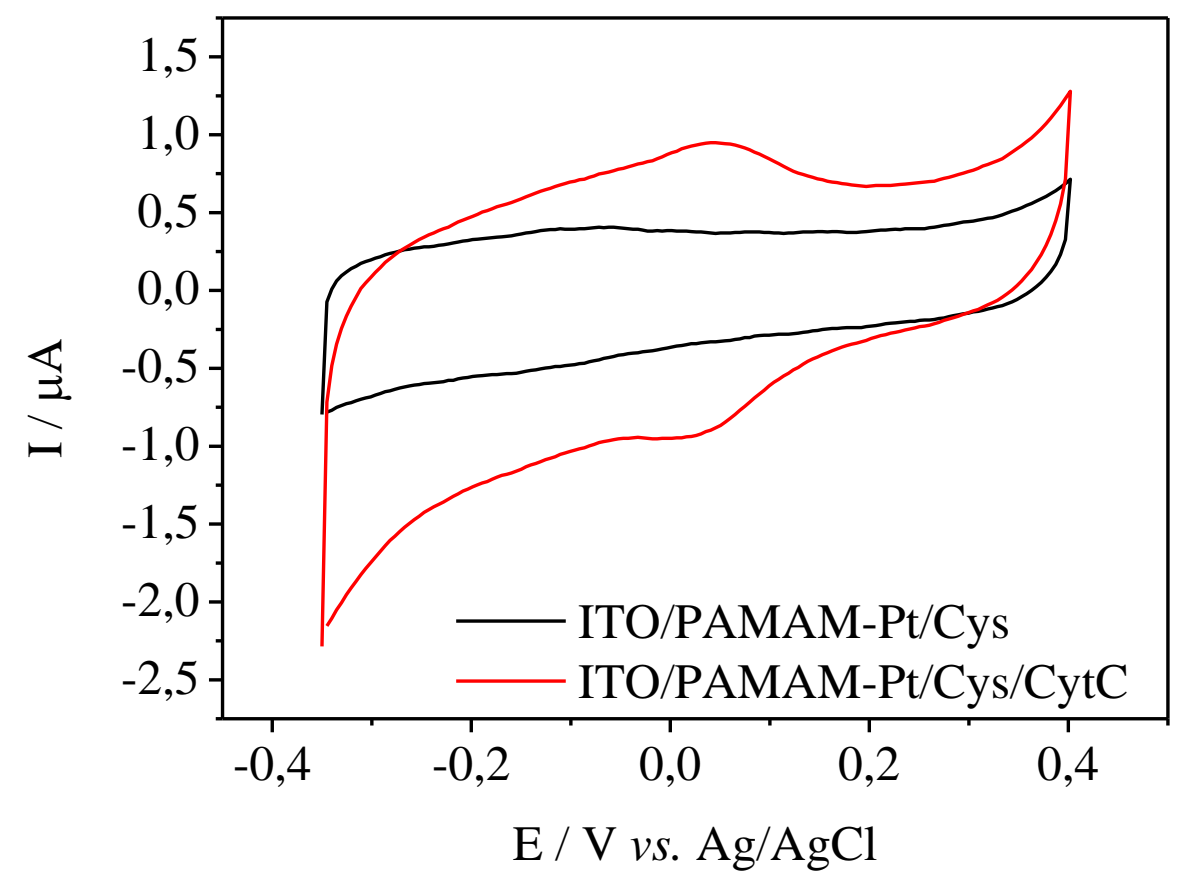

O eletrodo ITO/PAMAM-Pt/Cys/CytC foi submetido à varredura de potenciais em diferentes velocidades de varredura e os voltamogramas cíclicos e de varredura linear para o processo de oxidação do citocromo C são apresentados nas Figuras 45 e 46, respectivamente. Dos voltamogramas cíclicos obtiveram-se as correntes e potencias de pico de oxidação e redução do citocromo C e na Figura 47 observa-se que as correntes de pico anódica e catódica aumentam linearmente com a velocidade de varredura, indicando que a reação é limitada por transporte de carga, e que o $\Delta$ Ep também aumenta com o aumento da velocidade de varredura, indicando que a reversibilidade do processo redox do citocromo $\mathrm{C}$ é prejudicada. 
Figura 45 - Voltamogramas cíclicos e de varredura linear do eletrodo ITO/PAMAM-Pt/Cys/CytC em TF 5,0 mmol L ${ }^{-1}, \mathrm{pH} 7,0$, saturado com $\mathrm{N}_{2}$.
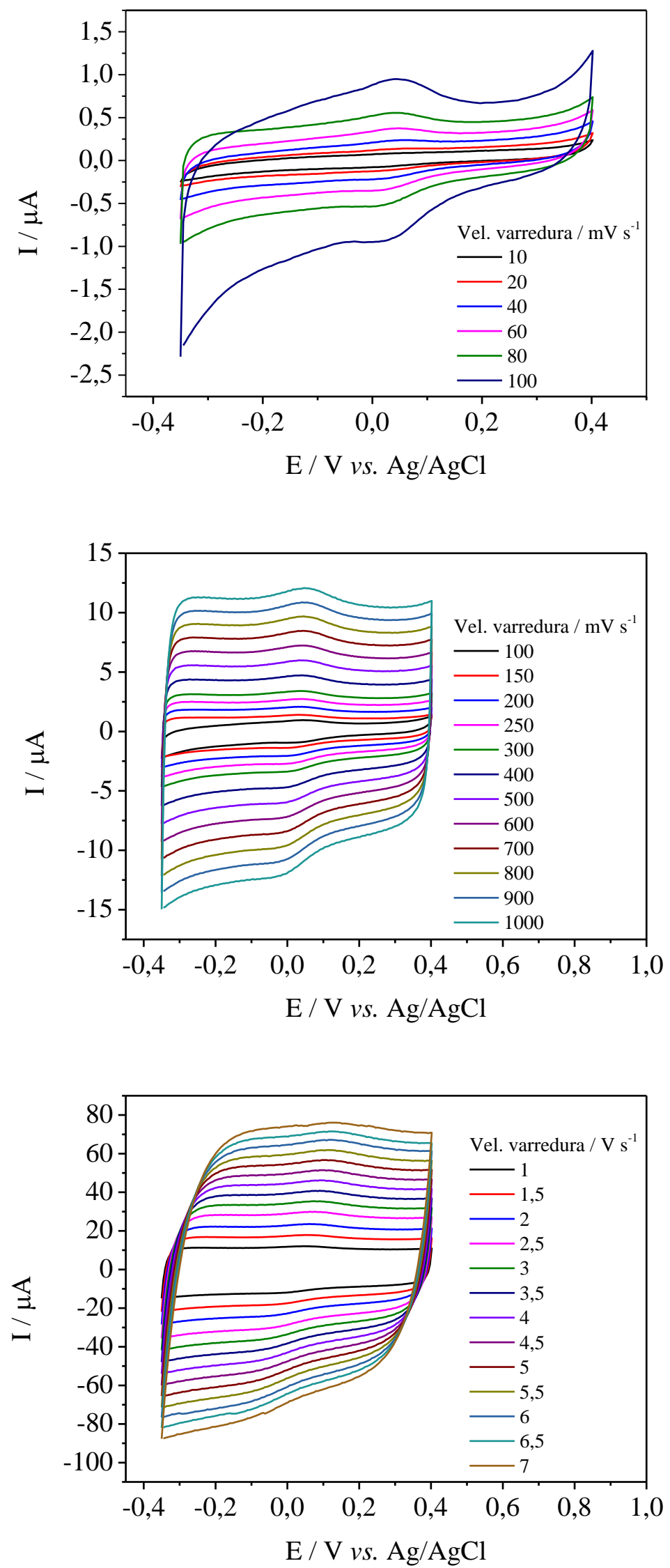
Figura 46 - Voltamogramas de varredura linear do eletrodo ITO/PAMAM-Pt/Cys/CytC em TF 5,0 $\mathrm{mmol} \mathrm{L}^{-1}$, pH 7,0, saturado com $\mathrm{N}_{2}$.
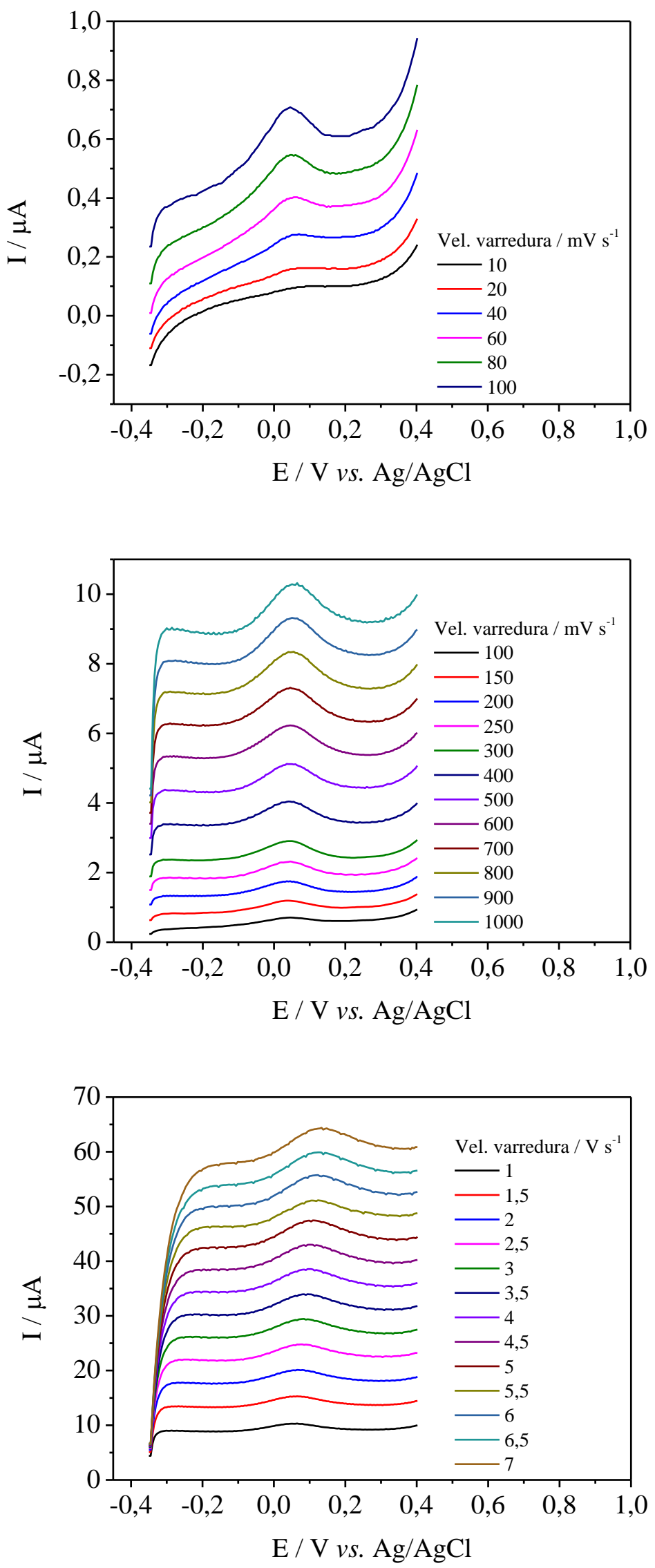
Figura 47 - (A) Variação das correntes de pico anódica e catódica, dos voltamogramas cíclicos da Figura 45, em função da velocidade de varredura. (B) Variação dos potenciais de pico anódico e catódico, dos voltamogramas cíclicos da Figura 45, em função da velocidade de varredura.
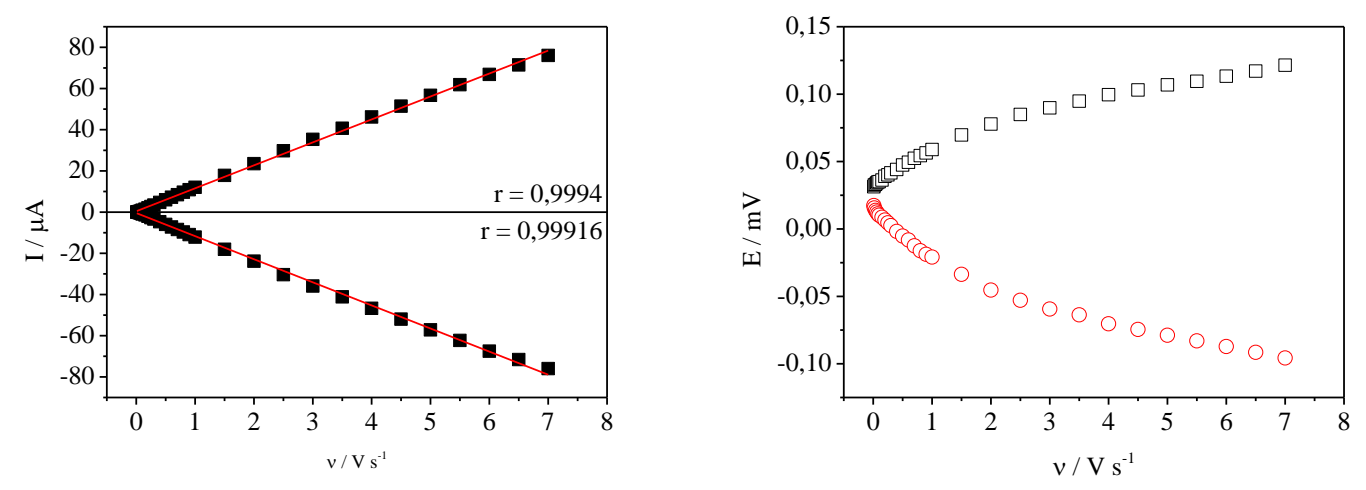

Na Figura 48 temos o gráfico dos potenciais de pico em função do logaritmo da velocidade de varredura, para o eletrodo ITO/PAMAM-Pt/Cys/CytC em TF 0,5 mmol L $\mathrm{L}^{-1}$, pH 7,0, saturado com $\mathrm{N}_{2}$. Como mostrado anteriormente, o coeficiente de transferência de carga, $\alpha=0,45$, foi estimado do slope das curvas da Figura 48. A constante de transferência de carga, $k_{s}=5,7 \mathrm{~s}^{-1}$, foi calculada de acordo com a equação 4 .

Figura 48 - Relação entre os potenciais de pico e o logaritmo da velocidade de varredura.

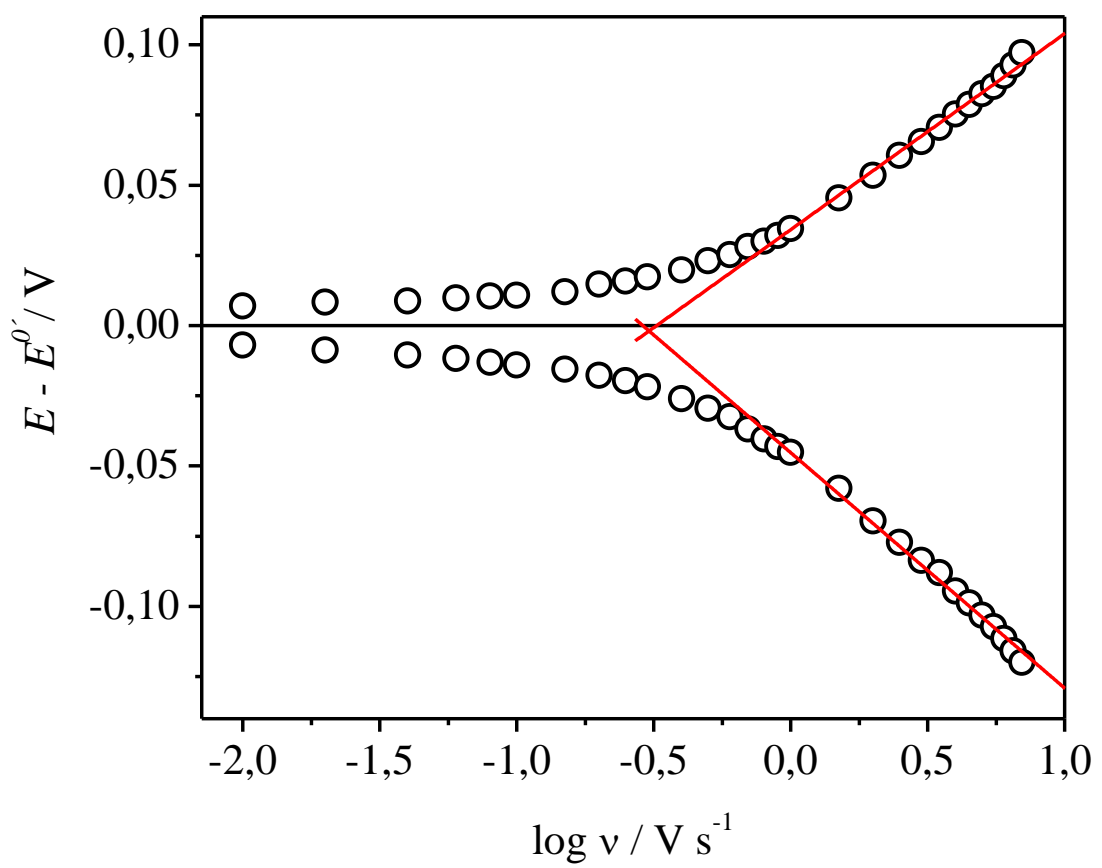


$\mathrm{Na}$ Figura 49 temos os voltamogramas dos eletrodos ITO/PAMAM/Cys/CytC e ITO/PAMAM-Pt/Cys/CytC onde se observam correntes de oxidação e redução de maior intensidade para o eletrodo com o híbrido PAMAM-Pt. Uma maior corrente é atribuída às $\mathrm{NPsPt}$, não só pelo aumento da área superficial do eletrodo, mas também pelo efeito catalítico observado nos voltamogramas da Figura 45 e nos valores de $k_{s}$. Nos voltamogramas das Figuras 41, 45 e 46 é possível notar que o sistema ITO/PAMAM-Pt/Cys/CytC mantem-se reversível mesmo a altas velocidades de varredura e é possível observar seus valores de corrente até a velocidade de $7 \mathrm{~V} \mathrm{~s}^{-1}$, enquanto que no sistema sem a presença das NPsPt, as correntes são observáveis até a velocidade de $4 \mathrm{~V} \mathrm{~s}^{-1}$.

Figura 49 - Voltamogramas cíclicos em TF 5,0 mmol L ${ }^{-1}$, pH 7,0, saturado com $\mathrm{N}_{2}$. Velocidade de varredura (A) $0,1 \mathrm{~V} \mathrm{~s}^{-1}$ e (B) $4,0 \mathrm{~V} \mathrm{~s}^{-1}$.
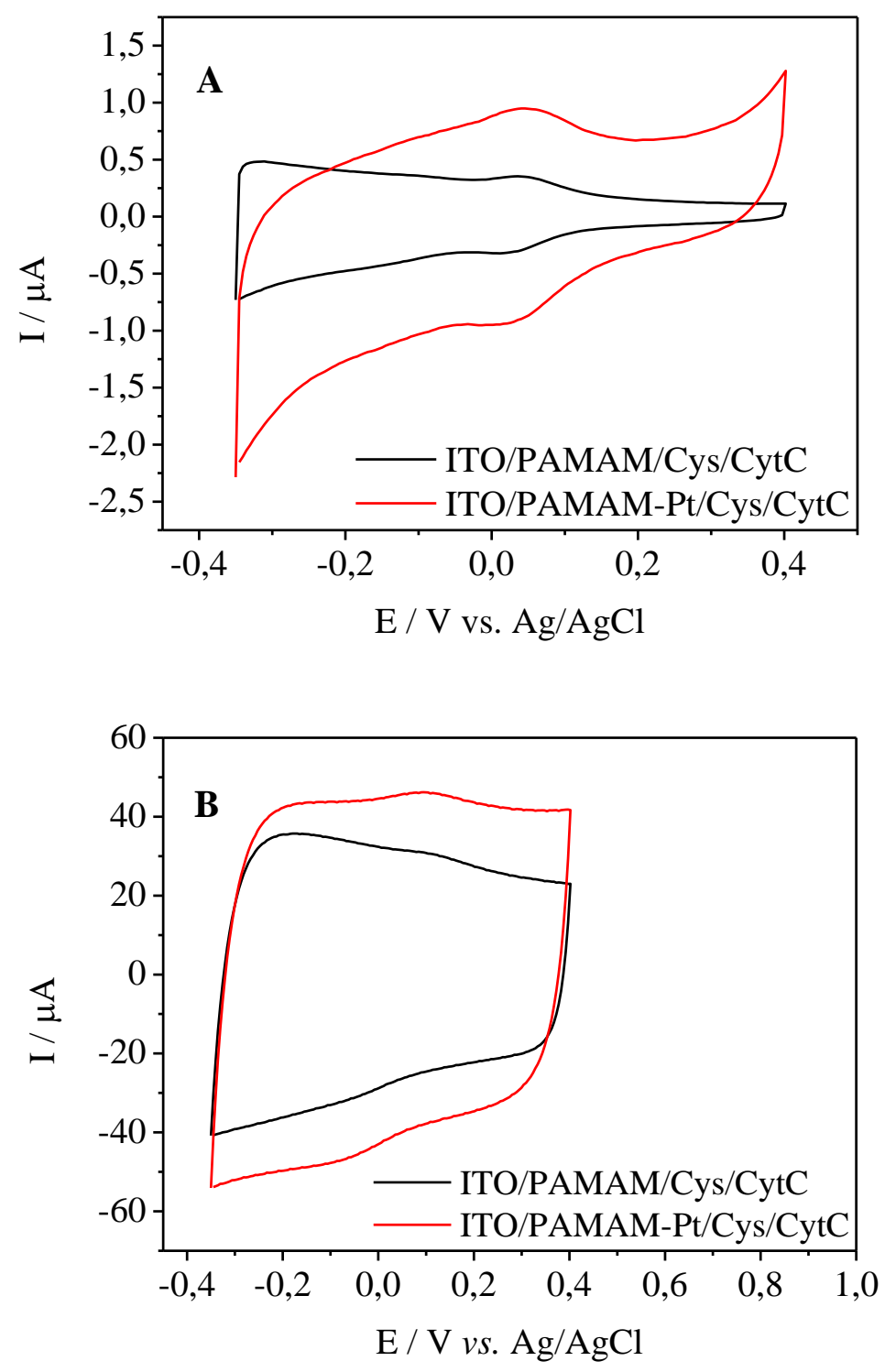
A tabela 4 nos mostra que o valor de $k_{s}$ obtido, 4,6 $\mathrm{s}^{-1}$ para o eletrodo ITO/PAMAM/Cys/CytC, é semelhante ao valor de $4,8 \mathrm{~s}^{-1}$, obtido por Zhang e Zheng com um eletrodo GC/MWCNTs-RTIL-CytC-Chi, e maior que os valores de $k_{s}$ apresentados nos demais trabalhos. Todos os trabalhos calcularam $k_{s}$ pelo método de Laviron, que é um tratamento matemático baseado no formalismo de Butler-Volmer. É importante mencionar que para outros sistemas (eletrodos modificados com enzimas, por exemplo), valores mais precisos de $k_{s}$ são obtidos utilizando a Teoria de Marcus ${ }^{82-86}$.

Tabela 4 - Dispositivos utilizados no estudo da eletroquímica do CytC e/ou como biossensores.

\begin{tabular}{|c|c|c|c|}
\hline Dispositivo & $k_{s} / s^{-I}$ & Meio & Referências \\
\hline GC/MWCNTS-RTIL-CytC-Chi & 4,8 & $\begin{array}{c}\text { TF } 0,1 \mathrm{~mol} \mathrm{~L}^{-1}, \mathrm{pH} \\
7,0\end{array}$ & 62 \\
\hline GC/Chi-PAMAM-MWCNTs/GA/CytC & 2,4 & $\begin{array}{c}\text { TF } 0,1 \mathrm{~mol} \mathrm{~L}^{-1}, \mathrm{pH} \\
7,0\end{array}$ & 63 \\
\hline ITO/NPsPt/CytC & 3,52 & TF $0,1 \mathrm{~mol} \mathrm{~L}_{6,0}^{-1}, \mathrm{pH}$ & 64 \\
\hline Au/MCH-MUA-NPsAu-Gp-PDDA-RTIL/CytC & 3,14 & $\begin{array}{c}\text { TF 0,2 mol L } \\
7,0\end{array}$ & 65 \\
\hline GC/PANS/NPsAu/CytC & 2,362 & TF 0,1 $\mathrm{mol} \mathrm{L}_{6,0}^{-1}, \mathrm{pH}$ & 66 \\
\hline ITO/PAMAM/Cys/CytC & 4,6 & $\begin{array}{c}\text { TF 5,0 mmol L } \\
\text { pH 7,0 }\end{array}$ & Este trabalho \\
\hline ITO/PAMAM-Pt/Cys/CytC & 5,7 & $\begin{array}{c}\text { TF 5,0 mmol L } \\
\text { pH 7,0 }\end{array}$ & Este trabalho \\
\hline
\end{tabular}

Os valores de $k_{s}$ 4,6 $\mathrm{s}^{-1}$ e $5,7 \mathrm{~s}^{-1}$ indicam que os eletrodos ITO/PAMAM e ITO/PAMAM-Pt atuam como excelentes dispositivos para a imobilização do citocromo C com excelente transferência de elétrons entre o citocromo $\mathrm{C}$ e a superfície do eletrodo. $\mathrm{O}$ PAMAM, por ser uma molécula aproximadamente esférica, fornece um espaço tridimensional, com um número maior de sítios disponíveis de interação com a cisteína e por consequência com o citocromo C. E as NPsPt encapsuladas em PAMAM atuam como sítios catalíticos para a transferência de elétrons entre o citocromo $\mathrm{C}$ e a superfície do eletrodo. Tais propriedades tornam o eletrodo ITO/PAMAM-Pt/Cys/CytC um excelente dispositivo para estudos fundamentais da eletroquímica do citocromo $\mathrm{C}$ e para aplicações em biossensores. 


\section{CONCLUSÕES}

O objetivo geral desta tese, modificar um eletrodo de ITO com um filme nanoestruturado de NPsPt encapsuladas em PAMAM, mostrar sua ativação por tratamento eletroquímico e aplicar o eletrodo ITO/PAMAM-Pt no estudo da eletroquímica direta do citocromo $\mathrm{C}$ foi alcançado.

O método de síntese das NPsPt encapsuladas em PAMAM, proposto por Crooks, foi reproduzido o mais fielmente possível e os resultados das caracterizações feitas por UV-VIS, TEM e FTIR mostram que foram obtidas NPsPt encapsuladas, com morfologia esférica, distribuição homogênea e diâmetro médio menor que $5 \mathrm{~nm}$.

O híbrido PAMAM-Pt foi utilizado na preparação de eletrodos de ITO modificados com um filme nanoestruturado de PAMAM-Pt e eletrodos de ITO modificados com membranas, contendo de 2 a 4 camadas de PAMAM-Pt, intercaladas com o poliânion PVS. As caracterizações feitas por CV e UV-Vis mostraram que um tempo de 7 min é necessário para a formação de uma camada de PAMAM-Pt sobre o ITO, e que 4 camadas são obtidas com a mesma quantidade de PAMAM-Pt sendo adsorvida em cada camada.

Os eletrodos de ITO modificados com um filme de PAMAM-Pt e os eletrodos de ITO modificados com até 4 camadas de PAMAM-Pt foram submetidos ao mesmo tratamento eletroquímico utilizado para condicionar eletrodos de Pt. Por CV e EIS investigou-se a influencia deste tratamento na resposta eletroquímica dos eletrodos com diferentes números de camadas, com e sem tratamento eletroquímico. Os resultados mostraram que o eletrodo de ITO modificado com um filme de PAMAM-Pt, submetido a tratamento eletroquímico durante o preparo, foi o que apresentou melhor desempenho, com maior intensidade de corrente para a reação de oxidação do hidrogênio adsorvido, maior área eletroativa e menor resistência à transferência de carga, além de apresentar voltamogramas bem definidos e característicos de eletrodos de Pt. Para os eletrodos de ITO modificados com até 4 camadas de PAMAM-Pt temos que, as correntes para a reação de oxidação do hidrogênio adsorvido e a área eletroativa aumentam para os eletrodos com tratamento eletroquímico entre as camadas, e diminuem para os eletrodos submetidos a tratamento eletroquímico após estarem prontos. A $\mathrm{R}_{\mathrm{tc}}$ aumenta com o número de camadas para todos os eletrodos, porém é menor para os eletrodos submetidos a tratamento eletroquímico entre as camadas.

O eletrodo de ITO modificado com um filme de PAMAM-Pt ativado eletroquimicamente apresentou $k_{s}$ de $5,7 \mathrm{~s}^{-1}$, calculada pelo método de Laviron, para a reação de transferência eletrônica entre o CytC e o eletrodo ITO/PAMAM-Pt/Cys, o maior valor 
quando comparado com os valores dos outros trabalhos citados nesta tese. Isso mostra que o PAMAM fornece um espaço tridimensional e compatível para a manutenção da atividade do CytC e as NPsPt encapsuladas em PAMAM atuam como sítios catalíticos para a transferência de elétrons entre o citocromo $\mathrm{C}$ e a superfície do eletrodo, fazendo do eletrodo ITO/PAMAM-Pt/Cys/CytC um excelente dispositivo para estudos fundamentais da eletroquímica do citocromo $\mathrm{C}$ e para aplicações em biossensores.

A principal contribuição desta tese foi mostrar que, mediante tratamento eletroquímico, podemos ativar, melhorar o desempenho de eletrodos modificados com membranas eletroativas de NPsPt encapsuladas em PAMAM. Podemos também, obter eletrodos modificados com um filme nanoestruturado de PAMAM-Pt eletroquimicamente ativado, com excelente desempenho, economia de materiais, sem a necessidade de se produzir membranas com várias camadas e sem o uso de polieletrólitos que possam aumentar a resistência à transferência de elétrons e diminuir a eficiência do eletrodo. 


\section{REFERÊNCIAS BIBLIOGRÁFICAS}

1. Moriarty, P. Nanostructured materials. Reports on Progress in Physics, v. 64, p. 297 $381,2001$.

2. GuO, S. J.; WANG, E. K. Functional micro/nanostructures: simple synthesis and application in sensors, fuel cells, and gene delivery. Accounts of Chemical Research, v. 44, n. 7, p. 491$500,2011$.

3. LI, H. H.; LIU, S. Q.; DAI, Z. H.; BAO, J. C.; YANG, X. D. Applications of nanomaterials in electrochemical enzyme biosensors. Sensors, v. 9, n. 11, p. 8547-8561, 2009.

4. GUO, S. J.; WANG, E. K. Noble metal nanomaterials: controllable synthesis and application in fuel cells and analytical sensors. Nano Today, v. 6, n. 3, p. 240-264, 2011.

5. WANG, R.; ZhANG, Y. F.; LU, D. N.; GE, J.; LIU, Z.; ZARE, R. N. Functional proteinorganic/inorganic hybrid nanomaterials. Wiley Interdisciplinary Reviews-Nanomedicine and Nanobiotechnology, v. 5, n. 4, p. 320-328, 2013.

6. Dong, S. M.; CHEN, X.; ZHANG, X. Y.; CUI, G. L. Nanostructured transition metal nitrides for energy storage and fuel cells. Coordination Chemistry Reviews, v. 257, n. 13-14, p. 1946-1956, 2013.

7. Camposeo, A.; Persano, L.; Pisignano, D. Light-emitting electrospun nanofibers for nanophotonics and optoelectronics. Macromolecular Materials and Engineering, v. 298, n. 5, p. 487-503, 2013.

8. LIU, Y.; DU, Y.; LI, C. M. Direct electrochemistry based biosensors and biofuel cells enabled with nanostructured materials. Electroanalysis, v. 25, n. 4, p. 815-831, 2013.

9. LI, X.; WEI, B. Q. Supercapacitors based on nanostructured carbon. Nano Energy, v. 2, n. 2, p. 159-173, 2013.

10. ZAERA, F. Nanostructured materials for applications in heterogeneous catalysis. Chemical Society Reviews, v. 42, n. 7, p. 2746-2762, 2013.

11. DeCHER, G. Fuzzy nanoassemblies: toward layered polymeric multicomposites. Science, v. 277, n. 5330, p. 1232-1237, 1997. 
12. Blodgett, K. B. Monomolecular films of fatty acids on glass. Journal of the American Chemical Society, v. 56, p. 495-495, 1934.

13. BlodgetT, K. B.; LANGMuiR, I. Built-up films of barium stearate and their optical properties. Physical Review, v. 51, n. 11, p. 964-982, 1937.

14. Ferretti, S.; PAynter, S.; Russell, D. A.; SAPSFORd, K. E.; Richardson, D. J. Selfassembled monolayers: a versatile tool for the formulation of bio-surfaces. Trac-Trends in Analytical Chemistry, v. 19, n. 9, p. 530-540, 2000.

15. DeCHER, G.; Hong, J. D.; SCHMITT, J. Buildup of ultrathin multilayer films by a selfassembly process 3 : consecutively alternating adsorption of anionic and cationic polyelectrolytes on charged surfaces. Thin Solid Films, v. 210, n. 1-2, p. 831-835, 1992.

16. Cheung, J. H.; Fou, A. F.; RUBner, M. F. Molecular self-assembly of conducting polymers. Thin Solid Films, v. 244, n. 1-2, p. 985-989, 1994.

17. Iost, R. M.; Madurro, J. M.; Brito-Madurro, A. G.; NANTES, I. L.; CASEli, L.; CRESPILHO, F. N. Strategies of nano-manipulation for application in electrochemical biosensors. International Journal of Electrochemical Science, v. 6, n. 7, p. 2965-2997, 2011.

18. Crespilho, F. N.; Zucolotto, V.; Oliveira, O. N.; NART, F. C. Electrochemistry of layer-by-layer films: a review. International Journal of Electrochemical Science, v. 1, n. 5, p. 194-214, 2006.

19. IOST, R. M.; CRESPILHO, F. N. Layer-by-layer self-assembly and electrochemistry: Applications in biosensing and bioelectronics. Biosensors \& Bioelectronics, v. 31, n. 1, p. 110, 2012.

20. LuO, X. L.; Morrin, A.; KILlard, A. J.; SMYTH, M. R. Application of nanoparticles in electrochemical sensors and biosensors. Electroanalysis, v. 18, n. 4, p. 319-326, 2006.

21. Hrapovic, S.; LiU, Y. L.; Male, K. B.; LuONG, J. H. T. Electrochemical biosensing platforms using platinum nanoparticles and carbon nanotubes. Analytical Chemistry, v. 76, n. 4, p. 1083-1088, 2004. 
22. ZhUO, Y.; YUAN, R.; ChaI, Y. Q.; TANG, D. P.; ZhANG, Y.; WANG, N.; LI, X. L.; ZHU, Q. A reagentless amperometric immunosensor based on gold nanoparticles/thionine/nafionmembrane-modified gold electrode for determination of alpha-1-fetoprotein.

Electrochemistry Communications, v. 7, n. 4, p. 355-360, 2005.

23. Fiorito, P. A.; Goncales, V. R.; Ponzio, E. A.; De Torresi, S. I. C. Synthesis, characterization and immobilization of prussian blue nanoparticles. A potential tool for biosensing devices. Chemical Communications, n. 3, p. 366-368, 2005.

24. XiaO, Y.; PATOlsky, F.; Katz, E.; Hainfeld, J. F.; Willner, I. "Plugging into enzymes": nanowiring of redox enzymes by a gold nanoparticle. Science, v. 299, n. 5614, p. 1877-1881, 2003 .

25. XU, J. J.; ZHAO, W.; LuO, X. L.; CHEN, H. Y. A sensitive biosensor for lactate based on layer-by-layer assembling $\mathrm{MnO}_{2}$ nanoparticles and lactate oxidase on ion-sensitive fieldeffect transistors. Chemical Communications, n. 6, p. 792-794, 2005.

26. WANG, L.; GuO, S. J.; HuANG, L. J.; DonG, S. J. Alternate assemblies of polyelectrolyte functionalized carbon nanotubes and platinum nanoparticles as tunable electrocatalysts for dioxygen reduction. Electrochemistry Communications, v. 9, n. 4, p. 827-832, 2007.

27. XU, L. H.; ZHU, Y. H.; TANG, L. H.; YANG, X. L.; LI, C. Z. Biosensor based on selfassembling glucose oxidase and dendrimer-encapsulated Pt nanoparticles on carbon nanotubes for glucose detection. Electroanalysis, v. 19, n. 6, p. 717-722, 2007.

28. TANG, L. H.; ZHU, Y. H.; YANG, X. L.; LI, C. Z. An enhanced biosensor for glutamate based on self-assembled carbon nanotubes and dendrimer-encapsulated platinum nanobiocomposites-doped polypyrrole film. Analytica Chimica Acta, v. 597, n. 1, p. 145150, 2007.

29. WANG, H. J.; ZhOU, C. M.; LIANG, J. H.; YU, H.; PENG, F. An enhanced glucose biosensor modified by Pt/sulfonated-MWCNTs with layer by layer technique. International Journal of Electrochemical Science, v. 3, n. 10, p. 1180-1185, 2008.

30. Zhang, Y. Y.; YuAn, R.; ChaI, Y. Q.; XIANG, Y.; HonG, C. L.; RAN, X. Q. An amperometric hydrogen peroxide biosensor based on the immobilization of HRP on multiwalled carbon nanotubes/electro-copolymerized nano-Pt-poly(neutral red) composite membrane. Biochemical Engineering Journal, v. 51, n. 3, p. 102-109, 2010. 
31. YANG, M. H.; YANG, Y.; YANG, H. F.; SHEN, G. L.; YU, R. Q. Layer-by-layer selfassembled multilayer films of carbon nanotubes and platinum nanoparticles with polyelectrolyte for the fabrication of biosensors. Biomaterials, v. 27, n. 2, p. 246-255, 2006.

32. TANG, L. H.; ZhU, Y. H.; XU, L. H.; YANG, X. L.; Li, C. Z. Amperometric glutamate biosensor based on self-assembling glutamate dehydrogenase and dendrimer-encapsulated platinum nanoparticles onto carbon nanotubes. Talanta, v. 73, n. 3, p. 438-443, 2007.

33. LI, W. J.; YUAN, R.; CHAI, Y. Q.; ZHONG, H. A.; WANG, Y. Study of the biosensor based on platinum nanoparticles supported on carbon nanotubes and sugar-lectin biospecific interactions for the determination of glucose. Electrochimica Acta, v. 56, n. 11, p. 4203 4208, 2011.

34. Zhang, J. M.; ZHU, Y. H.; Yun, J. P.; YANG, X. L.; LI, C. Z. Fabrication of (GOx/PtDENs) ${ }_{\mathrm{n}} / \mathrm{CNTs}$ nanocomposite and their electrochemical properties for anode in biofuel cell. Advanced Materials, v. 239-242, p. 3225-3230, 2011.

35. ZhaO, M. Q.; CROOKs, R. M. Dendrimer-encapsulated Pt nanoparticles: synthesis, characterization, and applications to catalysis. Advanced Materials, v. 11, n. 3, p. 217-220, 1999.

36. Ye, H. C.; SCOTT, R. W. J.; CROOKS, R. M. Synthesis, characterization and surface immobilization of platinum and palladium nanoparticles encapsulated within amineterminated poly(amidoamine) dendrimers. Langmuir, v. 20, n. 7, p. 2915-2920, 2004.

37. Crooks, R. M.; Zhao, M. Q.; Sun, L.; CheChiK, V.; Yeung, L. K. Dendrimerencapsulated metal nanoparticles: synthesis, characterization, and applications to catalysis. Accounts of Chemical Research, v. 34, n. 3, p. 181-190, 2001.

38. Esumi, K.; NAKAmura, R.; SUZUKI, A.; Torigoe, K. Preparation of platinum nanoparticles in ethyl acetate in the presence of poly(amidoamine) dendrimers with a methyl ester terminal group. Langmuir, v. 16, n. 20, p. 7842-7846, 2000.

39. YANG, L.; LUO, Y. F.; JIA, X. R.; JI, Y.; YOU, L. P.; ZHOU, Q. F.; WeI, Y. Preparation of monodisperse platinum nanocrystal core-poly(amidoamine) (PAMAM) dendrimer shell structures as monolayer films. Journal of Physical Chemistry B, v. 108, n. 4, p. 1176-1178, 2004.

40. Gu, Y. L.; SANDERs, P.; Ploehn, H. J. Quantitative analysis of Pt-PAMAM ligand exchange reactions: time and concentration effects. Colloids and Surfaces a-

Physicochemical and Engineering Aspects, v. 356, n. 1-3, p. 10-15, 2010. 
41. ZeNG, F. W.; ZimMERMAN, S. C. Dendrimers in supramolecular chemistry: from molecular recognition to self-assembly. Chemical Reviews, v. 97, n. 5, p. 1681-1712, 1997.

42. Chauhan, A. S.; Jain, N. K.; Diwan, P. V. Pre-clinical and behavioural toxicity profile of PAMAM dendrimers in mice. Proceedings of the Royal Society a-Mathematical Physical and Engineering Sciences, v. 466, n. 2117, p. 1535-1550, 2010.

43. RUTGERS CATALYSIS RESEARCH CENTER. 2011. Disponível em: $<$ http://catalysis.rutgers.edu/content/synthesis-characterization-and-electrocatalyticapplications-dendrimer-encapsulated>. Acesso em: 08 jul. 2013.

44. ZHAO, M. Q.; CROOKS, R. M. Homogeneous hydrogenation catalysis with monodisperse, dendrimer-encapsulated Pd and Pt nanoparticles. Angewandte Chemie-International Edition, v. 38, n. 3, p. 364-366, 1999.

45. CHeChIK, V.; ZhaO, M. Q.; CROOKS, R. M. Self-assembled inverted micelles prepared from a dendrimer template: phase transfer of encapsulated guests. Journal of the American Chemical Society, v. 121, n. 20, p. 4910-4911, 1999.

46. Chechik, V.; Crooks, R. M. Dendrimer-encapsulated Pd nanoparticles as fluorous phasesoluble catalysts. Journal of the American Chemical Society, v. 122, n. 6, p. 1243-1244, 2000 .

47. Crespilho, F. N.; NART, F. C.; Oliveira, O. N.; BretT, C. M. A. Oxygen reduction and diffusion in electroactive nanostructured membranes (ENM) using a layer-by-layer dendrimer-gold nanoparticle approach. Electrochimica Acta, v. 52, n. 14, p. 4649-4653, 2007.

48. SiqueiRA, J. R.; CRESPILHO, F. N.; ZuCOlOtTo, V.; OliVEIRA, O. N. Bifunctional electroactive nanostructured membranes. Electrochemistry Communications, v. 9, n. 11, p. 2676-2680, 2007.

49. Crespilho, F. N.; Huguenin, F.; Zucolotto, V.; Olivi, P.; Nart, F. C.; Oliveira, O. N. Dendrimers as nanoreactors to produce platinum nanoparticles embedded in layer-by-layer films for methanol-tolerant cathodes. Electrochemistry Communications, v. 8, n. 2, p. 348$352,2006$.

50. HAN, X. A.; ZHU, Y. H.; YANG, X. L.; ZhANG, J. M.; LI, C. Z. Dendrimer-encapsulated Pt nanoparticles on mesoporous silica for glucose detection. Journal of Solid State Electrochemistry, v. 15, n. 3, p. 511-517, 2011. 
51. TANG, L. H.; ZhU, Y. H.; XU, L. H.; YANG, X. L.; LI, C. Z. Properties of dendrimerencapsulated pt nanoparticles doped polypyrrole composite films and their electrocatalytic activity for glucose oxidation. Electroanalysis, v. 19, n. 16, p. 1677-1682, 2007.

52. Ledesma-Garcia, J.; Escalante-Garcia, I. L.; Chapman, T. W.; Arriaga, L. G.; Baglio, V.; AntonucCi, V.; ARICO, A. S.; ORnelas, R.; GodineZ, L. A. Pt dendrimer nanocomposites for oxygen reduction reaction in direct methanol fuel cells. Journal of Solid State Electrochemistry, v. 14, n. 5, p. 835-840, 2010.

53. YE, H. C.; CROOKS, R. M. Electrocatalytic $\mathrm{O}_{2}$ reduction at glassy carbon electrodes modified with dendrimer-encapsulated Pt nanoparticles. Journal of the American Chemical Society, v. 127, n. 13, p. 4930-4934, 2005.

54. Coutanceau, C.; Urchaga, P.; Brimaud, S.; Baranton, S. Colloidal syntheses of shape- and size-controlled Pt nanoparticles for electrocatalysis. Electrocatalysis, v. 3, n. 2, p. 75-87, 2012.

55. Ledesma-Garcia, J.; Arriaga, L. G.; Chapman, T. W.; VelazqueZ-Castillo, R.; GoDINEZ, L. A. Electrochemical synthesis of Pt nanoparticles inside of pamam dendrimers for oxygen reduction. Journal of the Electrochemical Society, v. 157, n. 1, p. E1-E5, 2010.

56. LEHNINGER, A. L. Lehninger princípios de bioquímica. São Paulo: Sarvier, 2007. $1202 \mathrm{p}$.

57. RESEARCH COLLABORATORY FOR STRUCTURAL BIOINFORMATICS. Protein Data Bank Home Page. 1998. Disponível em:

<http://www.rcsb.org/pdb/explore/images.do?structureId=2B4Z>. Acesso em: 05 jul. 2013.

58. NolL, T.; NOLL, G. Strategies for "wiring" redox-active proteins to electrodes and applications in biosensors, biofuel cells, and nanotechnology. Chemical Society Reviews, v. 40, n. 7, p. 3564-3576, 2011.

59. Yeh, P.; KuWANA, T. Reversible electrode-reaction of cytochrome-c. Chemistry Letters, n. 10, p. 1145-1148, 1977.

60. EdDOweS, M. J.; HiLl, H. A. O. Novel method for investigation of electrochemistry of metalloproteins - cytochrome c. Journal of the Chemical Society-Chemical

Communications, n. 21, p. 771-772, 1977. 
61. LAVIRON, E. General expression of the linear potential sweep voltammogram in the case of diffusionless electrochemical systems. Journal of Electroanalytical Chemistry, v. 101, n. 1, p. 19-28, 1979.

62. ZHANG, Y.; ZHENG, J. B. Direct electrochemistry and electrocatalysis of cytochrome c based on chitosan-room temperature ionic liquid-carbon nanotubes composite.

Electrochimica Acta, v. 54, n. 2, p. 749-754, 2008.

63. Chen, Q. P.; AI, S. Y.; ZhU, X. B.; YIN, H. S.; MA, Q.; QIU, Y. Y. A nitrite biosensor based on the immobilization of cytochrome $\mathrm{c}$ on multi-walled carbon nanotubes-PAMAM-chitosan nanocomposite modified glass carbon electrode. Biosensors \& Bioelectronics, v. 24, n. 10, p. 2991-2996, 2009.

64. LiAnG, F. F.; JiA, M. Z.; HU, J. B. Pt-implanted indium tin oxide electrodes and their amperometric sensor applications for nitrite and hydrogen peroxide. Electrochimica Acta, v. 75, p. 414-419, 2012.

65. SonG, Y. H.; LiU, H. Y.; WAN, L. L.; WANG, Y.; HoU, H. Q.; WANG, L. Direct electrochemistry of cytochrome c based on poly(diallyldimethylammonium chloride)graphene nanosheets/gold nanoparticles hybrid nanocomposites and its biosensing. Electroanalysis, v. 25, n. 6, p. 1400-1409, 2013.

66. XIAng, C. L.; Zou, Y. J.; QIU, S. J.; Sun, L. X.; XU, F.; ZHOU, H. Y. Bienzymatic glucose biosensor based on direct electrochemistry of cytochrome $\mathrm{c}$ on gold nanoparticles/polyaniline nanospheres composite. Talanta, v. 110, p. 96-100, 2013.

67. KERN, W. Purifying $\mathrm{Si}$ and $\mathrm{SiO}_{2}$ surfaces with hydrogen peroxide. Semiconductor international, p. 94-99, 1984.

68. Xu, Z. A.; GAO, N.; CHEN, H. J.; DONG, S. J. Biopolymer and carbon nanotubes interface prepared by self-assembly for studying the electrochemistry of microperoxidase-11.

Langmuir, v. 21, n. 23, p. 10808-10813, 2005.

69. Schlesinger, H. I.; Brown, H. C.; Finholt, A. E.; Gilbreath, J. R.; HoeKstra, H. R.; HYDE, E. K. New developments in the chemistry of diborane and of the borohydrides 9: sodium borohydride, its hydrolysis and its use as a reducing agent and in the generation of hydrogen. Journal of the American Chemical Society, v. 75, n. 1, p. 215-219, 1953. 
70. Crespilho, F. N.; Zucolotto, V.; Brett, C. M. A.; Oliveira, O. N.; Nart, F. C. Enhanced charge transport and incorporation of redox mediators in layer-by-layer films containing PAMAM-encapsulated gold nanoparticles. Journal of Physical Chemistry B, v. 110, n. 35, p. 17478-17483, 2006.

71. NIE, K. M.; HU, J. L.; PANG, W. M.; ZHU, Q. R. Poly(amidoamine)-G5 dendrimers/noble metal gold hybrid nanoparticles prepared by gamma-ray irradiation. Materials Letters, v. 61, n. 17, p. 3567-3570, 2007.

72. LI, R.; XIE, A. J.; PANG, W. M.; ZHU, Q. R.; NIE, K. M. Host-guest interaction and nanomicrostructure of spherical poly(amidoamine) dendrimer/gold hybrid colloids under gammaray irradiation. Materials Letters, v. 67, n. 1, p. 103-106, 2012.

73. YANG, R.; QIAN, Z. B.; DENG, J. Q. Electrochemical deposition of prussian blue from a single ferricyanide solution. Journal of the Electrochemical Society, v. 145, n. 7, p. 22312236, 1998.

74. YANG, C.; WANG, C. H.; WU, J. S.; XIA, X. Mechanism investigation of prussian blue electrochemically deposited from a solution containing single component of ferricyanide. Electrochimica Acta, v. 51, n. 19, p. 4019-4023, 2006.

75. Dos SANTOS, V. P.; TREMELIOSI FILHO, G. Correlação entre a estrutura atômica superficial e o processo de adsorção-dessorção reversível de hidrogênio em eletrodos monocristalinos $\operatorname{Pt}(111), \operatorname{Pt}(100)$ e Pt(110). Química Nova, v. 24, n. 6, p. 856-863, 2001.

76. Lvov, Y.; DeChER, G.; MoHwald, H. Assembly, structural, characterization, and thermalbehavior of layer-by-layer deposited ultrathin films of poly(vinyl sulfate) and poly(allylamine). Langmuir, v. 9, n. 2, p. 481-486, 1993.

77. BARANOVA, E. A.; KuZNETSOv, O. O. Impedance spectroscopy of platinum in sulfuric acid under cathodic and anodic polarizatin. ECS Transactions, v. 19, n. 20, p. 111-121, 2009.

78. LOSIEWICZ, B.; JURCZAKOWSKI, R.; LASIA, A. Kinetics of hydrogen underpotential deposition at polycrystalline platinum in acidic solutions. Electrochimica Acta, v. 80, p. 292$301,2012$.

79. Trasatti, S.; PetriI, O. A. Real surface-area measurements in electrochemistry. Pure and Applied Chemistry, v. 63, n. 5, p. 711-734, 1991. 
80. MYERS, V. S.; FRENKEL, A. I.; CROOKS, R. M. In situ structural characterization of platinum dendrimer-encapsulated oxygen reduction electrocatalysts. Langmuir, v. 28, n. 2, p. 1596-1603, 2012.

81. EXPASY. Bioinformatics resource portal. 2011. Disponível em:

<http://web.expasy.org/cgi-bin/protparam/protparam>. Acesso em: 05 jul. 2013.

82. MARCUS, R. A. Electrostatic free energy and other properties of states having nonequilibrium polarization 1. Journal of Chemical Physics, v. 24, n. 5, p. 979-989, 1956.

83. MARCUS, R. A. On the theory of oxidation-reduction reactions involving electron transfer 1. Journal of Chemical Physics, v. 24, n. 5, p. 966-978, 1956.

84. MARCus, R. A. Chemical and electrochemical electron-transfer theory. Annual Review of Physical Chemistry, v. 15, p. 155, 1964.

85. MARCUS, R. A.; SuTIN, N. Electron transfers in chemistry and biology. Biochimica Et Biophysica Acta, v. 811, n. 3, p. 265-322, 1985.

86. Silva, A. T. B.; Coelho, A. G.; Lopes, L. C. D. S.; Martins, M. V. A.; Crespilho, F. N.; MerkoçI, A.; Silva, W. C. D. Nano-assembled supramolecular films from chitosan-stabilized gold nanoparticles and cobalt(II) phthalocyanine. Journal of the Brazilian Chemical Society, p. 1-9, 2013. 